\title{
WORKSHOP \\ On \\ BODY COMPOSITION IN BASIC AND CLINICAL RESEARCH AND THE EMERGING TECHNOLOGIES
}

December $14^{\text {th }}, 2000$

Held at Medical Department

Brookhaven National Laboratory

Upton, New York

BROOKHAVEN NATIONAL LABORATORY

BROOKHAVEN SCIENCE ASSOCIATES, LLC.

UNDER CONTRACT NO. DE-AC02-98CH10886 WITH THE

UNITED STATES DEPARTMENT OF ENERGY 
BNL -52630

Formal Report

\title{
BODY COMPOSITION IN BASIC AND CLINICAL RESEARCH AND THE EMERGING TECHNOLOGIES
}

\author{
December $14^{\text {th }}, 2000$
}

\section{Organizing Committee:}

\author{
Lucian Wielopolski (Chairman)
}

William Gunther Steven B. Heymsfield

Richard N. Pierson Jr. Walton Shreeve

\section{Location}

\section{Brookhaven National Laboratory}

Medical Department

Bldg. 490

Upton, NY 11973 


\section{ACKNOWLEDGEMENT}

I wish to express many thanks to those who helped me to organize this workshop; W. Gunther, RN. Pierson Jr., E. Rugerio, W. Shreeve, K. Vodopia, and L. Warkentein. This workshop was supported by the Office of Biological and Environmental Research of the U.S. Department of Energy under Prime Contract No., DE-AC02-98CH10886 with Brookhaven National Laboratory, and by the subcontract with St. Luke's/Roosevelt Clinical Center.

This report was prepared as an account of work sponsored by an agency of the United States Government. Neither the United States Government nor any agency thereof, nor any of their employees, nor any of their contractors, subcontractors, or their employees, makes any warranty, express or implied, or assumes any legal liability or responsibility for the accuracy, completeness, or usefulness of any information, apparatus, product, or process disclosed, or represents that its use would not infringe privately owned rights. Reference herein to any specific commercial product, process, or service by trade name, trademark, manufacturer, or otherwise, does not necessarily constitute or imply its endorsement, recommendation, or favoring by the United States Government or any agency, contractor or subcontractor thereof. The views and opinions of authors expressed herein do not necessarily state or reflect those of the United States Government or any agency, contractor or subcontractor thereof. 


\section{FOREWORD}

We can only stop and gaze in bewilderment at this complex marvelous "machine" we call the human body. Undoubtedly its secrets of function and its ability to reproduce itself without a blue-print of our design, stimulates our desire to unveil the mysteries of its workings "in vivo", while it is still functioning, and even more so, for diagnosis, when it is malfunctioning. There are many panels to peek through into this "machine", for a biopsy; body composition is one of them. It is fundamentally upon us to further our knowledge of the composition of the body;s various compartments at the atomic, molecular, cellular, and organ levels. However, this inquiry is hampered by the constraints imposed on the quality of data we can retrieve, by various sizes, shapes, and types of "machines", which will affect these compartments, and by the restrictions imposed by the limitations on the radiation doses, and the costs, involved. Nevertheless, the desire to analyze without opening the covers has led to an array of ingenious instruments, based on a variety of analytical methods that extend our normal senses of touch and vision, which are in turn continuously improved by the new instruments we may evolve. This conference depends in equal parts on the inventiveness of our previous efforts, and on the vision that the physicists among us are now applying in presenting a new method.

... science is based on confirmation of a thought and that is where the art of measurement is coming in...

Lucian Wielopolski

5/01/01 


\section{TABLe of CONTENTS}

Table of Content

Executive Summary

Workshop Announcement $\quad 6$

$\begin{array}{ll}\text { Introduction } & 7\end{array}$

$\begin{array}{ll}\text { Abstracts } & 9\end{array}$

Presentations:

Body Composition Research and Brookhaven; a Mandate for the Future RN. PIERSON JR., M.D.

Instrumentation for Body Composition Analysis Present and Future LUCIAN WIELOPOLSKI, PH.D.

Bone Loss, Therapeutic Interventions, and Quantification of Skeletal Changes in Persons with Spinal Cord Injury

WILLIAM A. BAUMAN, M.D.

The Effect of Immobilization on Soft Tissue Body Composition in Persons with Spinal Cord Injury

ANN M. SPUNGEN, ED.D.

Multi-Component Body Composition Models: Recent Advances and Future Directions

STEVEN B. HEYMSFIELD, MD

The Impact of Growth Hormone on the Body Composition of Children with Chronic Renal Failure

VALERIE L. JOHNSON

Evidence for Intracellular Edema in Euvolemic Heart Failure Patients JONATHAN SACKNER-BERNSTEIN, M.D

Protein Metabolism in Specific Organs and Tissues (Regional Protein

Metabolism)

PETER J. GARLICK

Multiple Sclerosis

PATRICIA K. COYLE, M.D. 


\section{EXECUTIVE SUMMARY}

A special one-day workshop was held to review the status, the need for, and the future role of BNL in the Body Composition Analysis Program (BCAP). Two speakers succinctly outlined the status and future new developments using gamma nuclear resonance technology as it applies to BCAP. Seven speakers from three institutions outlined the continued need for BCAP and presented new clinical applications of BCAP in theirs respective fields of expertise. Extensive increase in the use of surrogate instrumentation, e.g., DXA and BIA, in BCAP was recognized as a significant contributing factor to the growth in BCAP. The growing role of MRI in BCAP was also emphasized.

In light of these developments BCAP at BNL, with its specialized In Vivo Neutron Activation (IVNA) facilities, was recognized as a unique user oriented resource that may serve the community hospitals in the area. Three regional large institutions expressed their desire to use these facilities. In addition, IVNA provides direct measure of the human compartments in vivo, thus providing a gold standard for the surrogate methodologies that are in use or to be developed. It was strongly felt that there is a need for a calibration center with a national stature for the different methodologies for in vivo measurements, a role that befits very well a national laboratory. This offers an exquisite justification for DOE to support this orphan technology and to develop BCAP at BNL to, 1, provide a user oriented regional resource, 2 , provide a national reference laboratory, and 3, develop new advanced technologies for BCAP. 


\section{BNL WORKSHOP \\ Body COMposition IN THE BASIC AND CLINICAL RESEARCH \\ AND THE EMERGING TECHNOLOGIES \\ December $14^{\text {th }}, 2000$}

A workshop will be held to address the roles of - and the needs for - whole body, partial body, and organ compartmental analysis in body composition research. The relevance of new high technology methods to disease identification and progression, and to the efficacy of countermeasures, will be emphasized in each speaker's subject area. The state of the current in vivo neutron activation analysis systems used in body composition studies will be presented, but the emphasis will be on new emerging technologies capable of providing elemental quantitative measurement and imaging, and their impact on body composition research.

A discussion period after each series of presentations will focus on identifying the needs and issues pertinent to each application. These proceedings, with particular attention to the discussions between physicists and clinicians, will be recorded and edited for the participants and other interested individuals as a BNL report.

Agenda:
$9: 00-9: 20$
Coffee/Registration
9:20 - 9:30 Opening Remarks:
$9: 30-9: 50$
The Need for this Review
P. Paul, L. Chang (BNL)
9:50-10:10
Emerging Technologies in BCR
R.N. Pierson (SLR)
10:10-10:25
Spinal Cord Injury, Bone
L. Wielopolski (BNL)
$10: 25-10: 40$
Spinal Cord Injury, Muscle
W. Bauman (Bronx VA-MSMS)
10:40-11:00
Discussion
A. Spungen (Bronx VA-MSMS)
11:00-11:20
11:20-11:40
11:40-12:00
$12: 00-1: 00$
Better Human Models
S. B. Heymsfield (SLR)
Does Dialysis stunt growth?
V. Johnson (NY-PH)
Fluid space changes in $\mathrm{CHF}$
J. Sackner-Bernstein (SLR)
Discussion

$(\sim$ 12:00 Working Lunch to be served)

$1: 00-1: 20$
$1: 20-1: 40$

$2: 00-2: 15$

$2: 15-3: 30$
Regional Protein Metabolism

Multiple Sclerosis

Discussion

Comments from the audience

Discussion/summary
P. Garlick (SUNY-SB)

P. Coyle (SUNY-SB)

P. Kirchner (DOE)

P. Kirchner (DOE)

BNL: Brookhaven National Laboratory SLR: St. Luke's/Roosevelt Hospital MSMS: Mount Sinai Medical School

VA: Veterans Administration DOE: Department of Energy SUNY-SB: State University of New York at Stony Brook NY-PH: New York Presbyterian Hospital 


\section{INTRODUCTION}

Once in each decade for the past fifty years, a new insight, a new method, has appeared, breathing new life into the crusade initiated by Behnke in 1945, to contribute to Medicine and Science, to Research and to Clinical Care, by the non-invasive study of body composition.

$\begin{array}{ll}\text { 1940's Underwater weighing } & \text { Al Behnke } \\ \text { 1950's Body potassium measurement } & \text { G. Forbes, E. Anderson, F. Moore } \\ \text { 1960's In-vivo Neutron Activation } & \text { J. Nelp, S. Cohn } \\ \text { 1970's Body nitrogen } & \text { D. Vartsky } \\ \text { 1980's DXA, MRI } & \text { A. Mazess } \\ \text { 1990's Carbon (Inelastic scattering) } & \text { J. Kehayias } \\ \text { 2000's Gamma Nuclear Resonance? } & \text { D. Vartsky, L. Wielopolski }\end{array}$

Although basic concepts in the body composition analysis were laid down in the second half of the nineteenth century, it is only with the advent of a new generation of analytical instrumentation for in vivo analysis, from the fifties and sixties, that a systematic progression has begun, albeit slowly. Skeptics may ask why, after 50 years, we do not have more to show for our efforts: an established industry, a larger research audience, a clinical urgency, a sprouting of body composition laboratories? If we were really needed, the World would beat a path to our door. To the Skeptics: we may track growth in the field by the series of International Symposia on the study of human body composition, from the first one held in 1986 at BNL, and the subsequent ones at the University of Toronto in 1989, the Baylor College of Medicine in Houston in 1992, Mälmo Sweden 1996, and the last one in 1999, in which more than twenty countries were represented by 150 scientists, was held again at BNL. In MEDLINE, we record an exponential growth in chosen key-word-published articles, from hundreds in 1986 to 18,821 in 2000; a fourty-fold growth of interest. For example, WEB search using Google search engine under body composition (BC) research yields 449,000 entries, under BC measurements 150,000 , under in vivo BC measurements 9450, and under in vivo neutron activation BC measurements 800 . Based on the 2001 Directory of National Center for Research Resources out of the seventy nine General Clinical Research Centers thirteen carry research in body composition, albeit, all of them use secondary indirect methods of analysis. This growth parallels the proliferation of surrogate instrumentation for in vivo analysis.

This proliferation of surrogate techniques, developed and calibrated against definitive methods (such as neutron activation), will provide a methods "platform". The concept of developing surrogate methods is a key to growth. It will contain DXA as a base, and it will add anthropometrics, TBW, and ECW measurements, and body potassium when possible. Measurements of adipose tissue and regional fat distribution, fat-free mass, water, ECW, and body cell mass, provide a rich collection of volume and mass measurements, and the critical derivatives, fat, fat-free mass, water, $\mathrm{K} / \mathrm{FFM}, \mathrm{E} / \mathrm{I}$ ratio, $\mathrm{K}_{\mathrm{i}}$ bone mass, and bone density. This "body composition panel" has already resulted in 12 collaborators from around the country who using our body water measurements, and their own versions of our laboratory. We predict that we are at the inflection point in the growth curve.

Can body composition cottage-industry function entirely on surrogate methods? Why do we need and what is the role of BNL? We submit that the surrogates will have acceptance because they have been established by validations at Brookhaven with its armament of primary methods.

The second large question: is there a future for new-methods research? Our seminar addresses this question also. We have reached a high level of competence in measuring the mass/volume components of body composition. There is no current need (and no near-term future need) for achieving any higher precision for measuring organ volumes than the $\pm 1 \%$ or better we now have. These masses and volumes are the denominators for the body composition equations. We are now ready to study the 
quality of body compartments, the elemental contents of the organs. These are the numerators: the most biologically "powerful" numerators we could request are potassium and nitrogen for cells, sodium and chloride for the extracellular spaces, and calcium for bone. Also, measurement of carbon provides a powerful multi-compartment numerator, being present in high density in fat, and in lower density in carbohydrates; we can use measurements of carbon in multi-compartment equations for both. All of these are measurements of elements, almost uniquely the province of activation methods. This track, our second question, leads us directly to the arguments for gamma nuclear resonant absorption. This brings us to the December 2000 conference where this new method was introduced.

The objectives for this one-day advanced workshop on body composition studies addressed specifically new needs and future trends in body composition analysis, based on the effectiveness of current studies. Five broad objectives can be stated as:

- To expose physicians and clinical scientists to current and newly emerging methods, and their power to perform elemental analysis in vivo.

- To bring into focus the current status of the primary methods, primarily neutron activation, -and the role they play vis-à-vis emerging surrogate methods such as DXA, BIA, and potentially other types of devices.

- To identify new applications for body composition research outside the traditional fields of osteoporosis, obesity, aging, and normal populations, where it has been applied in the past.

- To identify whether the new fields and research directions impose new requirements on the future instrumentation for in vivo elemental analysis.

- To identify the clinical utility of body composition measurements 


\section{ABSTRACTS}

9:30 - 9:50 Are Elemental Studies Relevant to Clinical Medicine? In Search of the Numerators Some Boundary Conditions in Body Composition

Richard N. Pierson Jr., M.D.

Professor of Clinical Medicine

Nutrition Research Center

St. Luke's/Roosevelt Hospital Center

Columbia College of Physicians and Surgeons

The denominators. Imaging technologies have recently revolutionized Body Composition by providing measurements of organ volume, and other organ characteristics such as calcification, lipid content, and density, with increasing resolution - progressing from inches down to millimeters and beyond - with increasing ease of performance in clinical settings. What Heymsfield first envisioned with Computerized Tomography in 1978 has progressed, via the increasingly well-inhabited pathways of Dual Energy Absorptiometry, Magnetic Resonance Imaging, MR spectroscopy, to provide astounding anatomic insights, which could be made relevant to quantitative physiology and medicine. The capacity to produce, manipulate, and analyze images has been funded and disseminated in Radiology by marketdriven advances which have motivated the design of new instruments, an industry which has served Body Composition research with spectacular advances, providing a richness of non-invasive anatomical precision for measuring organ volumes and structure. These developments have made measurement of the denominators for body composition, organs and tissues, both specific and exquisite.

The numerators. A parallel but less traveled track in body composition research begins at the atomic level, in search of the molecular biochemistry, which runs our engines and organizes our activities. A basic example of "why the numerators" is the search for a solution to the Nernst equation, which describes the molecular engine for generating electric potential in muscles and nerves, based on the transmembrane concentration differentials of sodium and potassium, and their energy-requiring transfers with depolarization and repolarization. Two other examples will be given in which measurement of the numerator must be married to the denominator volumes to accomplish research goals. My generation has attended the marriage these two tracks in body composition research. The program today will give examples of where this marriage leads us - which is not far enough. Essential for measuring the elements, the technologies of neutron activation have left us far short of matching Imaging in achieving spatial precisions relevant to studying organs smaller than skeletal muscle. We need to do better with the numerators.

A new technology? Gamma nuclear resonance will measure some of the elements we need, with some spatial definition, with excitingly low radiation exposures, and with exciting quantitative precisions. Dr. Wielopolski will describe this technology, in an audience of some of those best equipped to apply it, and in the presence of a sprinkling of the physical scientists who have attended the birth of the method, and who may learn from and contribute to the interactions.

9:50 - 10:10 INSTRUMENTATION FOR BODY COMPOSITION ANALYSIS, PRESENT AND FUTURE

Lucian Wielopolski*, and Walton Shreeve

*ucian Wielopolski, Ph.D.

Scientist

Brookhaven National Laboratory 
Adjunct Associate Professor

Radiation Oncology Department

SUNY Stony Brook

Environmental Sciences Department

Upton, NY

The need to determine the composition of a human body on atomic, molecular, cellular, and tissue-system levels, is tightly related to whether and how the study elucidates the body's metabolism, or organ's functions. The effect of an environmental change, e.g., illness, and the efficacy of a countermeasure, must be evaluated. These four levels relate to each other through empirical and stoichiometric coefficients that in the past have been determined through in vitro and in vivo methods. It has also been established that these relationships are age- and ethnicity-, as well as ailment-, dependent.

Two general types of methods can be identified: 1) direct with high specificity, and 2) indirect with little or no specificity. The current status and characteristics of in vivo neutron activation analysis (IVNA), highly specific systems for in vivo elemental whole body analysis, is described. IVNA includes; delayed gamma neutron activation (DGNA), prompt gamma activation (PGNA), and inelastic neutron scattering (INS). These highly specific systems fundamentally differ from surrogate methods in that on the atomic level they measure explicitly the element of interest. This is in contrast to the indirect systems that measure some general property that is associated with the compartment of interest. New trends and requirements in body composition research, and an emerging new technology with 3D elemental imaging capability and increased regional sensitivity that satisfies these new requirements will be also presented.

10:10 - 10:25 BONE LOSS, THERAPEUTIC INTERVENTIONS, AND QUANTIFICATION OF SkELetal CHaNGes IN PERSONS WITH SPINAL CORD INJURY

William A. Bauman, M.D.

Professor of Medicine

Mount Sinai School of Medicine

Director of the Spinal Cord Damage Research Center

VA Medical Center, Bronx, NY

After acute skeletal immobilization from spinal cord injury (SCI), bone mass of the legs and pelvis is markedly reduced. To control for genetic diversity, a study was performed in monozygotic twins (one of each set of twins having chronic, motor complete paraplegia) which permitted the study of the effect of chronic immobilization on bone mass and for the evaluation of regional effects of muscle and fat on bone mass. Despite not having been validated in persons with SCI, DXA was used to determine regional skeletal and soft tissue mass. In our twin model, significant leg bone mass continued to decline throughout the chronic phase of immobilization. Although muscle was significantly related to BMC in the legs of non-SCI twins, this was not found in SCI twins, but was significantly related to regional fat mass. Interventions should be directed first at bone loss during the acute period of immobilization with agents that interfere with osteoblastic activity, i.e., reduce bone resorption. During the chronic phases of SCI, therapies should be considered to up-regulate the osteoblast, i.e., stimulate bone formation. Application of IVNA will permit quantification of total and regional calcium changes and its relationship to soft tissue with definitive accuracy after acute and chronic injury, as well as after therapeutic intervention.

10:25 - 10:40 THE EFFECT OF IMMOBILIZATION ON SOFT TISSUE BODY COMPOSITION IN PERSONS WITH SPINAL CORD INJURY

Ann M. Spungen, Ed.D. 


\section{Assistant Professor of Medicine \\ Mount Sinai School of Medicine \\ New York, NY \\ Assistant Director, Spinal Cord Damage Research Center \\ VA Medical Center, Bronx, NY}

Acute spinal cord injury ( $\mathrm{SCl}$ ) is associated with the rapid loss of skeletal muscle in the denervated regions with atrophy of the remaining innervated muscles within the first 2 months due to disuse. Percent fat appears to be greater and increases more rapidly with advancing age than in the ablebodied population. Only a few studies have attempted to document any of these adverse changes. These studies report on the use of a variety of lean and fat tissue measurement methods, all of which have been validated only in an able-bodied population. The methods currently employed for measuring lean and fat tissue mass in persons with $\mathrm{SCI}$ may not be sensitive enough to determine efficacy from therapeutic interventions. Additionally, the ability to isolate specific regions of the body for changes (e.g., to determine the effect of anabolic steroid administration on the muscles of breathing by measuring the lean tissue of the trunk in persons with tetraplegia) is of relevance, but this technology is not readily available Questions arise as to the severity of the effects of acute and chronic immobilization on soft tissue (lean and fat) body composition, as well as the additional effect of aging. This presentation will review the existing literature and discuss the limitations of our knowledge of body composition in persons with SCI. The potential application of IVNA to body composition measurements in persons with $\mathrm{SCI}$ also will be discussed. AND FUTURE DIRECTIONS

Steven B. Heymsfield, M.D.

Professor of Clinical Medicine

Nutrition Research Center

St. Luke's/Roosevelt Hospital Center

Columbia College of Physicians and Surgeons

An important aspect of the contemporary study of nutritional diseases is establishing the phenotypic characteristics of human subjects. These phenotypes are then linked with underlying genetic mechanisms. The process of simultaneously studying human phenotypes and genotypes has given rise to the increasingly important area of characterizing human body composition.

Early workers had relatively simple means of measuring the various body compartments, particularly total body fat. The so-called "two-compartment model" served this process very well and was based on the concept that human body mass consists of two major components, fat and fat-free mass. In order to divide body mass into these two components a number of assumptions were usually required. For example, the water content, the potassium content, and the density of fat-free mass were assumed stable and constant in all adult human subjects. This assumption allowed development of various twocompartment models, as water, potassium, and the density of fat-free mass were all measurable in vivo using underwater weighing. The two-compartment model estimates using these various assumed constants served the field of clinical nutrition for over four decades.

Recently however, interest in developing more refined and accurate phenotypes has led to intense scrutiny of the two-compartment model. In particular, it is now clear that the various assumptions involved in the two-compartment model are not appropriate when examining subjects across wide age ranges and particularly between groups that differ in ethnicity. The two-compartment model also completely fails when diseased subjects are considered. This has led to the search for improved methods of phenotyping human subjects that are based on assumptions that are not violated by age and ethnic 
effects. From these endeavors has emerged the concept of multi-component models, the subject of this presentation.

The presentation describes the various families of multi-component models, that is, those methods of fractionating body mass that involve more than two body composition components. I consolidate the ideas of earlier studies and provide the listener with an overview of the various available multi-component models and the required instrumentation for model verification. That is instrumentation capable of measuring regional and organ composition with high specificity that can also serve as a reference standard for the evolving surrogate instrumentation.

11:40 - 12:00 DOES CHRONIC RENAL FAILURE STUNT GROWTH?

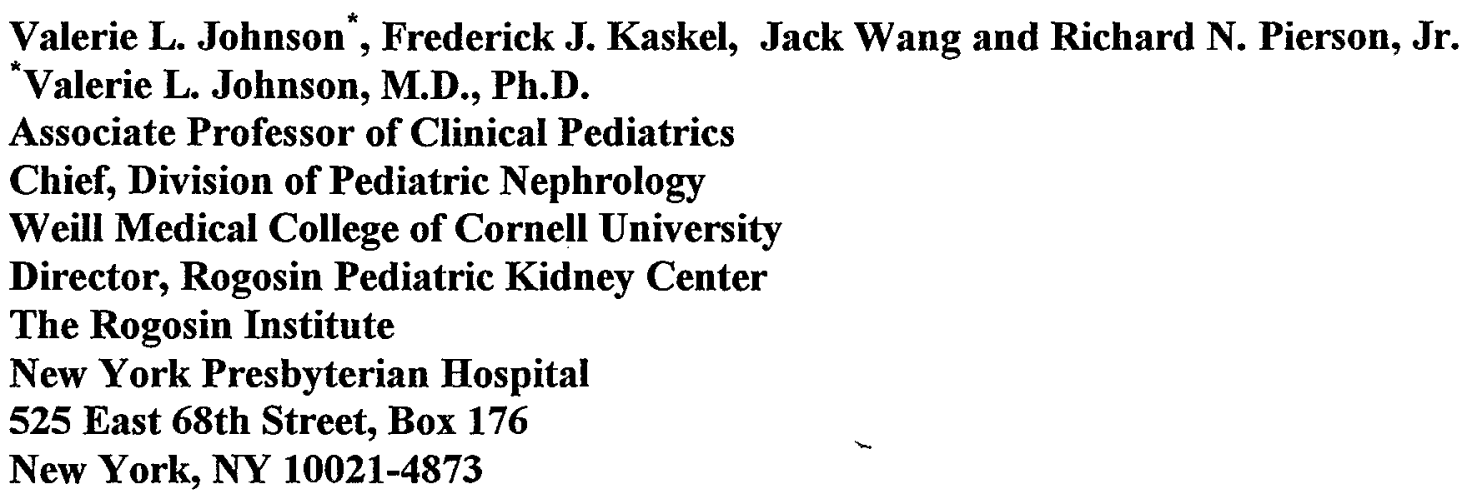

Alterations in body composition are seen in children with chronic renal insufficiency (CRI) and end-stage renal disease (ESRD) who have failed to grow. Recombinant human Growth Hormone (rhGH) has been widely used in the past several years to improve the somatic growth of children with CRI/ESRD. Significant correction of body compositional changes already can be seen in these children after 6 mos of rhGH therapy. To evaluate growth and attendant body compositional changes 7 pre-pubertal $(n=6)$ and pubertal $(n=1)$ children (4.3-13.4 years) were studied longitudinally with body compositional analyses after 6,12 and 18 mos of rhGH. Total body fat (FM; $\pm 1.8 \%$ ), fat free mass (FFM; $\pm 4 \%$ ), total bone mineral mass (TBBM; $\pm 1 \%$ ), total body water (TBW; $\pm 1.8 \%$ ), and potassium (TBK; $\pm 4.2 \%$ ) pre- and postrhGH SQ at $0.35 \mathrm{mg} / \mathrm{kg} /$ week were measured.

As expected significant increases in height and weight were seen following hGH therapy. These increases were accompanied initially by a decrease in fat\% and FM, which leveled off by 18 mos of rhGH. Concomitantly, FFM, TBK, TBW, and ICW, all measures of body cell mass, significantly increased compared to pre-rhGH values. The improvement in the TBBM was profound with significant increases also observed in TBBM corrected for weight by 18 mos post-rhGH. No significant changes in the Body Mass Index were seen. Growth in these children is occurring with repletion of the FFM and TBBM compartments. BMI measurements alone clearly miss these significant changes.

Total body compositional analysis obviously plays a crucial role in our understanding of how growth is occurring in children with CRI/ESRD. The limitations of the technology, however, have prevented evaluation of infants and small children during a period of one of the most rapid growth phases of childhood. Although calcium accretion is certainly occurring in these children, we also need to know more about the quality as well as quantity of bone mineral.

The key issue in applying serial body composition measurements to growing subjects is to identify the upward vectors of growth, the downward vectors of chronic disease, and the upward vectors of treatment. Where the vector parameters are the newly available measurements of body compartments: bone, cell mass, and adipose tissue, in addition to the traditional parameters of renal function. We study small people whom we would like to grow larger, and any radiation we use must be minimal. Have we, and will we, in the new era we have come to expect from Brookhaven, have enough precision in measuring these compartments, to apply these more fundamental measurements to influence patient care? 
Jonathan Sackner-Bernstein ${ }^{*}$, Catalin Toma, Pilar Haynes, Jack Wang, Chris Nunez, John Thornton, Donald Kotler, Richard N. Pierson, Steven B. Heymsfield.

*Jonathan Sackner-Bernstein, M.D.

Associate Director of Cardiology at STL

Assistant Professo of Medicine at Columbia University

St. Luke's-Roosevelt Hospital Center

New York, NY 10025.

Background. Volume overload is the hallmark of congestive heart failure (HF). Yet despite use of diuretics to rid patients of edema, symptoms persist. We hypothesized that patients treated with optimal diuretic doses remain affected by congestion. To test this hypothesis, we assessed body composition of euvolemic HF patients.

Methods. In the fasting state, HF patients $(n=19)$ underwent measurement of: 1) extracellular, intracellular and total body water via bromide and deuterium dilution techniques (ECW, ICW, and TBW, respectively), 2) total cell mass measured by total body potassium (TBK) using whole body 40K counting, and 3) fat-free mass (FFM) by DXA scanning. Results were compared to normal values matched for age, gender, race, height, and weight by Mann-Whitney $U$ test. Patients treated $(n=11)$ and not treated $(\mathrm{n}=8)$ with digoxin were compared.

Results. Patients had left ventricular ejection fraction $<35 \%$, NYHA Class I $(n=1)$, II $(n=13)$, III $(n=4)$ or IV $(n=1)$ symptoms, and were $66 \pm 14$ years old. Compared to normal values, patients were euvolemic (normal TBW and TBW/FFM) and were not cachectic (normal weight, BMI and FFM). However, the ECW/ICW ratio was significantly lower than normal $(14 \%$ lower, $p=.006)$ which paralleled reduced intracellular potassium concentration (Ki) $(19 \%$ lower, $\mathrm{p}<0.0001)$, indicating intracellular edema. Digoxin treatment was not associated with differences in ECW/ICW or Ki.

Conclusions. HF patients without clinical evidence of edema, whose TBW is normal, can have "intracellular edema." This intracellular volume expansion is not a function of $\mathrm{Na}-\mathrm{K}$ ATPase inhibition by digoxin, and may represent an important mechanism in the functional abnormalities of heart failure and a new therapeutic target. These are the first data describing "intracellular edema" measured in vivo in human disease.

\begin{tabular}{|l|l|l|l|l|l|l|l|l|l|l|l|}
\hline & Age & BMI & FFM & $\%$ Fat & TBK & TBW & ECW & ICW & $\begin{array}{l}\text { ECW/ } \\
\text { ICW }\end{array}$ & $\begin{array}{l}\text { TBW/ } \\
\text { FFM }\end{array}$ & Ki \\
\hline HF & $66 \pm$ & $27.3 \pm$ & $50.5 \pm$ & $32 \pm$ & 2721 & $36.7 \pm$ & 13.3 & $23.4 \pm$ & $0.58 \pm$ & $0.72 \pm$ & $114 \pm 13$ \\
& 14 & 6.0 & 13.6 & 8 & \pm 904 & 10.2 & \pm 3.5 & 7.1 & 0.09 & 0.02 & \\
\hline Nml & $66 \pm$ & $27.2 \pm$ & $54.0 \pm$ & $28 \pm$ & 2822 & $36.7 \pm$ & $13.5 \pm$ & $23.2 \pm$ & $0.67 \pm$ & $0.73 \pm$ & $141 \pm 4$ \\
& 14 & 6.0 & 18.3 & 7 & \pm 739 & 7.5 & 1.4 & 6.6 & 0.10 & 0.01 & \\
\hline p & NS & NS & NS & 0.13 & NS & NS & NS & NS & 0.006 & NS & $<0.0001$ \\
\hline
\end{tabular}

$\underline{1: 00-1: 20}$ PROTEIN METABOLISM IN SPECIFIC ORGANS AND TISSUES

Peter J. Garlick, PhD

Professor of Surgery 


\section{Director of Surgical Research GCRC Core Lab Director SUNY Stony Brook}

Malnutrition and many disease states result in body protein wasting, with attendant muscle weakness and increased susceptibility to infection. This has traditionally been investigated by nitrogen balance, which is a measure of protein loss or gain by the whole body. The use of stable isotopic labeling techniques has refined this approach by enabling the mechanisms of protein gain or loss to be attributed to changes in protein synthesis and/or degradation. Originally these methods were used to investigate protein metabolism in the whole body, but have now been refined so that rates of protein synthesis and degradation can be determined in many individual tissues, particularly in skeletal muscle and splanchnic organs. However, despite the increase in knowledge of the regulation of rates of protein synthesis and degradation, information on their net effect on protein balance in these tissues is lacking. Techniques for determining the elemental composition of specific body regions, in particular the nitrogen content, might therefore fill the current void, by showing how treatments that modify protein synthesis or degradation can lead to sustained gain or loss of tissue protein.

\section{$1: 20-1: 40 \quad$ MULTIPLE SCLEROSIS}

Patricia K. Coyle, M.D.

Professor of Neurology and

\section{Director, Stony Brook MS Comprehensive Care Center}

Health Sciences Center

SUNY at Stony Brook

Stony Brook, NY 11794-8121

Multiple Sclerosis (MS) is an organ-specific immune mediated disease, the major non-traumatic neurologic disorder of young adults. 350,000 Americans, and one to 2.5 million individuals worldwide, are affected. In 1994 US dollars, the cost of MS was 10 billion dollars a year. Such costs reflect that most MS patients become disabled.

MS affects the central nervous system (CNS), the brain and spinal cord. Blood immune cells and water move into the CNS through a break in the blood brain barrier (BBB). This results in damage to myelin and axons, destruction of oligodendrocytes (the CNS myelin making glia), and astrocytic gliosis. These focal lesions (called plaques) occur in waves throughout the disease course. They produce disrupted nerve conduction and multiple clinical abnormalities. Most plaques are clinically silent, detected only by magnetic resonance imaging (MRI). MRI is considered the best MS current disease marker. It reveals widespread abnormalities in normal appearing brain tissue, BBB disturbances, heterogeneous pathology, variable iron deposition, chemical disturbances, ongoing atrophy, and axon abnormalities.

The following are current major clinical issues in MS:

- We do not know the cause of MS; it is likely heterogeneous. It may involve CNS infection, a cross-reactive immune attack on a CNS component, or a metabolic or toxic process.

- There is no one definitive diagnostic test for MS.

- Clinical evaluation grossly underestimates disease status. At the current time there is no effective way to follow disease activity and severity.

- There is no established way to follow individual response to therapy. 
Body composition research offers new possibilities to examine MS brain and spinal cord for:

- Water content. This is likely to reflect disease activity/blood brain barrier abnormalities. It could be used to measure disease severity/course, and response to treatment.

- Iron content. Iron deposition disturbances have been described in MS. The question of an iron disturbance could be addressed directly.

- MS heterogeneity could be examined based on CNS chemical changes.

- Early chemical changes might give us clues to the etiology of this disease.

- A chemical which measured a specific pathologic process (myelin breakdown, remyelination, oligodendrocyte loss, axon/neuron dysfunction, gliosis, inflammation) would offer a novel and valuable assessment tool.

Body composition research will provide a new window to the CNS to investigate MS. At the least, accurate measure of CNS water content will be valuable in this disease. At the most, it could lead to critical new insights into MS pathogenesis, severity, and response to therapy. 


\title{
Presentations:
}

\section{Body Composition Research and Brookhaven; a Mandate for the Future}

\author{
RN. PIERSON JR., M.D. \\ Professor of Clinical Medicine \\ Nutrition Research Center \\ St. Luke's/Roosevelt Hospital Center \\ Columbia College of Physicians and Surgeons
}

The beginnings and the ends of several epochs in Body Composition have centered on Brookhaven three times. In 1970, Stanton Cohn started the modern era of elemental analysis in Body Composition by establishing the Neutron Activation program to measure body calcium in Osteoporosis research. This famous beginning, with John Aloia as collaborator, accomplished a great deal, putting the IVNA method on the map in the field of body composition. The second epoch began in 1986 with Stan Cohn's retirement, punctuated by the First International Seminar, which was held at Brookhaven, and included most of the world's pundits in this smallest new specialty at the intersection of Nuclear Medicine and Nutrition Science. At that time in 1986 a Consortium of 53 research-community physicians from the Northeast met to propose a major support grant to carry on and extend the Body Composition program at Brookhaven. This culminated in the NIIH Program Project Grant, led by investigators at St. Luke's/Roosevelt Hospital, first funded in 1989, and carried forward now to its third five-year continuation as of next July.

The third epoch, the application of a new physical method, gamma neutron resonance absorptiometry, to human studies, begins approximately with this workshop. With this method, the exciting advances in 3D imaging reconstructions for body, organ, and tissue volumes from both CT and MRI images, will be matched by a method able to perform regional and 3D measurements of selected elements, which inhabit these volumes. Nitrogen will be the first element so imaged; calcium, carbon, and chlorine will next be researched.

This workshop showcases six clinical studies, which demonstrate in different ways the vitality of body composition research to a current medical discipline. The goal of the workshop is to bring visibility of their work in this field to three groups: to each other, to leaders at BNL who will determine the future allocation of resources at the Laboratory, and to leaders at the DOE. By hearing each-other, and by sharing notes on their projects, we expect that they may choose to expand the range of their research, and that they will participate in and benefit from the next decade of methods development.

National Laboratories have consistently, and by design, been sites for research and development, not for the pursuit of clinical diagnoses and treatments, which are better delivered closer to large hospitals and populations. We have for ten years now brought many patients to Brookhaven, against gradients of inconvenience, making a strong case for the value of these measurements. Under the new leadership at Brookhaven of Drs. Marburger and Paul, we are now presented the exhilarating prospect that Research in Body Composition methods may again occur 
at BNL laboratories, a strong vote of confidence for Lucian Wielopolski, one already backed by the allocation of funds for the accelerator for the GNRA project. The testimony given by these physician-researchers today bears witness to the relevance of this work, and to its future promise.

BODY COMPOSITION: A LITTLE SPECIALTY

\section{A SHORT HISTORY; THE TYRANNY OF METHODS}

\section{SPECIFICS}

First Epoch:

$1850-1942$

PRECISION without BIOLOGY

Chemistry

Second Epoch:

$1942-1963$

BIOLOGY without PRECISION

Indicator

Dilution

Third Epoch:

1963-1986

IN SEARCH of PRECISION

DXA, CT,

IVNA

Fourth Epoch:

$1986-2001$

IN SEARCH of ACCURACY

MRI, GNRA

\section{The Four Compartment Model}

III The Quality of the Body Cell Mass: To Solve the Nernst Equation

$$
\text { Membrane potential }=(f) \frac{\mathrm{K}_{\mathrm{i}}+* *}{\mathrm{~K}_{\mathrm{e}}+* *}
$$

IV The NUMERATORS: Ions

$\mathrm{K}, \mathrm{Na}, \mathrm{Ca}, \mathrm{N}, \mathrm{Cl}$

\section{The DENOMINATORS: Mass and Volume}

TBW, Liver, Muscle, Kidney, Brain

1950-1975 Submission to Tyranny

\section{THE METHODS}

When methods are inadequate; In the Kingdom of the Blind

Surfing the smorgasbord:

Anthropometry

Indicator dilution methods; Water, potassium, sodium, sulfate, plasma, RBC Biolmpedance Analysis

Metabolic spaces, and other transients

1975-2000 Escape from Tyranny?

The methods revolutions

Dual Energy X-Ray Absorptiometry for Everyman

CT/MRI

for the Rich

In-vivo Neutron Activation Analysis

for the Very rich and Fortunate

THE AGENDA 
In Search of the Body Cell Mass: The quality of the body cell mass: why should we measure it?

To Solve the Nernst Equation: The quality of the body cell mass: how we shall measure it.

In normals

To describe growth and development

To describe aging

To guide interventions
Age, sex, race, fatness

Serial studies

\section{Accounting For Body Fat:}

The unruly compartment; the ten methods. Domain specificity

The principle of orthogonal measurements; (the Uncertainty principle)

\section{The Nernst Equation}

The "average cell" problem: from cardiac muscle to liver to intestinal epithelium

The numerators: $\quad \mathrm{K}, \mathrm{Na}$

The denominators: $\quad$ TBW $-\mathrm{ECW}=\mathrm{ICW}$

The Quality Of The Body Cell Mass

How can we measure it?

Intracellular $\mathrm{K}$ and $\mathrm{Na}: \mathrm{K}_{1}$ and $\mathrm{Na}_{1}$, or $\mathrm{K}_{\mathbf{1}}$ alone?

K/FFM

E/I (Extracellular/Intracellular ratio)

Functional measurements as surrogates:

Grip strength, Peak flow rate (Dominance of the skeletal muscle)

The propagation of errors

If Osmolality is conserved; a reasonable compromise?

"Easiest" to measure (where $\mathrm{K}$ is available)

At the bedside

"In the Kingdom of the Blind...."

\section{THE EFFECTS OF DISEASE STATES}

\section{Chronic Diseases: Acute States, Chronic States, And Serial Measurements}

\section{Agendas we have known:}

\section{AIDS}

Osteoporosis

Spinal Cord Injury

Renal Failure; Dialysis regimens, transplantation

Obesity

COPD

Anorexia Nervosa/Bulimia
Kotler, many others

Aloia, Vaswani, many others

Bauman, Spungeon

Cornell, AECOM, Lenox Hill

Kral, PiSunyer, Shapses

Few; Waiting to be done

Walsh, Warren, Mayer 
Rheumatoid states

Aging: a chronic disease, or a normal state?

Sepsis, Trauma
Roubenoff, Merrill

Gallagher, Harris, Heymsfield

Moore, Kinney, Abumrad 


\title{
INSTRUMENTATION FOR BODY COMPOSITION ANALYSIS
}

Present AND FUture

\author{
LUCIAN WIELOPOLSKI \\ Brookhaven National Laboratory \\ Environmental Sciences Department \\ Upton, NY 11973
}

$\&$

WALTON SHREEVE

Brookhaven National Laboratory

Medical Department,

Upton, NY 11973

\begin{abstract}
The need to determine the composition of a human body on an atomic, molecular, cellular, or tissue-system level, is tightly related to whether and how the study involves the body's metabolism or organ function. The effect of an environmental change, e.g., illness, and the efficacy of a countermeasure can be importantly evaluated. These compartments relate to each other through empirical and stoichiometric coefficients that in the past have been determined, at least partially, through in vitro and in vivo methods. It has also been established that these relationships are age and ethnicity, as well as ailment, dependent.

Two general types of systems can be identified: 1) direct with high specificity, and 2) indirect with low or no specificity. The current status and characteristics of in vivo neutron activation analysis (IVNA), highly specific systems in use for in vivo elemental whole body analysis, are described. IVNA includes; delayed gamma neutron activation (DGNA), prompt gamma activation (PGNA), and inelastic neutron scattering (INS). These highly specific systems fundamentally differ from other surrogate instrumentation in that on the atomic level they measure explicitly the element of interest. This is in contrast to the indirect systems that measure some general property that is associated with the compartment of interest. New trends and requirements in body composition research and an emerging new technology with 3D elemental imaging capability and increased regional sensitivity that satisfy these new requirements are also presented.
\end{abstract}

\section{INTRODUCTION}

Body Composition Analysis (BCA), a little-known specialty with great potential as a diagnostic tool for clinical research and patient care, remains by and large misunderstood and underutilized in medical practice. These facts are disappointing in light of the great strides that were made in many of the BCA concepts since the initial introduction of the subject about fifty 
years ago, that span from pure Physics and Chemistry to bedside Physiology in patient care [1]. The concepts and merits of viewing human body on four different levels, i.e., atomic, molecular, cellular, and tissue-system, and how they relate to body metabolism and function were outlined in the literature $[2,3]$, and it is also discussed in this workshop by Heymsfield. Each level consists of several compartments that in several cases are quantifiable through an indirect measurement of a quantity that is related to the compartment. However, the atomic compartments are the only ones that can be measured explicitly because of the direct and specific measurements of the elements present in the human body. The surrogate type of instrumentation that measures the compartments indirectly is usually calibrated or cross-validated against the nuclear direct measurements. Traditionally these measurements involved whole body and were referred to as such. However, in this continuously evolving field, there is a shift in emphasis and there is a growing interest toward partial body and organ level compartmental analysis. This in turn redefines the old requirements and imposes new specifications on the next generation of the instrumentation for in vivo compartmental analysis.

\section{ELEMENTAL ANALYSIS:}

Elemental analysis of the human body in vivo consists of, but is not limited to, measuring the basic atomic constituents such as $\mathrm{C}, \mathrm{Ca}, \mathrm{Cl}, \mathrm{N},-\mathrm{K}, \mathrm{Na}, \mathrm{P}, \mathrm{H}, \mathrm{O}$ (and water) and subsequently relating them to the size of the compartments on either the molecular, cellular, or tissue-system level. These elements are measured directly in vivo utilizing nuclear methodologies that involve neutron activation, thus are frequently referred to as IVNA. Three basic neutron interactions with nuclei are taken advantage of to measure different elements. Those are delayed gamma neutron activation, DGNA, prompt gamma neutron activation PGNA, and prompt gamma inelastic neutron scattering, PGINS, this reaction is also labeled as $\left(n, n^{\prime} \gamma\right)$ [4-8].

\section{DGNA}

In DGNA, developed during the sixties, various elements capture thermal neutron and becomes radioactive. Subsequent to activation the elements are measured in a special counter. During DGNA a subject is irradiated with neutrons in an irradiation facility for about five minutes, Fig. 1A. The elements such as, $\mathrm{Ca}, \mathrm{Na}, \mathrm{Cl}$, and $\mathrm{P}$ capture thermalized neutrons in the human body and become radioactive. Following irradiation the patient is transferred to a low background counting facility, Fig. 1B, where the characteristic gamma radiation emitted from the activated elements is detected, counted and translated into elemental concentration in the body. Natural $\mathrm{K}$ in the human body, being radioactive, is measured in the same counting facility prior to the patient irradiation. The irradiation facility consists of $14 \times 40 \mathrm{Ci} \mathrm{PuBe}$ neutron sources that deliver about 560 mrem during $5 \mathrm{~min}$ irradiation. During $3 \mathrm{~min}$ following irradiation patient is transferred to the counting facility for $15 \mathrm{~min}$. The counting facility consists of 16 above the bed and 16 below the bed 4 " $\times 4$ "'x18" $\mathrm{NaI}$ detectors. The resulting spectrum with $\mathrm{Ca}, \mathrm{Cl}, \mathrm{Na}$, and $\mathrm{P}$ is shown in Fig. 2. This spectrum is analyzed for the peak intensities and using proper calibrations converted into elemental abundance.

\section{PGNA}


PGNA, developed during the seventies, is very similar to DGNA where instead of measuring delayed gammas the excited nucleus decays promptly to the ground state with concomitant emission of gamma radiation that is measured immediately by the detection system. PGNA system, shown in Fig. 3, is used for detection of $\mathrm{N}$ in the human body. Because of the short time of the excited level these gamma rays must be counted during the irradiation resulting in a facility design that differs fundamentally from that for the delayed neutron activation. The facility consists of a $70 \mathrm{Ci} \mathrm{PuBe}$ neutron source and two large 6" by 6" high NaI detectors. A dose of $80 \mathrm{mrem}$ is delivered during $40 \mathrm{~min}$ scan. Finally, the $\mathrm{N}$ yield in the measured spectrum is converted into elemental concentration and the corresponding compartment mass in the subject.

\section{PGINS}

In PGINS, developed during the eighties, an element absorbs a fast neutron and returns promptly to the ground state via emission of a neutron, at lower energy, and concurrent gamma ray specific to the element. The configuration of this facility is similar to that of PGNS except the PuBe neutron source is replaced with a $14 \mathrm{MeV}(\mathrm{D}, \mathrm{T})$ neutron generator. PGINS, shown in Fig. 4, is used to measure total body carbon and oxygen. To provide more uniform irradiation conditions in this facility and in PGNA the patient is scanned twice (supine and prone). A dose of $50 \mathrm{mrem}$ is delivered during the $40 \mathrm{~min}$ scan.

\section{DIRECT VERSUS SURROGATE INSTRUMENTATION}

In direct methods the quantity of interest is measured directly by whatever available means. Such were the methods described above in which high specificity is attained using nuclear spectroscopy that measures characteristic gamma radiation from a given element of interest. Alternatively, other compartments on higher levels cannot be measured directly. For that purpose different methods, often referred to as surrogate methods, are used to measure a given compartment. In this approach a quantity related to the compartment of interest is measured. For example whole body density is measured using underwater weighing (UWW), body impedance (BIA) is measured as an indicator of the electrolytes in the water, and dual energy x-ray absorptiometry (DXA) provides information on electron density from which bone mineral and soft tissue density are extracted. There are assumptions and models involved with the surrogate instrumentation that were developed for specific cases and span over determined region. However, whenever new populations or cases are analyzed indirect methods require crosscalibration and new validation. It is pointed out that some of the indirect methods are those that will actually spread into clinical surroundings because of theirs simplicity, e.g., DXA.

Similarly, CT and MRI that measure electron and proton densities, respectively, provide after segmentation an indirect measure of volume, which can subsequently be related to a given compartment of interest. Undoubtedly, availability of MRI in the hospitals and clinics will facilitate spread of body composition measurements for routine use. MRI spectroscopy in some limited cases may provide a measure of a functional compartment of interest. This approach is in developmental stages and the quantitative aspects of it are cumbersome. 


\section{FUTURE TRENDS AND INSTRUMENTATION}

An excellent overview of the future trends in clinical research using body composition analysis was given in the proceedings of the Serono Symposium by Pierson [1]. It is apparent that the questions posed to the clinical researchers are more challenging, specific, and regional. The results for the whole body, as important as they are, are inadequate and the emphasis shifts to the composition of a region or an organ. There is a ceaseless desire to reduce the radiation dose or even to eliminate it all together when possible. In this regard the emergence of MRI in assessing body composition is very promising, although it is an indirect measurement. Similarly, additional work in calibrating multi-frequency BIA is also recommended. Thus with the trend of improving and developing new surrogate instrumentation there will be a need for stricter calibration requirements to be provided by the primary methods.

The new demands for the primary instrumentation can be summarized as:

1. To reduce the radiation dose so that the methodology can be expand to include children and pregnant women.

2. To provide regional or organ localization capability.

3. To provide absolute results independent of human habitus, i.e., to eliminates the need for phantoms.

A new method based on gamma nuclear resonance absorption (GNRA) offers new capabilities in elemental analysis in human body in vivo. The GNRA principle is that gamma radiation in addition to the conventional attenuation undergoes resonance attenuation specific to a given element such as $\mathrm{N}, \mathrm{Ca}, \mathrm{Cl}$, or $\mathrm{C}$, see Table $\mathrm{I}$, [9]. A resonance gamma beam, a beam that is tuned to interact with a specific nuclear level of an element of interest, is emitted as a fan beam from a target impinged upon by a proton beam from an accelerator. Schematically this is shown in Fig. 5. A GNRA system was originally developed for detection of explosives in aviation by detecting nitrogen in cargo containers. For that purpose a special high intensity proton tandem accelerator $[10,11]$ and resonance detectors [12] were developed and a proof-of-principle for $\mathrm{N}$ detection was demonstrated. The system was subsequently proposed for use in elemental analysis in vivo $[13,14]$.

The fundamental difference between GNRA and previously presented IVNA systems, apart of using gamma radiation instead of neutrons, is the positioning of the detectors in GNRA in a transmission mode. This is schematically shown in Fig. 6 where the patient is placed in the beam between the source and the detection system. This is an identical configuration to that of a CT, thus allowing by rotating the patient to image nitrogen distribution in vivo.

A second critically important advantage of GNRA is the use of resonance detectors that measure simultaneously in resonance and out of resonance beam attenuation. Thus correcting the resonance intensity by the total attenuation, i.e., non-resonance attenuation provides an absolute measure of the nitrogen concentration that is independent of patient size. This eliminates the need for size dependent phantom calibrations. 
Finally for similar measurements a GNRA system will deliver about $1 \%$ of the dose delivered by PGNA.

Table I. Elements that can be analyzed using GNRA.

\begin{tabular}{|c|c|c|c|c|c|}
\hline Element & $\begin{array}{l}\mathbf{E}_{\boldsymbol{\gamma}} \\
(\mathrm{MeV})\end{array}$ & $\begin{array}{l}\sigma_{\text {abs }} \\
\text { (barns) }\end{array}$ & Target & $\begin{array}{l}\mathbf{E}_{p} \\
(\mathrm{MeV})\end{array}$ & Reaction \\
\hline${ }^{\mathbf{m}} \mathbf{N}$ & 9.17 & 2.6 & ${ }^{13} \mathrm{C}$ & 1.75 & ${ }^{13} \mathrm{C}(\mathrm{p}, \gamma){ }^{\mathbf{1}} \mathrm{N}$ \\
\hline${ }^{40} \mathrm{Ca}$ & 10.32 & 5.0 & ${ }^{39} \mathbf{K}$ & 2.04 & ${ }^{39} \mathrm{~K}(\mathrm{p}, \gamma)^{40} \mathrm{Ca}$ \\
\hline${ }^{35} \mathrm{Cl}$ & 8.21 & 1.0 & ${ }^{34} \mathrm{~S}$ & 1.89 & ${ }^{34} \mathrm{~S}(\mathrm{p}, \gamma)^{35} \mathrm{Cl}$ \\
\hline${ }^{16} \mathrm{O}$ & 6.92 & 2.4 & ${ }^{19} \mathbf{F}$ & 2.6 & ${ }^{\ominus} F(p, \alpha \gamma)^{16} \mathbf{O}$ \\
\hline${ }^{2} \mathbf{C}$ & 4.43 & 1.1 & ${ }^{15} \mathbf{N}$ & 2.6 & ${ }^{15} \mathrm{~N}(\mathrm{p}, \alpha \gamma)^{12} \mathrm{C}$ \\
\hline
\end{tabular}

\section{SUMMARY}

A distinction was made between primary, IVNA, systems that provide a direct measure of the compartment in question and secondary or surrogate systems that are simpler but easily deployable. The lack of specificity in the surrogate instrumentation has to be thoroughly calibrated and or validated using primary systems. An exception to this is MRI spectroscopy that might evolve into a primary system. The importance of the surrogate systems is in their deployability that will allow the spread of body composition analysis in the clinic. However, normative values for the clinic have to be established before these system will gain wide spread use by the physicians.

The development of GNRA offers an unparalleled capability of elemental imaging in vivo for key important elements in human body. This will facilitate organ compartmental analysis or specific regions of interest such as chest muscles that are impossible to measure any other way. The absolute measurement and reduced dose will allow expanding compartmental analysis to children and pregnant women, two populations excluded from IVNA measurements. In summary the role of the primary systems is to provide reference values, the development of GNRA will introduce new dimensions and infuse new life into body composition studies.

\section{REFERENCES}

1. Pierson Jr. RN., "Quality of the Body Cell Mass; Body Composition in the Third Millennium." Serono Symposia USA, Norwell, Massachusetts, Springer, 2000.

2. Wang ZM, Pierson RN Jr, Heymsfield SB. The five level models: a new approach to organizing body composition research. Am. J. Clin. Nutr., 56:19-28, 1992.

3. Wang ZM, Heshka S, Pierson RN Jr, Heymsfield SB. Systematic organization of body composition methodology: overview with emphasis on component-based methods. Am. J. Clin. Nutr., 61:457-465, 1995. 
4. Forbes GB., Gallup j., and Mrsch JB., Estimation of total body fat from content, Science, $133,101-102,1961$.

5. Anderson J., Osborn SB., Thomlison RWS., Newton D., Rundo J., Salmon L., and Smith J. Neutron activation analysis in man in vivo: a new technique in medical investigation. Lancet, ii, 1201-1205, 1964.

6. Vartsky D., Ellis KJ., and Cohn SH., In vivo measurement of body nitrogen by analysis of prompt gammas from neutron capture. J. Nucl. Med. 20, 1158-1165, 1979.

7. Cohn SH., and Parr RM., Nuclear-based techniques for the in vivo study of human body composition. Clin. Phys. Physiol. Meas., 6, 275-301, 1985.

8. Kehayias JJ., Ellis KJ., Cohn SH., and Weinlein JH., Use of high-repetition rate neutron generator for in vivo body composition measurements via neutron inelastic scattering. Nucl. Instr. \& Methods in Phys. Research, B24/25, 1006-1009, 1987.

9. Metzger F.R., Resonance Fluorescence in Nuclei, Progress in Nuclear Physics Vol. 7, 54-88, 1959.

10. Sredniawski J.J., Debiak T.W., Kamykowski E., Rathke J., Milton B., Rogers J., Schmor P., Stanford G., and Brondo J., A Contraband Detection System Proof-Of-Principle Device Using Electrostatic Acceleration, Proc. Of the $18^{\text {th }}$ Int. Linear Accelerators Conf., Geneva, 444-446, 1996.

11. Melnychuk S.T., Cole M.D., and Sredniawski J.J., Beam Emittance, Transmission, and Intensity Distribution Measurements of the Northrop Grumman Corporation $1,76 \mathrm{MeV}$ Pulsed Beamline and Contraband Detection System Target Test Facility, Proc. Of the $18^{\text {th }}$ Int. Linear Accelerators Conf., Geneva, 476-478, 1996.

12. Vartsky D., Engler G., and Goldberg M.B., A Method for Detection of Explosives Based on Nuclear Resonance Absorption of Gamma Rays in ${ }^{14} \mathrm{~N}$, Nucl. Inst. Meth., A348, 688-691, 1994.

13. Vartsky D. Goldberg M.B., Bar D., Goldschmidt A., Feldman G., Sayag E., Katz D., Stronach I.M., Stark J.W., Prestwich W.V., McNeili F.E., and Chattel D.R, Gamma Ray Nuclear Resonance Absorption: An Alternative Method for In Vivo Body Composition Studies. In Vivo Body Composition Studies, Eds. S. Yasumura, J. Wang, and RN Pierson Jr. Annals of the New York Academy of Sciences 904: 236-246, 2000.

14. Wielopolski L., Vartsky D., Pierson R., Goldberg M., Heymsfield S., Yasumura S., Melnychuk S., and Sredniawski J., Gamma Resonance Absorption New Approach in Human Composition Studies. In In Vivo Body Composition Studies, Eds. S. Yasumura, J. Wang, R. N. Pierson Jr., Annals of the New York Academy of Sciences, 904 (2000) 229235 . 
$\mathbf{A}$

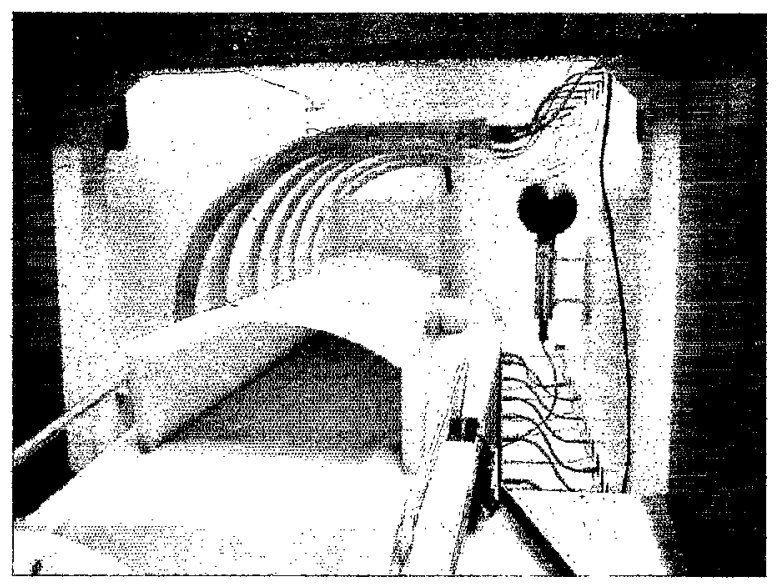

B

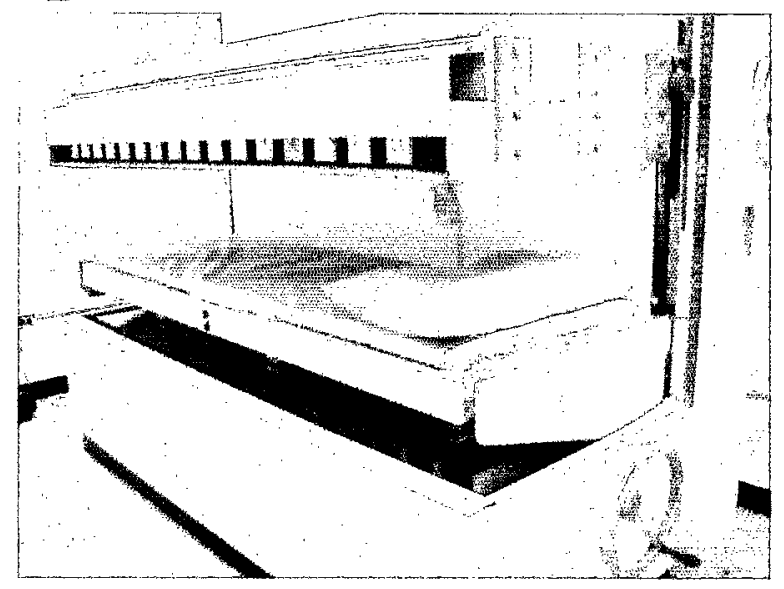

FIG. 1 Delayed Neutron Activation facilities, A) irradiation facility with a sliding patient bed, B) patient whole body counter.
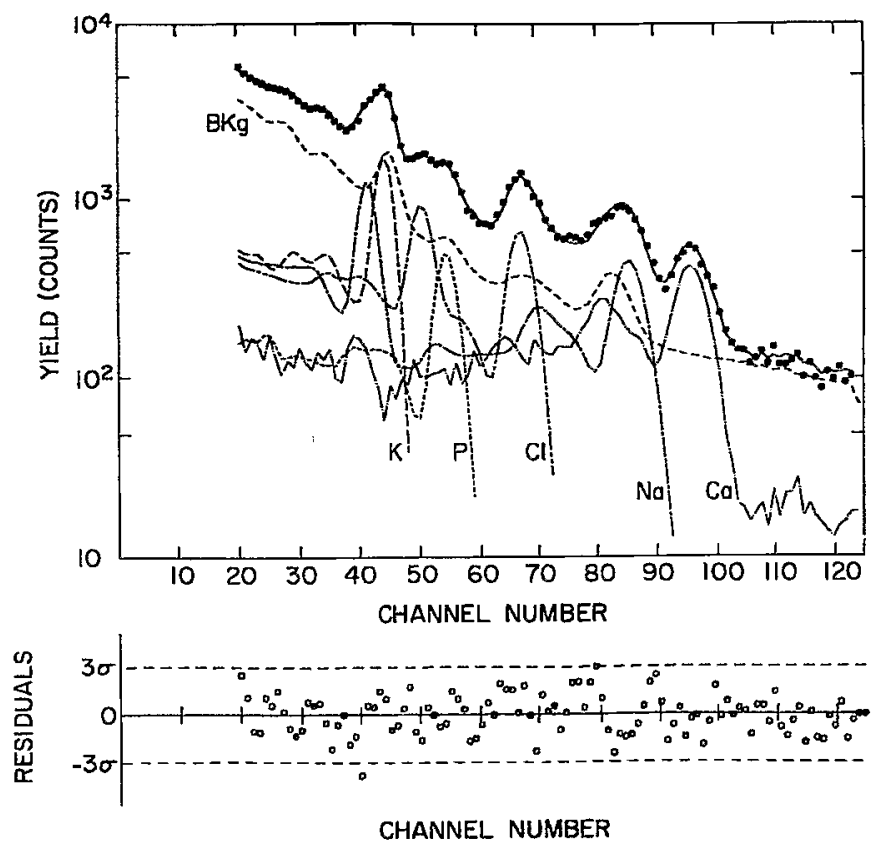

Figure 2. A typical spectrum from an irradiated patient measured in the whole body counting facility. 


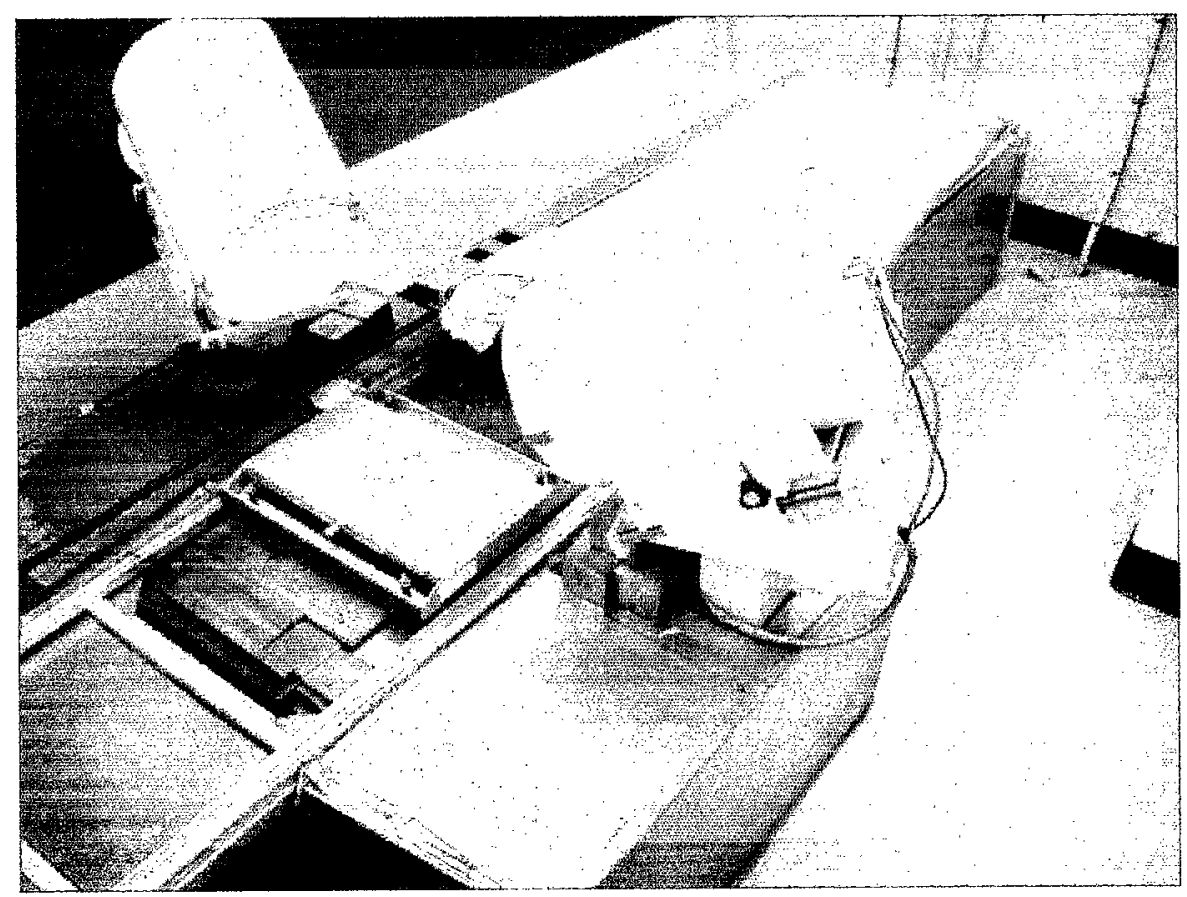

Figure 3. Prompt gamma irradiation and counting facility.

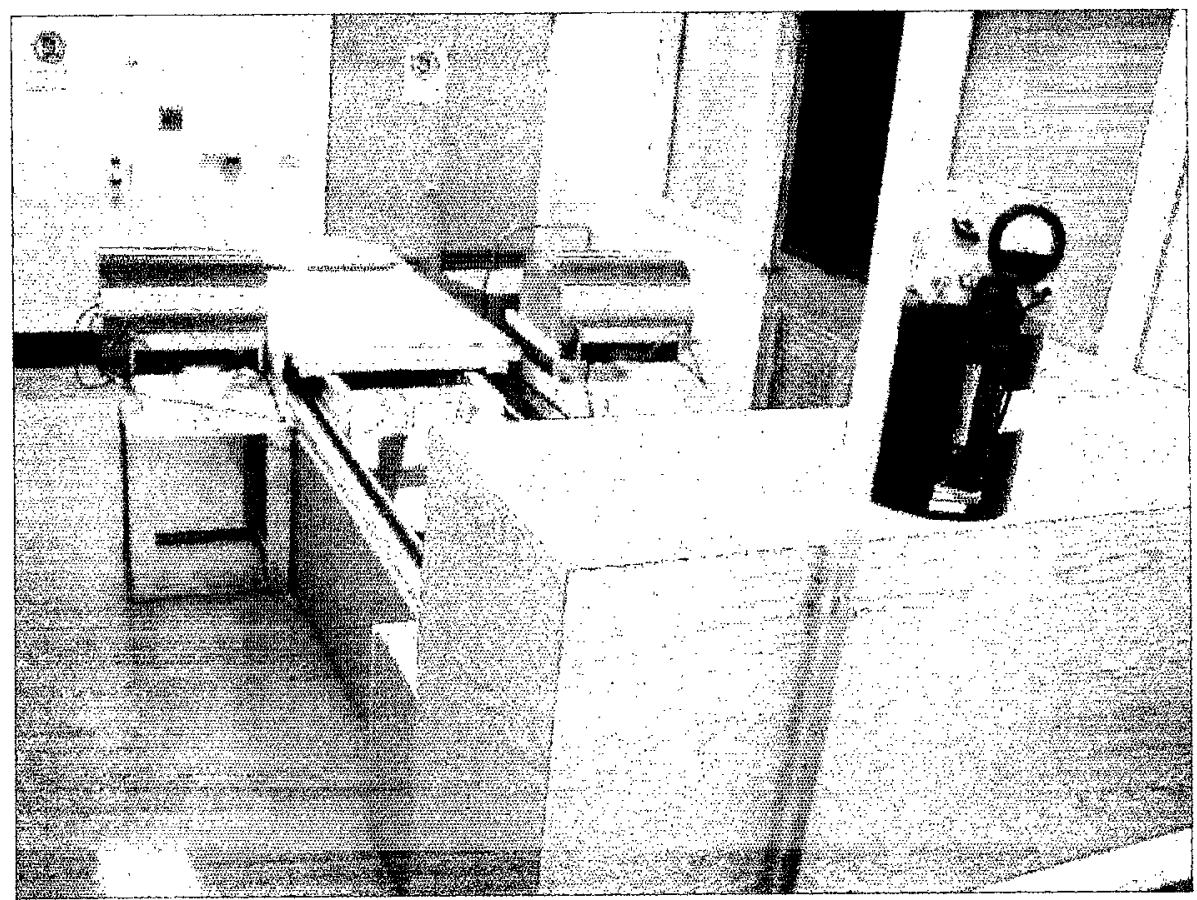

Figure 4. Inelastic neutron scattering irradiation and counting facility. 


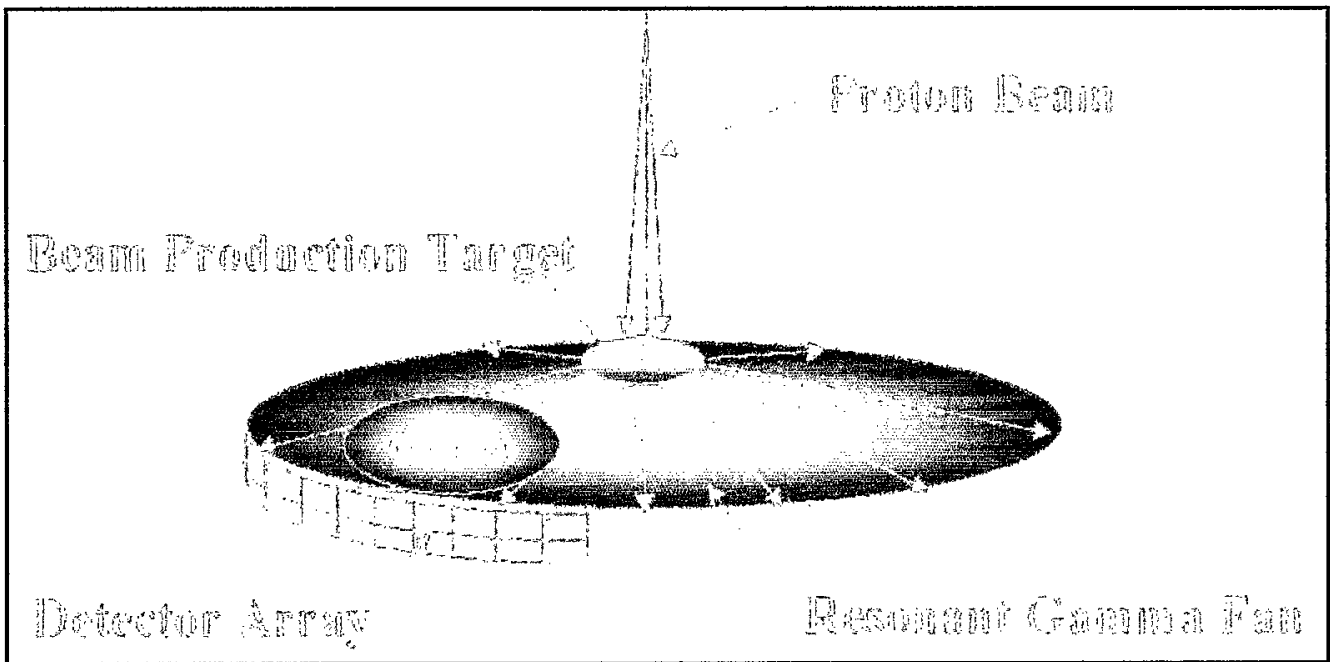

Figure 5. Artist drawing of the resonant gamma beam production.

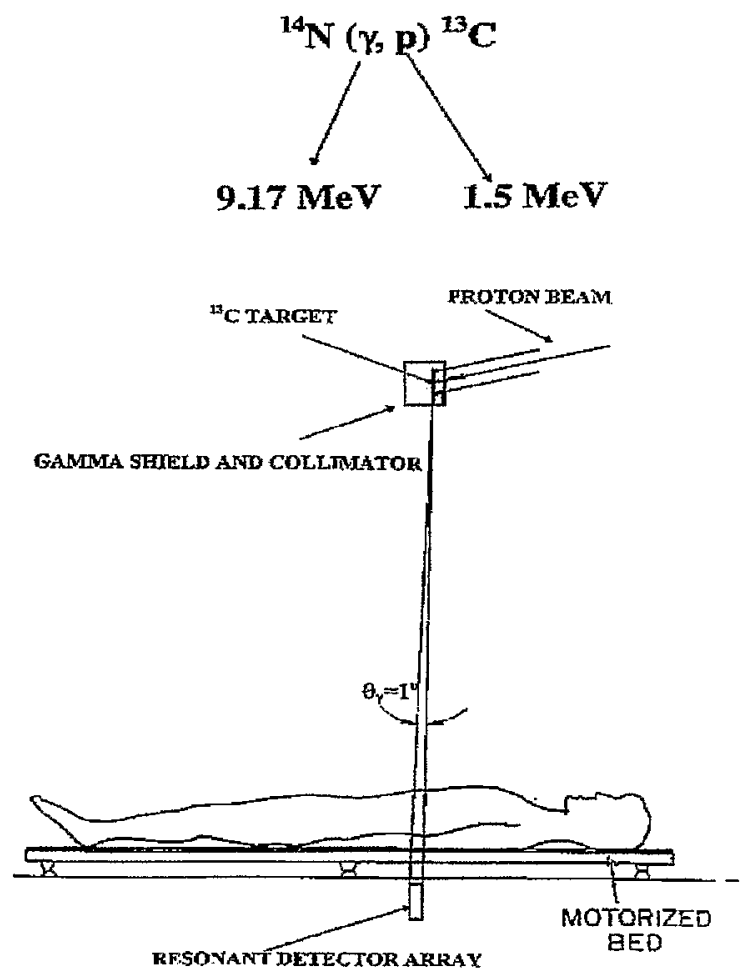

Figure 6. Schematic configuration of the gamma beam, patient, and detection system for nitrogen imaging in vivo. 
BONE LOSS, THERAPEUTIC INTERVENTIONS, AND QUANTIFICATION OF SKELETAL Changes in PERsons wITH SPINAL CORD INJURY

\author{
William A. Bauman, M.D. \\ Director, Spinal Cord Damage Research Center \\ Professor of Medicine and Rehabilitation Medicine \\ Mount Sinai School of Medicine \\ New York, NY \\ $\&$ \\ ANN M. SPUNGEN, ED.D. \\ Associate Director, Spinal Cord Damage Research Center \\ Research Associate Professor of Medicine and Rehabilitation Medicine \\ Mount Sinai School of Medicine \\ New York, NY
}

\title{
Acknowledgements:
}

This work was supported by the Department of Veterans Affairs, Spinal Cord Research Foundation, the Eastern Paralyzed Veterans of Association, Mount Sinai School of Medicine, and the National Institute on Disability and Rehabilitation Research (NIDRR) Grant \# H133B30029. 


\begin{abstract}
Spinal cord injury produces immediate and permanent unloading of the gravity-bearing skeletal regions with structural and metabolic consequences. During the acute phase, a proliferation of osteoclasts with immobilization-induced resorptive hypercalciuria occurs, with associated suppression of the parathyroid hormone-1,25-dihydroxyvitamin D axis. Subsequently, from a study performed in identical twins, one of each set having a spinal cord injury, it appears that there is a continuous loss of bone mass in the legs and pelvis of those with chronic paraplegia. Interventions have been considered to reduce the rapid bone loss after acute injury by inhibiting bone resoportion with bisphosphonates or to increase bone mass in those with chronic injury by stimulating bone formation. In able-bodied twins there is a relationship between lean tissue and limb bone mass, which is not present in those with paralysis. However, in twins with spinal cord injury there appears to be a relationship between regional fat and bone mass, which is absent in ambulatory twins. Because these bone and soft tissue measurements were made using dual energy $x$-ray absorptiometry, legitimate questions may be raised concerning their accuracy and reliability because this technique has been validated in the ablebodied population, not in those with spinal cord injury who have regional changes of an extreme magnitude. In individuals with spinal cord injury, it would be important to validate dual energy $\mathrm{x}$-ray absorptiometry by performing in vivo neutron activation analysis. The new technology of gamma ray nuclear resonance absorptiometry would provide an element specific imaging capability, e.g., $\mathrm{N}, \mathrm{Ca}, \mathrm{C}$, while generating a conventional radiograph of the subject that may be used to determine regional measurements of bone and soft tissue components.
\end{abstract}

\title{
Acute Spinal Cord Injury
}

After acute immobilization, calciuria increases in 10 days, peaking between 1 and 6 months after injury (Figure 1) $(1,2)$. The maximum urinary calcium in those with spinal cord injury was between two to four times that of able-bodied subjects who were voluntarily placed at prolonged bed rest. After acute spinal cord injury, the parathyroid hormone (PTH)-vitamin D axis is suppressed with depressed PTH, 1,25-dihydroxyvitamin D and nephrogenous cyclic AMP levels (Figure 2) (3). Although urinary calcium was markedly elevated on a low calcium diet, increasing dietary calcium in a subset of patients with acute spinal cord injury did not further increase either urinary or serum calcium concentrations (3).

Histomorphometry performed in rat models after immobilization suggests that bone loss occurs in two phases, each by different mechanisms. In the first phase, which is the period immediately after immobilization $(4,5)$, increased osteoclastic activity is evident, with peak activity between 3 and 5 days. There is a disruption of trabecular architecture, with loss of trabeculae and loss of connections between trabeculae. Because bone grows and remodels appositionally, the loss of trabeculae and intervening struts compromises the normal deposition of bone because of the absence of an existing framework, thus reducing bone structural integrity. Bone resorption in the rat returns to normal levels by about 10 days of immobilization (6). During the second phase, loss of bone is slower and osteoclastic activity returns to normal levels.

\section{Chronic Spinal Cord Injury}

During chronic immobilization, diminished osteoblastic activity appears to be responsible for the major fraction of bone loss. The bone formation rate was reduced in rats studied at the end of a long space flight $(7,8)$, resulting in a slow rate of bone loss (9). Chronic states of skeletal unloading result in a reduced pool of osteogenic cells within the bone marrow (10). The 
mechanisms by which the physical stress and strain placed upon bone are transduced into bone cellular activity have not been elucidated.

A dramatic reduction in bone mineral content (BMC) and bone mineral density (BMD) has been amply documented in persons with chronic spinal cord injury (11-13). Osteoporosis generally involves the pelvis and lower extremities in persons with paraplegia, while bone is lost in the upper extremities as well in those with tetraplegia (14-17). Bauman et al. (14) have studied 8 pairs of male identical twins (age, $40 \pm 10$, range 25 to 58 years), one of whom had paraplegia (average duration of injury of $16 \pm 9$ years with a range of 3 to 26 years). The twins were compared for total and regional bone mineral content (BMC) and bone mineral density (BMD) measured by dual energy $x$-ray absorptiometry. In the spinal cord injured twins, total body BMC was significantly reduced $(22 \pm 9$ percent, $\mathrm{P}<0.001)$, with the predominant sites of reduction for $\mathrm{BMC}$ and $\mathrm{BMD}$ being the legs $(42 \pm 14$ and $35 \pm 10$ percent, $\mathrm{P}<0.0001)$, and pelvis $(50 \pm 10$ and $29 \pm 9$ percent, $\mathrm{P}<0.0001$ ) (Figure 3 ). The vertebral column of the twins with spinal cord injury appeared to significantly increase in BMD. Perhaps the vertebral column in paralysis is generally spared bone loss due to its continued weight bearing function while in the seated position. However, a potentially confounding consideration is the possibility that the increase in vertebral $\mathrm{BMD}$ by dual energy $\mathrm{x}$-ray absorptiometry (DXA) is an artifact due to neuropathic osteoarthropathy (loss of disk space, bone sclerosis, fragmentation, osteophytosis, and subluxation), masking actual vertebral osteoporsis (18). Quantitative computerized tomographic imaging has the ability to provide bone mass measurements of the vertebral body while excluding extraneous calcification from the field of interest. This methodology provides a more appropriate determination of bone mass of the vertebral bodies, as would other methods that localize the area of interest with greater accuracy. In the identical twin study, duration of spinal cord injury, not age, was found to be linearly related to the rate of leg bone loss in spinal cord injured twins (BMC: $\mathrm{r}^{2}=0.60, \mathrm{P}<0.05$; $\mathrm{BMD}: \mathrm{r}^{2}=0.70, \mathrm{P}<0.01$ ) (Figure 4). Leg bone continues to be lost throughout the chronic phase of immobilization in individuals with spinal cord injury, and this bone loss appears to be independent of age. Leg BMD is significantly associated with lean tissue in the legs of the able-bodied twins, as has been previously reported in the general population by several investigators, but not in the co-twins with spinal cord injury. Of note, a significant relationship was found between total body fat mass or regional fat mass in the legs and leg BMD in those with spinal cord injury, but not in the co-twins who were able-bodied. The possibility should be considered that the technique of DXA may produce an artifactual reduction in bone mass and density with increasing regional fat tissue mass. This may be directly addressed by employing in vitro neutron activation analysis (IVNA) to validate the regional soft tissue and bone findings obtained by using DXA (19).

Osteoporosis and increased risk of fractures are well-established complications of persons with chronic spinal cord injury. Pathologic fractures of the long bones occur in individuals with spinal cord injury after negligible stress or trauma, such as during transfer manuevers, range of motion exercises, bending or minor falls. Several studies have reported the prevalence of lower extremity fractures in persons with spinal cord injury (20-24). Attempts to improve bone mass and strength by modulating muscle tone, activity, or weight-bearing have yielded negligible benefits.

\section{Therapeutic Interventions}

Although disuse may be the primary cause of osteopenia in persons with spinal cord injury, there is reason to believe that nutritional deficiencies may be contributory, particularly 
involving calcium and vitamin $\mathrm{D}$. Because of the tendency for calcium nephrolithiasis soon after acute injury, individuals with chronic spinal cord injury are often instructed to restrict calcium intake, chiefly dairy products. This may also result in vitamin D deficiency because dairy products, especially milk, are fortified with vitamin D and serve as the main source of dietary intake for this vitamin. In addition, those with spinal cord injury may have reduced sunlight exposure or may receive anti-convulsants and other medications which accelerate vitamin $D$ metabolism. Reduced calcium and vitamin D intake would be expected to lower the serum calcium concentration and stimulate the release of PTH, resulting in increased bone resorption and accentuation of osteopenia. Bauman et al. studied calcium and vitamin D metabolism in 100 subjects with chronic spinal cord injury compared with 50 normal control subjects (25). Subjects with spinal cord injury had significantly lower 25 -hydroxyvitamin D levels, the major storage form of vitamin D, which was negatively correlated with serum parathyroid hormone (PTH). Serum 1,25-dihydroxyvitamin $D$ levels were significantly elevated in persons with chronic spinal cord injury, and positively correlated with PTH levels, suggesting a state of secondary hyperparathyroidism and associated increased bone turnover. Higher levels of PTH would be expected to accelerate bone resorption of a skeleton already regionally osteoporotic as a consequence of bone loss secondary to acute immobilization. Patients identified with this deficiency state should be appropriated treated with vitamin D and calcium supplementation.

Bisphosphonates, which are analogues of pyrophosphate, markedly inhibit osteoclastic activity. This class of agents reduces osteoclast number by inhibition of osteoblast recruitment, adhesion and life-span, as well as reducing osteoclast activity. The utility of these agents, especially alendronate, has been demonstrated in the treatment of diseases with increased bone turnover. Animal studies have suggested that bisphosphonates reduce bone loss after skeletal unloading $(26,27)$. Although removed from the market because of incidental reports of associated myeloproliferative disorders, disodium dichloromethylene diphosphate, when administered soon after acute spinal cord injury, ablated resorptive hypercalciuria and prevented loss of BMC of the tibia and femur (28). Administration of tiludronate, another bisphosphonate, to subjects with paraplegia has been shown to reduce bone resorption by reducing the number of osteoclasts without impairing bone formation (29). The role of bisphosphonates in the treatment of bone loss in acute and chronic spinal cord injury remains to be defined.

\section{Discussion}

At present in individuals with acute or chronic spinal cord injury, bone mass is quantitated in most studies by employing DXA. With varying amounts of fat tissue mass present in atrophied limbs, there may be uncontrolled and variable attenuation of the $\mathrm{x}$-ray beam, resulting in spurious reductions in the bone mass in association with increases in fat mass. It would be vital to validate bone and soft tissue mass measurements that have been acquired with DXA with the more direct methodology of IVNA (19). It is anticipated that regional IVNA may be performed in persons with acute spinal cord injury before, as well as after, tissue compartments have undergone dramatic changes. Validation of DXA is imperative to have confidence in the accuracy of findings, especially when performing intervention studies. Accurate quantification of bone mass changes after the administration of pharmacological agents to prevent bone loss in those with acute immobilization or to enhance bone formation in those with chronic immobilization requires that DXA or other methodologies applied for this purpose be validated. The distinct possibility exists that these studies may be performed with a new technology, gamma ray nuclear resonance absorption (GNRA). At a markedly reduced radiation 
exposure compared with IVNA, the method of GNRA would provide a full body imaging technique that provides element-specific absorptiometry while generating a conventional radiograph of the subject that may be used to determine regional measurements of bone and soft tissue components $(30,31)$. Thus, the method of GNRA may be applied to provide a highly accurate appraisal of vertebral body bone mass, or that of other areas of the skeleton. DXA, and other methods incapable of localizing a specific region with as great a precision of measurement, may provide spurious results secondary to extraneous calcification.

\section{References}

1. Claus-Walker J, Campos RJ, Carter RE, et al. Calcium excretion in quadriplegia. Arch Phy Med Rehabil, 1972;53:14-18.

2. Naftchi NE, Viau AT, Sell GH, et al. Mineral metabolism in spinal cord injury. Arch Phy Med Rehabil, 1980;61:139-142.

3. Stewart AF, Adler M, Byers CM; et al. Calcium homeostasis in immobilization. An example of resorptive hypercalciuria. New Eng JMed, 1982;306:1136-1140.

4. Baron R, Vignery A, Lang R. Reversal phase and osteopenia: Defective coupling of resorption to formation in the pathogenesis of osteoporosis. In: Frost HF, Jee WSS, Johnston $\mathrm{CC}$, eds. Osteoporosis: Recent Advances in Pathogenesis and Treatment. Baltimore: University Park Press, 1981; 311-320.

5. Tran Van P, Vignery A, Baron R. Cellular kinetics of the bone remodeling sequence in the rat. Anat Rec, 1982;202:445-451.

6. Weinreb M, Rodan GA, Thompson DD. Osteopenia in the immobilized rat hind limb is associated with increased bone resorption and decreased bone formation. Bone, 1984;10:123-128.

7. Morey ER, Baylink DJ. Inhibition of bone formation during space flight. Spinal cord injuryence, 1978;201:1138-1141.

8. Wronski TJ, Morey ER. Effect of spaceflight on periosteal bone formation in rats. Am $J$ Physiol, 1983;244:305-309.

9. Kannus $\mathbf{P}$, Sievanen $H$, Jarvinen TLN, et al. Effects of free mobilization and low- to highintensity treadmill running on the immobilization-induced bone loss in rats. $J$ Bone Miner Res, 1994;9:1613-1619.

10. Manolagas SC, Jilka RL. Bone marrow, cytokines and bone remodeling. $N$ Engl $J$ Med, 1995;332:305-311.

11. Biering-Sorensen $\mathrm{F}$, Bohr $\mathrm{H}$, Schaadt $\mathrm{O}$. Bone mineral content of the lumbar spine and lower extremities years after spinal cord lesion. Paraplegia, 1988;26:293-301.

12. Garland DE, Maric Z, Adkins R, et al. Bone mineral density about the knee in spinal cord injured patients with pathologic fractures. Contemp Ortho, 1993;26:375-379.

13. Griffiths HJ, Zimmerman RE. The use of photon densitometry to evaluate bone mineral in a group of patients with spinal cord injury. Paraplegia, 1973;10:279-284.

14. Bauman WA, Spungen AM, Wang J, et al. Continuous loss of bone during chronic immobilization: A monozygotic twin study. Osteopor Internat, 1999;10:123-127.

15. Garland DE, Adkins RH, Ashford R, et al. Regional osteoporosis in females with complete spinal cord injury. J Bone Joint Surg, Accepted for publication.

16. Garland DE, Foulkes $\mathrm{G}$, Adkins $\mathrm{RH}$, et al. Regional osteoporosis following incomplete spinal cord injury. Contemp Ortho, 1994;28:134-138. 
17. Garland $\mathrm{DE}$, Stewart $\mathrm{CA}$, Adkins $\mathrm{RH}$, et al. Osteoporosis after spinal cord injury. $J$ Orthopaed Res, 1992;10:371-378.

18. Jaovisidha S, Sartoris DJ, Martin EME, et al. Influence of sponylopathy on bone densitometry using dual energy x-ray absorptiometry. Calcif Tissue Int, 1997;60:424-429.

19. Pierson RN, Wang J, Thornton JC. Body composition comes of age: a modest proposal for the next generation, the new reference man. In: In vivo Body Composition Studies, Eds. S. Yasumura, J Wang, RN Pierson, Jr, Annals of the New York Academy of Sciences, 2000, 904:1-11.

20. Comarr AE, Hutchinson RH, Bors E. Extremity fractures of patients with spinal cord injuries. Am J Surg, 1962;103:732-739.

21. Freehafer A, Coletta M, Becker CL. Lower extremity fractures in patients with spinal cord injury. Paraplegia, 1981;19:367-372.

22. Ingram $R$, Suman $R$, Freeman $P$. Lower limb fractures in the chronic spinal cord injured patient. Paraplegia, 1989;27:133-139.

23. Nottage WM. A review of long-bone fractures in patients with spinal cord injuries. Clin Orthop, 1981;155:65-70.

24. Ragnarsson K, Sell G. Lower extremity fractures after spinal cord injury: A retrospective study. Arch Phys Med Rehabil, 1981;62:418-423.

25. Bauman WA, Zhong YG, Schwartz E. Vitamin D deficiency in veterans with chronic spinal cord injury. Metab, 1995;44:1612-1616.

26. Kurokouchi K, Ito T, Ohmori $\mathrm{S}$, et al. Changes in the markers of bone metabolism following skeletal unloading. Environ Med, 1995;39:12-24.

27. Kurokouchi K, Ito T, Ohmori S, et al. Effects of bisphosphonate on bone metabolism in tailsuspended rats. Environ Med, In Press.

28. Minaire P, Berard E, Meunier PJ, et al. Effect of disodium dichloromethylene diphosphonate on bone loss in paraplegic patients. J Clin Invest, 1981;68:1086-1092.

29. Chappard D, Minaire $P$, Privat $C$, et al. Effects of tiludronate on bone loss in paraplegic patients. J Bone Miner Res, 1995;10:112-117.

30. Wielopolski, L, Vartsky D, Piersons R, Goldberg M, Heymsfield S, Yasumura S, Melnyschuk S, Sredniawski J. Gamma resonance absorption: new approach in human composition studies. In: In vivo Body Composition Studies, Eds. S. Yasumura, J Wang, RN Pierson, Jr, Annals of the New York Academy of Sciences, 2000, 904:229-235.

31. Varsky D, Goldberg MB, Bar D, Goldschmidt A, Feldman G, Sayag E, Katz D, Stronach IM, Stark JW, Prestwwich WV, McNeill FE, Chettle DR. Gamma ray nuclear resonance absorption: an alternative method for in vivo composition studies. In: In vivo Body Composition Studies, Eds. S. Yasumura, J Wang, RN Pierson, Jr, Annals of the New York Academy of Sciences, 2000, 904:236-246. 


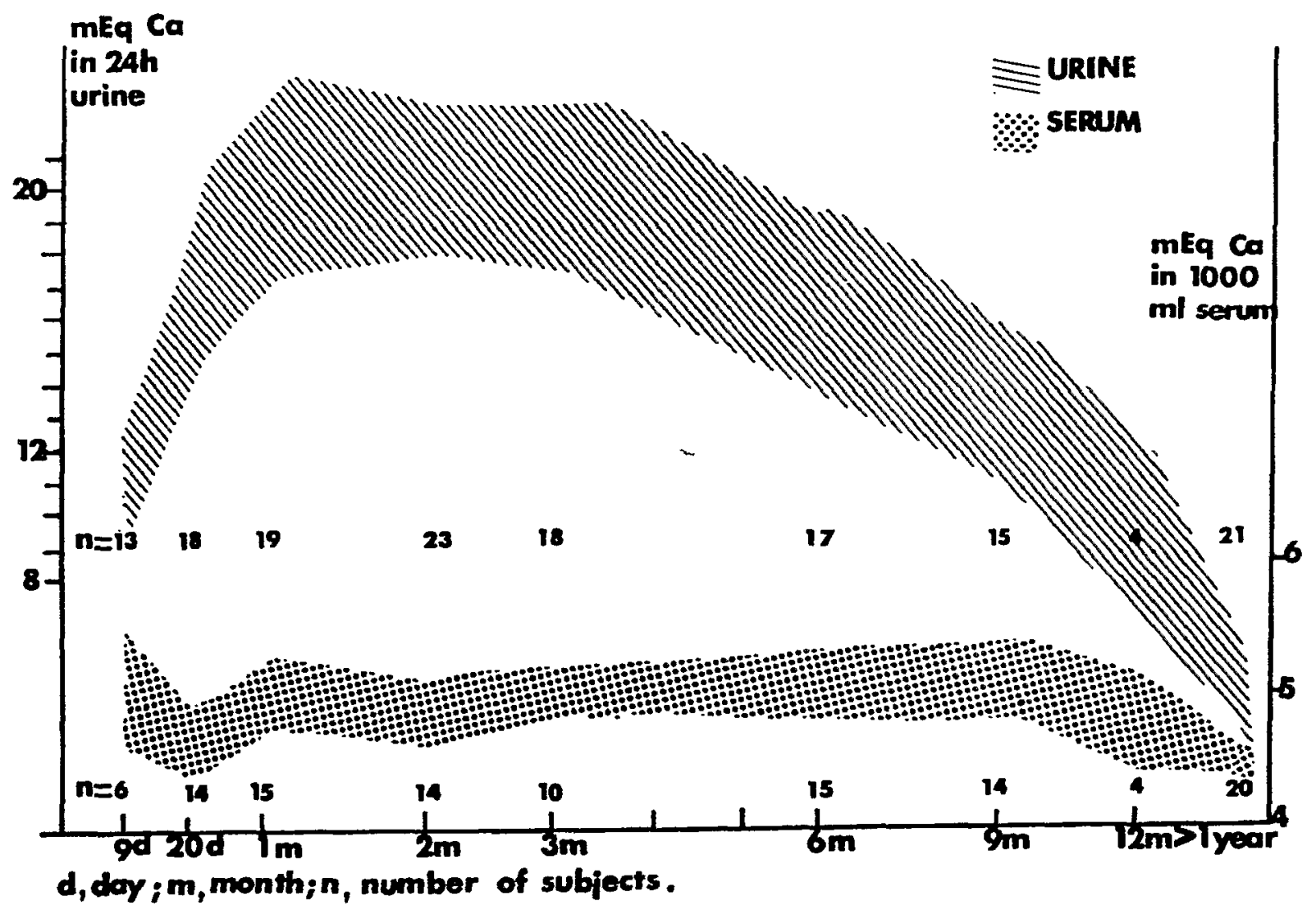

Figure 1: Urinary Excretion of Calcium and Serum Calcium Concentrations in Persons after Acute SCI. (From Claus-Walker J, Campos RJ, Carter RE, et al. Calcium excretion in quadriplegia. Arch Phy Med Rehabil, 1972;53:14-18; with permission.) 


\section{PLASMA \\ $25 \mathrm{OHD}$ \\ $(\mathrm{ng} / \mathrm{ml})$}

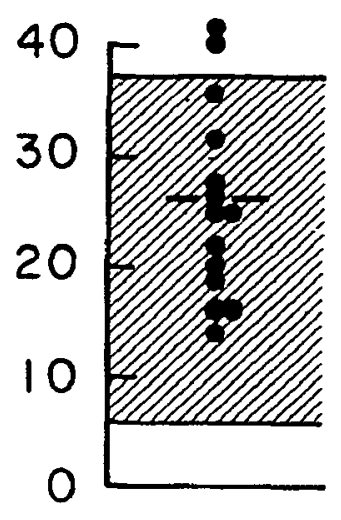

\section{PLASMA \\ $1,25(\mathrm{OH})_{2} \mathrm{D}$ \\ $(\mathrm{pg} / \mathrm{ml})$}

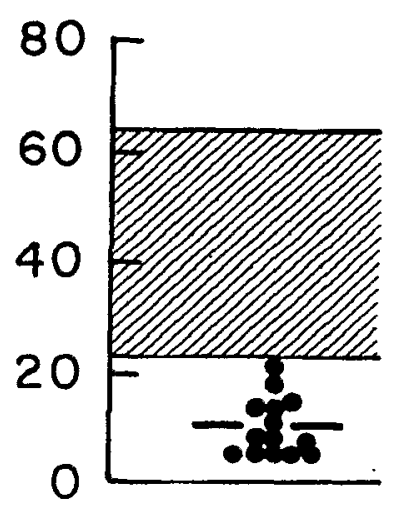

B

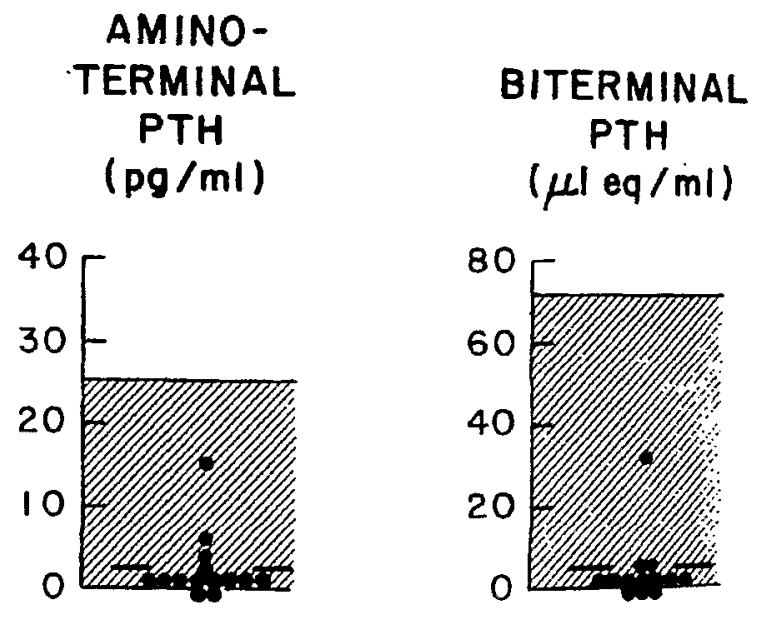

Figure 2: Calcium Metabolism in Persons with Acute SCI. (A) Plasma levels of 25hydroxyvitamin D (25 OH D) and 1,25-Dihydroxyvitamin D $\left(1,25(\mathrm{OH})_{2} \mathrm{D}\right)$. Despite normal plasma $25 \mathrm{OH} \mathrm{D}$ values, $1,25(\mathrm{OH})_{2} \mathrm{D}$ values were reduced, suggesting a reduction in circulating parathyroid hormone levels. (B) Levels of nephrogenous cyclic AMP and plasma immunoreactive parathyroid hormone (PTH). Mean urinary cyclic AMP $( \pm S . D$.) was $2.28 \pm 0.63$ nmol per $100 \mathrm{ml}$ of glomerular filtrate. Both the biologic and immunologic indexes revealed a reduction in circulating parathyroid hormone concentration. GF denotes glomerular filtrate. (From Stewart AF, Adler M, Byers CM, et al: Calcium homeostasis in immobilization. An example of resorptive hypercalciuria. New Eng JMed, 1982;306:1136-1140; with permission.) 

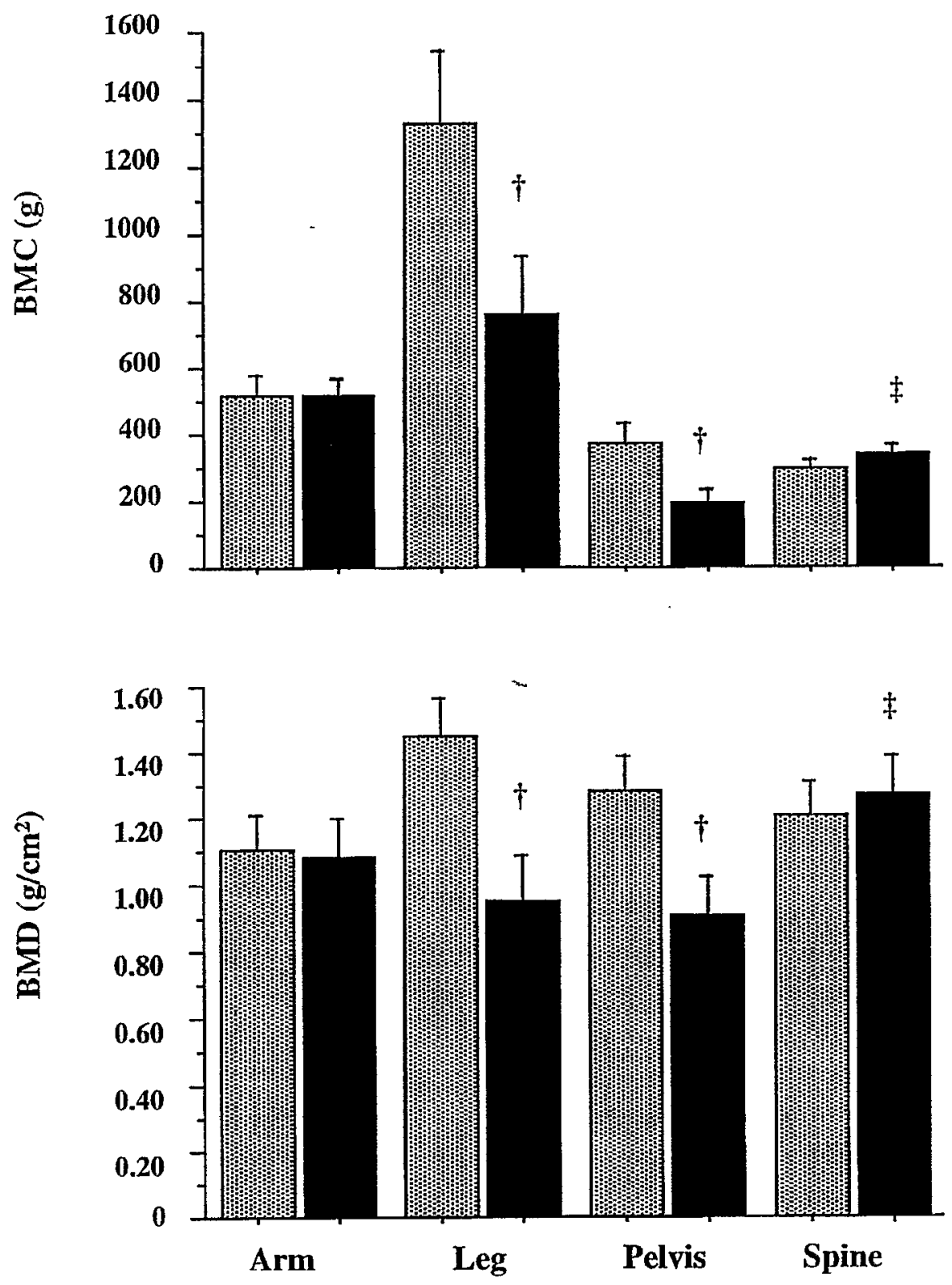

Figure 3: Comparison of Mean Regional Bone Mineral Content Between Twin Groups. (A) BMC is presented in grams (g). (B) BMD is presented in grams per centimeter squared $\left(\mathrm{g} / \mathrm{cm}^{2}\right)$. The darkly shaded bars are the SCI twins and the lightly shaded bars, the nonSCI twins. Arm was not significantly different (BMC: $508 \pm 72$ vs. $506 \pm 66$, n.s.; BMD: $1.100 \pm 0.110$ vs. $1.080 \pm 0.120$, n.s.); leg was significantly lower in the SCI twins '(BMC: $1323 \pm 225$ vs. $759 \pm 170, P<0.0001$; BMD: $1.450 \pm 0.120$ vs. $0.940 \pm 0.140$, $\mathrm{P}<0.0001)$; pelvis was significantly lower in the $\mathrm{SCI}$ twins ${ }^{\dagger}(\mathrm{BMC}: 370 \pm 64$ vs. $186 \pm 44, \mathrm{P}<0.0001$; BMD: $1.277 \pm 0.110$ vs. $0.904 \pm 0.120, \mathrm{P}<0.0001)$; and spine was significantly higher in the SCI twins ${ }^{f}(\mathrm{BMC}$ : $289 \pm 38$ vs. $332 \pm 39, \mathrm{P}<0.01$; BMD: $1.199 \pm 0.110$ vs. $1.268 \pm 1.200, \mathrm{P}<0.05$ ). (From Bauman WA, Spungen AM, Wang J, et al. Continuous loss of bone during chronic immobilization: A monozygotic twin study. Osteopor Internat, 1999;10:123-127; with permission.) 
A

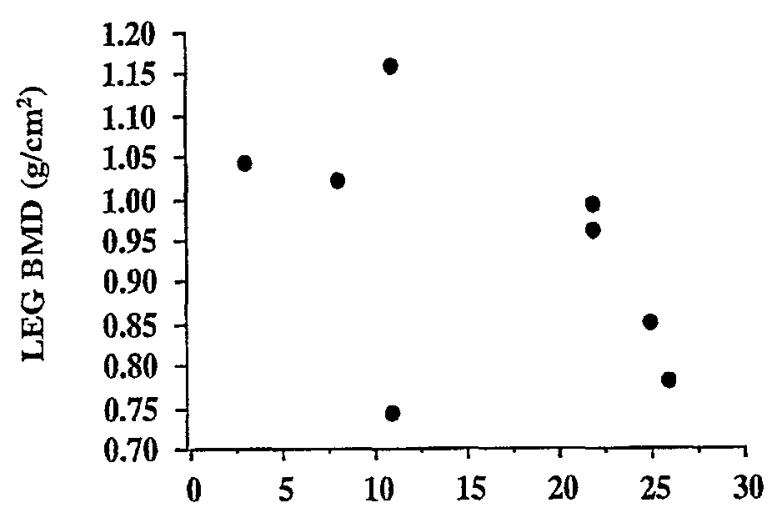

$\mathrm{C}$

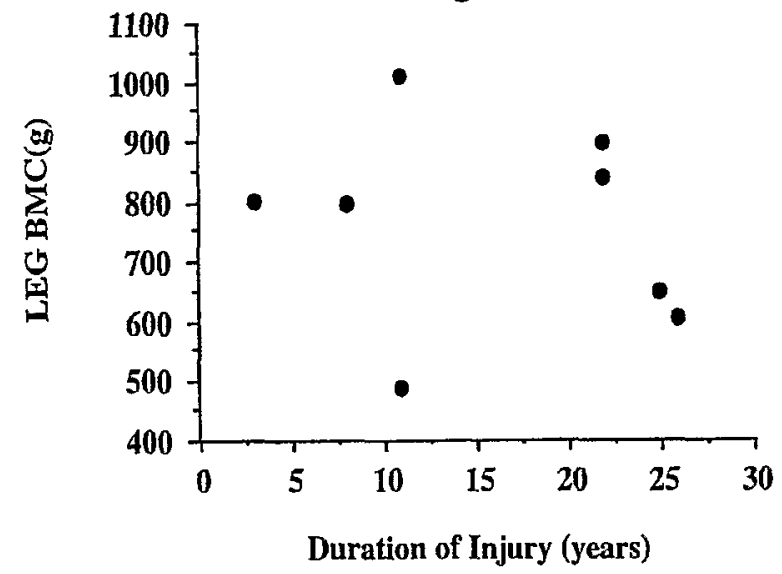

B

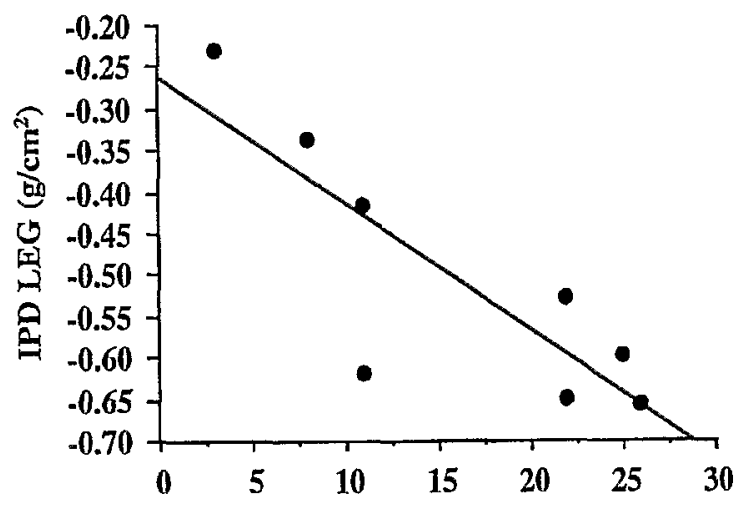

D

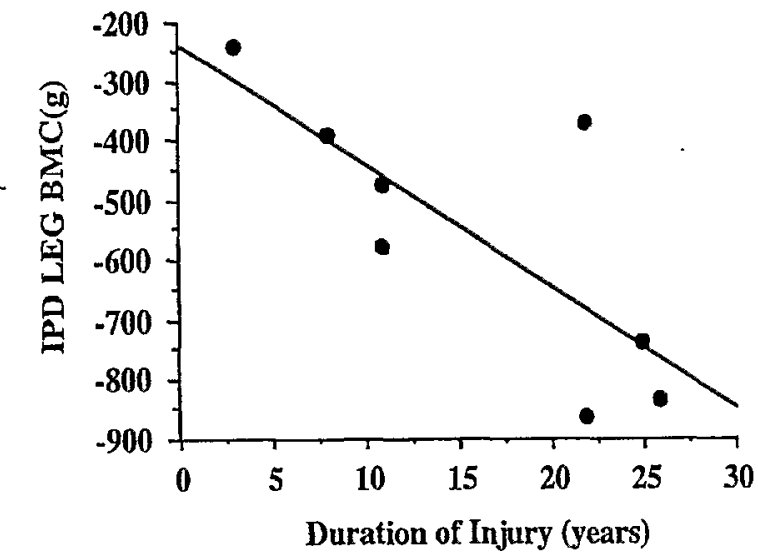

Figure 4: Associations between Leg Bone Mineral Content and Density with Age and Duration of Injury. In the SCI twins, (A) bone mineral content (BMC) and (C) bone mineral density (BMD) are plotted against duration of injury. (Note the lack of a significant association.) Linear regression analyses of leg intrapair difference (IPD) scores are plotted for (B) $B M C\left(R^{2}=0.60\right.$, $P<0.05)$ and $(D) B M D\left(R^{2}=0.70, P<0.01\right)$. The IPD score represents the quantity of bone lost in the SCI twin compared with the nonSCI co-twin. (From Bauman WA, Spungen AM, Wang J, et al. Continuous loss of bone during chronic immobilization: A monozygotic twin study. Osteopor Internat, 1999;10:123-127; with permission.) 


\title{
THE EFFECT OF IMMOBILIZATION ON SOFT TISSUE BODY COMPOSITION IN PERSONS WITH SPINAL CORD INJURY
}

\author{
ANN M. SPUNGeN, ED.D. \\ Associate Director, Spinal Cord Damage Research Center \\ Research Associate Professor of Medicine and Rehabilitation Medicine \\ Mount Sinai School of Medicine \\ New York, NY \\ \& \\ WILLIAM A. BAUMAN, M.D. \\ Director, Spinal Cord Damage Research Center \\ Professor of Medicine and Rehabilitation Medicine \\ Mount Sinai School of Medicine \\ New York, NY
}

Acknowledgements: This work was supported by the Department of Veterans Affairs, Spinal Cord Research Foundation, the Eastern Paralyzed Veterans of Association, Mount Sinai School of Medicine, and the National Institute on Disability and Rehabilitation Research (NIDRR) Grant \# H133B30029. 


\section{ABSTRACT}

Immobilization from acute spinal cord injury results in rapid loss of muscle tissue and a relative gain in adiposity. A more gradual but relatively increased loss of muscle subsequently ensues at a rate that exceeds that of aging in the able-bodied population, suggesting a state of accelerated sarcopenia. In addition to immobilization, reductions in endogenous anabolic hormones may be partially responsible for these adverse body composition changes. Present surrogate techniques for the determination of body composition rely on assumptions that have not been validated in persons with regional body composition changes of extreme magnitudes, such as in persons with spinal cord injury. In vivo neutron activation analysis would permit a direct determination of body soft tissue compositional analysis in individuals with paralysis. Strategies must be sought to preserve skeletal muscle with aging in order to maintain function and independence, as well as reduce the risk of several chronic illnesses associated with advancing age. The application of prompt in vivo neutron activation analysis to detect nitrogen, allowing the quantification of relatively small changes in muscle mass after therapeutic intervention, may be particularly efficacious. Regional measurement of muscle is now deemed possible at Brookhaven National Laboratory, as well as at satellite centers in the New York metropolitan area. The body composition modality of gamma nuclear resonance absorption, presently being developed, will permit similar direct measurements of soft tissue compartments at a greatly reduced radiation exposure to that of in vivo neutron activation analysis. It is envisioned that gamma nuclear resonance absorption will someday allow the isolation and quantification of the muscles of respiration in the chest wall, presently not possible with any other body composition technique.

\section{Soft Tissue Body Composition Changes in Persons with Spinal Cord Injury}

Spinal cord injury predisposes the individual to medical complications and secondary disabilities such as obesity, lipid abnormalities, carbohydrate intolerance, and cardiovascular disease. One hypothesis for these secondary disabilities is that they are the result of adverse body composition changes, i.e. increased adiposity and decreased muscle mass. Persons with spinal cord injury have body compositional changes that are similar to those in aged humans, including loss of lean tissue mass and increase of fat tissue mass. Only a few longitudinal studies have been reported that have captured body composition immediately after spinal cord injury, before changes from paralysis have occurred, and have then performed serial measurements. These studies are relatively small in the size of cohorts. Using baseline measurements performed several weeks after acute spinal cord injury, Wilmet et al. reported on bone mineral and soft tissue changes in 31 subjects over the course of the first year of injury (1). In all subjects, lean soft tissue decreased dramatically in regions of the body that were paralyzed. Fat content tended to increase in the paralyzed areas as well. Rossier et al. studied 17 subjects with spinal cord injury within one-month after injury and then again 2-12 months post injury. This group demonstrated that within the first year after injury there was a significant amount of total body potassium depletion and weight loss of lean body mass (2). By using cross-sectional designs comparing age- and height-matched reference populations, previous investigators have demonstrated lean tissue loss and/or fat tissue gain in individuals following chronic spinal cord injury (3-5). Rasmann Nuhlicek et al. studied 37 subjects with spinal cord injury classified into 
four levels of lesion subgroups and 10 controls (3). Total body water, intracellular water and lean body tissue were significantly decreased. Fat mass increased as the level of neurological deficit increased (3). In a cross-sectional study, Spungen et al. reported significant decreases in percent of regional and total body lean tissue in male subjects with tetraplegia $(\mathrm{n}=66)$ or paraplegia $(n=66)$ with a mean age of $39 \pm 1.5$ years (range 20-71) compared with gender-, age-, height-, and weight- matched controls ( $\mathrm{n}=66$ ) (Figure 1) (6). These differences were most pronounced in the arms and legs, and less so in the trunk. Of particular interest, the arms in persons with paraplegia had significantly less percent lean tissue compared with controls $(67.3 \pm 1.26$ vs. $79.9 \pm 1.03 \%$, $\mathrm{p}<0.0001$ ) (Figure 1). The slope of change across age for total body lean tissue was steeper in subjects with SCI than in controls $(-0.306 \pm 0.073$ vs. $-0.093 \pm 0.89, \mathrm{p}<0.07)$ (Figure 2$)$. No total body or regional differences in this cross-sectional rate of loss were observed between subjects with tetraplegia and paraplegia. Male subjects with spinal cord injury can be expected to lose about $3.2 \%$ per decade of their total body lean tissue versus $1 \%$ per decade in able-bodied males (Figure 2).

Due to the individual variability in body composition, a cross-sectional design limits the ability to determine the precise amount of lean tissue loss and fat tissue gain attributable exclusively to paralysis. Longitudinal studies are relatively expensive and pose enormous logistical problems; it is crucial to perform measurements before the body composition changes have occurred immediately after immobilization and then to enlist subjects to perform these body composition measurements intermittently over the following decades. A creative solution to defining these changes in body composition, independent of genetic variability and aging, is the use of a cross-sectional monozygotic twin model. In an identical twin study, with one co-twin in each of the 8 pairs having spinal cord injury, Spungen et al. reported a loss of total body and extremity muscle mass that was continuous and directly related to duration of injury; $3.9 \pm 0.2 \mathrm{~kg}$ of total body lean tissue lost per 5 year period of injury (Figure 3) (7). Possibly related to these adverse body compositional changes and reduced levels of activity, individuals with spinal cord injury have a pattern of metabolic alteration that is atherogenic, with adverse lipid changes $(8,9)$, glucose intolerance $(10,11)$, insulin resistance $(10)$, and a reduction in metabolic rate $(12,13)$.

Individuals with spinal cord injury have unique changes in body composition. Present techniques for the determination of body composition rely on assumptions that have not been validated in persons with regional body composition alterations of such extreme magnitudes as that seen in persons with spinal cord injury. For instance, dual energy $\mathrm{x}$-ray absorptiometry relies on traditional constants developed from hydrostatic weighing of a cross section of the population. Because of inherent difficulty in performing hydrodensitometry in persons with spinal cord injury for the determination of accurate soft tissue compartments (12), the application of dual energy $\mathrm{x}$-ray absorptiometry for the determination of lean or fat mass measurements in this population must also be suspect. Spungen et al. has demonstrated the variability of clinical methods that are commonly used in the determination of body fat in individuals with tetraplegia (13). In vivo neutron activation (14) analysis would permit a direct determination of body soft tissue compositional analysis in individuals with paralysis and provide a standard for validation of more readily available methods, such as those of dual energy $x$-ray absorptiometry and bioelectrical impedance analysis.

The losses in lean body tissue are directly reflected in the metabolic rate. In 12 subjects with spinal cord injury, Spungen et al. demonstrated a strong relationship $(r=0.803, p<0.002)$ between metabolic rate and fat free mass in persons with spinal cord injury (14). The greater the reduction in lean body tissue, the greater the decrease in resting metabolic rate (Figure 4) (14) 
Supporting the findings of Spungen et al., in 48 subjects with spinal cord injury Mollinger et al. described a 12 to $29 \%$ reduction from predicted values for basal energy expenditure, with those who had higher levels of injury and presumably less lean tissue mass having the greater reductions in basal energy expenditure (15).

\section{Anabolic Hormonal Changes in Persons with Spinal Cord Injury}

A deficiency state of endogenous anabolic hormones has the potential for adverse soft tissue changes. Although the literature in persons with spinal cord injury is controversial, there are undoubtedly subsets of individuals with a relative or absolute androgen deficiency state. The etiology of a relative deficiency of testosterone in persons with spinal cord injury has not been elucidated. In a group of 20 healthy subjects, 12 with paraplegia and 8 with quadriplegia, Tsitouras et al. reported that a subset had reduced serum total and free testosterone levels without a significant increase in serum gonadotropin concentrations (16). Of note, serum testosterone levels were already low in younger individuals with spinal cord injury, therefore a decrease with age was not observed, as in the able-bodied controls. However, serum testosterone levels significantly decreased with duration of injury. Wang et al. also reported on a subset of subjects with spinal cord injury who had low serum testosterone levels, but none had increased serum gonadotropin levels (17).

Growth hormone and insulin-like growth factor 1 (IGF-1) have been reported to be depressed in individuals with spinal cord injury. In a group of 16 subjects with spinal cord injury, Bauman et al. reported a blunted growth hormone release to provocative stimulation with intravenous arginine (18). The average plasma IGF-1 level was lower in younger individuals with spinal cord injury than that in younger able-bodied controls. Similarly, Shetty et al reported that the average plasma IGF-1 level in persons with tetraplegia was depressed compared with ambulatory controls (19). In a study of persons with post poliomyelitis syndrome, lower plasma IGF-1 levels were found to be a potent discriminator of those who had decreased capacity to perform activities of daily living, reduced functional independence, and increased pain (20). Although it is not possible from this investigation to determine cause or effect (21), it would appear that depression in plasma IGF-1 in persons with spinal cord injury is associated with reductions in muscle mass and strength, and, hence, functional capacity.

Therapeutic intervention with physiological replacement of endogenous anabolic hormones has been performed in the able-bodied population with beneficial results. Such clinical interventions in individuals with SCI have been undertaken experimentally in limited trials. The application of prompt in vivo neutron activation analysis to detect nitrogen, allowing the quantification of relatively small changes in muscle mass after therapeutic intervention, may be particularly efficacious. In addition, regional measurement of muscle is now deemed possible at Brookhaven National Laboratory and at St. Lukes Roosevelt Hospital Center, as well as at other satellite centers in the New York metropolitan area. The body composition modality being presently developed of gamma nuclear resonance absorption will permit similar direct measurements of soft tissue compartments at a greatly reduced radiation exposure compared with that of in vivo neutron activation analysis.

In addition to attempts at physiological replacement of endogenous anabolic hormones, another potential consideration is the limited administration of anabolic steroids for specific indications in persons with spinal cord injury. A recent report demonstrated that oxandrolone increased parameters of inspiratory and expiratory pulmonary function in subjects with 
tetraplegia (22). Changes in diaphragm mass after the administration of this anabolic steroid have been directly correlated with changes in maximal inspiratory effort. After therapy, breathlessness significantly decreased (23). In addition to increased diaphragm mass, in those with incomplete motor spinal cord injury, the question arises as to whether the chest wall, intercostal muscles, and abdominal wall muscles were augmented with anabolic steroid therapy. The technique of gamma nuclear resonance absorption $(24,25)$ holds promise to allow the isolation and quantification of the muscles of respiration in the chest wall, presently not possible with any other technique to assess body composition.

\section{Summary}

In persons with spinal cord injury, there is an initial, dramatic loss of muscle mass following acute paralysis. However, even decades after injury, there is a continuous loss of lean body tissue that is at an increased rate compared to that observed in able-bodied persons. This depletion of muscle mass in individuals with spinal cord injury may be viewed as a form of accelerated sarcopenia, greater than that of the general aging process. Current body composition techniques rely on assumptions that have not been validated in persons with extreme body composition changes. In vivo neutron activation analysis would permit a direct determination of soft tissue body compositional analysis in individuals with spinal cord injury. Validation of existing techniques for the determination of body composition, specifically dual energy $\mathrm{x}$-ray absorptiometry is of importance for measuring potential changes due to therapeutic intervention. The superimposition of on-going, age-related loss in muscle mass on an already reduced lean body mass places persons with spinal cord injury at increased risk of adverse consequences, such as an increased risk of diabetes mellitus, increased rate of infection, reduced tissue repair, decreased pulmonary function, and further impaired functional mobility.

In older persons with spinal cord injury, there is a relative increase in adiposity, especially intraabdominal, that may increase the risk of cardiovascular disease. It is conceivable that an unfavorable hormonal environment with depressions of the endogenous anabolic hormones, testosterone and growth hormone/IGF-1, may worsen body composition in individuals who are partially or completely paralyzed. Reversal of this catabolic hormonal milieu with physiological replacement therapy may help preserve muscle mass, strength, function, as well as preserve a more rewarding and independent quality of life. In addition, a reduction in relative or absolute adiposity may lower the risk of cardiovascular disease.

Another potential consideration is the limited administration of anabolic steroids for specific indications in persons with spinal cord injury. With regard to this therapeutic intervention, the technique of gamma nuclear resonance absorption holds promise to allow the isolation and quantification of the muscles of respiration in the chest wall.

\section{REFERENCES}

1. Wilmet E, Ismail AA, Heilporn A, Welraeds D, Bergmann $P$. Longitudinal study of bone mineral content and soft tissue composition after spinal cord section. Paraplegia.1996; 33: 674-677.

2. Rossier $\mathrm{AB}$, Favre $\mathrm{H}$, Valloton MB. Body composition and endocrine profile in spinal cord injured patients, Chapter 13, p. 163-170. In: Lee BY, Ostrander E, George J, 
Cochran B, Shaw WW The Spinal Cord Injured Patient. Comprehensive Management. WB Saunders Co., 1991.

3. Rasmann Nuhlicek DN, Spurr GB, Barboriak JJ, Rooney CB, El Ghatt AZ, Bongard RD. Body composition of patients with spinal cord injury. Euro J Clin Nutr. 1988;42:765773.

4. Cardus D, McTaggart WG. Body composition in spinal cord injury. Arch Phys Med Rehabil. 1985;66:257-259.

5. Shizgal HM, Roza A, Leduc B, Drouin G, Villemure JG, Yaffe C. Body composition in quadriplegic patients. J Parenteral \& Enteral Nutr. 1986;10:364-368.

6. Spungen AM, Adkins RH, Bauman WA, Kemp BJ, Waters RL. The effect of level and completeness of lesion on body composition in subjects with spinal cord injury. J Spinal Cord Med. 1999;22:43.

7. Spungen AM, Wang J, Pierson, Jr., RN, Bauman WA. Soft tissue body composition differences in monozygotic twins discordant for immobilization. J Applied Physiol. 2000;88: 1310-1315.

8. Bauman WA, Adkins RH, Spungen AM, et al. The effect of residual neurological deficit on serum lipoproteins in individuals with chronic spinal cord injury. Spinal Cord. 1998;36:13-17.

9. Bauman WA, Spungen AM, Zhong YG, et al. Depressed serum high density lipoprotein cholesterol levels in veterans with spinal cord injury. Paraplegia. 1992;30:697-703.

10. Bauman WA, Spungen AM. Disorders of carbohydrate and lipid metabolism in veterans with paraplegia or quadriplegia: a model of premature aging. Metabolism, 1994;43:949756.

11. Bauman WA, Adkins RH, Spungen AM, et al. The effect of residual neurological deficit on oral glucose tolerance in persons with chronic spinal cord injury. Spinal Cord. 1999;37:765-771.

12. George CM, Wells CL, Dungan NL. Validity of hydrodensitometry for determination of body composition in spinal cord injured subjects. Hum Biol. 1976;60:771-780.

13. Spungen AM, Bauman WA, Wang J, Pierson, $J_{r}$, RN. Measurement of body fat in individuals with tetraplegia: a comparison of eight clinical methods. Paraplegia. 1995;33:402-408.

14. Pierson RN, WangJ, Thornton JC, Body Composition Comes of Age: A Modest Proposal for the Next Generation, the New Reference Man, in In VivoBody Composition studies, Eds. S. Yasumura, J. Wang, RN. Pierson Jr., Annals of the Acadaemy of Sciences, 904 (2000) 1-11.

15. Mollinger LA, Spurr GB, El Ghatit AZ, et al. Daily energy expenditure and basal metabolic rates of patients with spinal cord injury. Arch Phys Med Rehabil. 1985;66:420426.

16. Spungen AM, Bauman WA, Wang J, Pierson, Jr., RN. The relationship between total body potassium and resting energy expenditure in individuals with paraplegia. Arch Phys Med Rehabil. 1993;73:965-968.

17. Tsitouras PD, Zhong YG, Spungen AM, and Bauman WA. Serum testosterone and insulin-like growth factor-I/growth hormone in adults with spinal cord injury. Horm Met Res. 1995;27:287-292.

18. Wang YH, Huang TS, Lien IN. Hormonal changes in men with spinal cord injuries. Am J Phys Med Rehabil. 1992;71:328-332. 
19. Bauman, WA, Spungen, AM, Flanagan, S, Zhong, YG, Alexander, LR, and Tsitouras, PD. Blunted growth hormone response to intravenous arginine in subjects with a spinal cord injury. Horm Met Res. 1994;26:149-153.

20. Shetty K, Sutton CH, Mattson DE, et al: Hyposomatomedinemia in quadriplegic men. Am JM Med Sci. 1993;305:95-100.

21. Rao U, Shetty KR, Mattson DE, et al. Prevalence of low plasma IGF-I in poliomyelitis survivors. J Am Geriatr Soc 1993;41:697-702.

22. Spungen AM, Grimm DR, Strakhan M, Pizzolato PM, Bauman WA. Treatment with an anabolic agent improves respiratory function in persons with tetraplegia: A pilot study. Mount Sinai J of Med. 1999;66:201-205.

23. Spungen AM, Grimm DR, Dumitrescu OL, Lesser M, McCool FD, Bauman WA. Improvements in diaphragm width and pulmonary function following anabolic steroid therapy in subjects with tetraplegia. Am J Resp Crit Care Med. A586 (1999) 159.

24. Wielopolski, L, Vartsky D, Piersons R, Goldberg M, Heymsfield S, Yasumura S, Melnyschuk S, Sredniawski J. Gamma resonance absorption: new approach in human composition studies. In: In vivo Body Composition Studies, Eds. S. Yasumura, J Wang, RN Pierson, Jr, Annals of the New York Academy of Sciences, 2000, 904:229-235.

25. Varsky D, Goldberg MB, Bar D, Goldschmidt A, Feldman G, Sayag E, Katz D, Stronach IM, Stark JW, Prestwwich WV, McNeill FE, Chettle DR. Gamma ray nuclear resonance absorption: an alternative method for in vivo composition studies. In: In vivo Body Composition Studies, Eds. S. Yasumura, J Wang, RN Pierson, Jr, Annals of the New York Academy of Sciences, 2000, 904:236-246. 

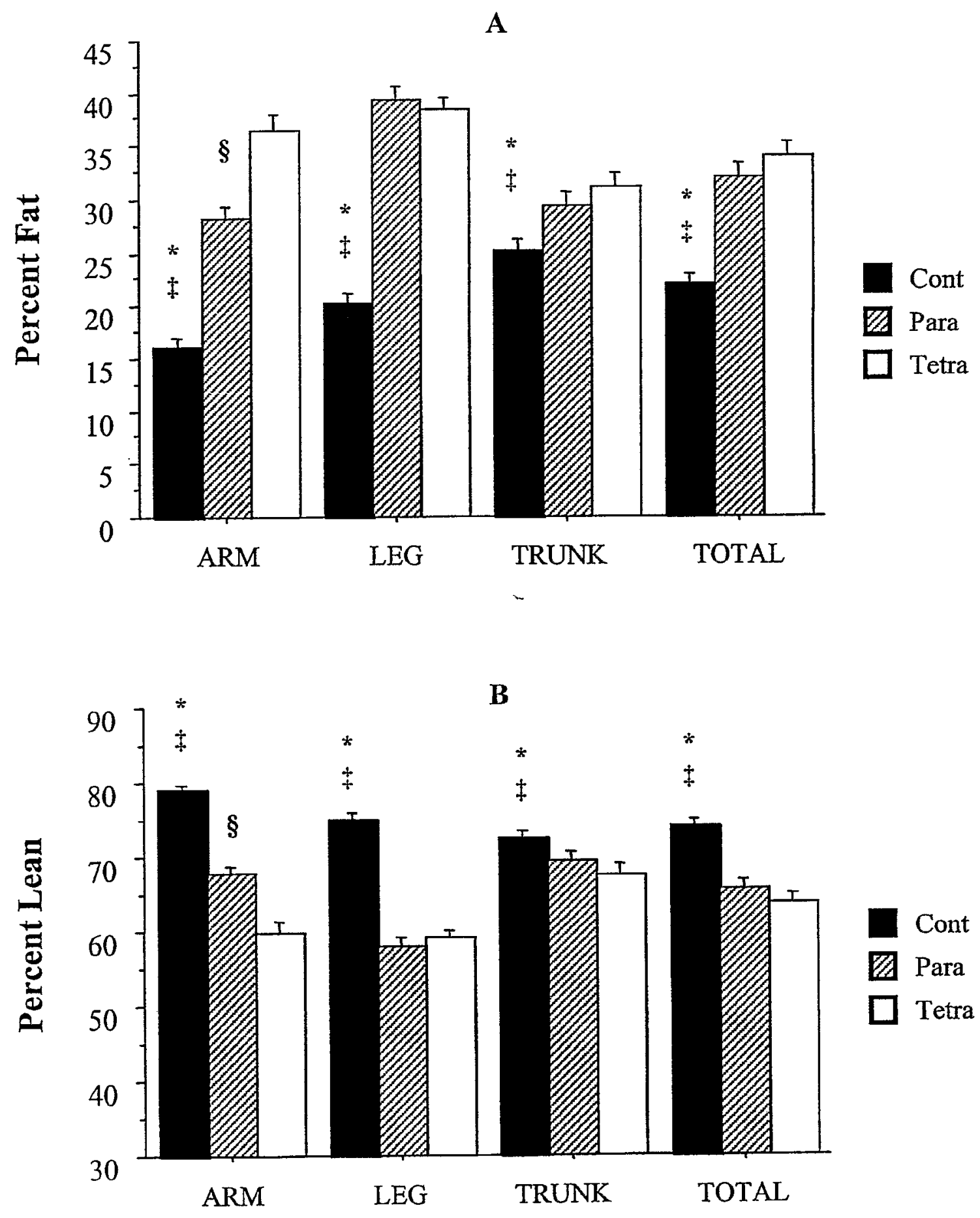

Figure 1: Regional and total body lean tissue percent comparisons among controls and persons with tetraplegia (Tetra) and paraplegia (Para). ${ }^{*} p<0.0001$ for Tetra vs. Para; $p<0.0001$ for Tetra vs. Control; $\mathrm{p}<0.0001$ for Para vs. Control; $\mathrm{p}<0.01$ for Para vs. Control. (Unpublished data provided by Drs. William A. Bauman and Ann M. Spungen.) 


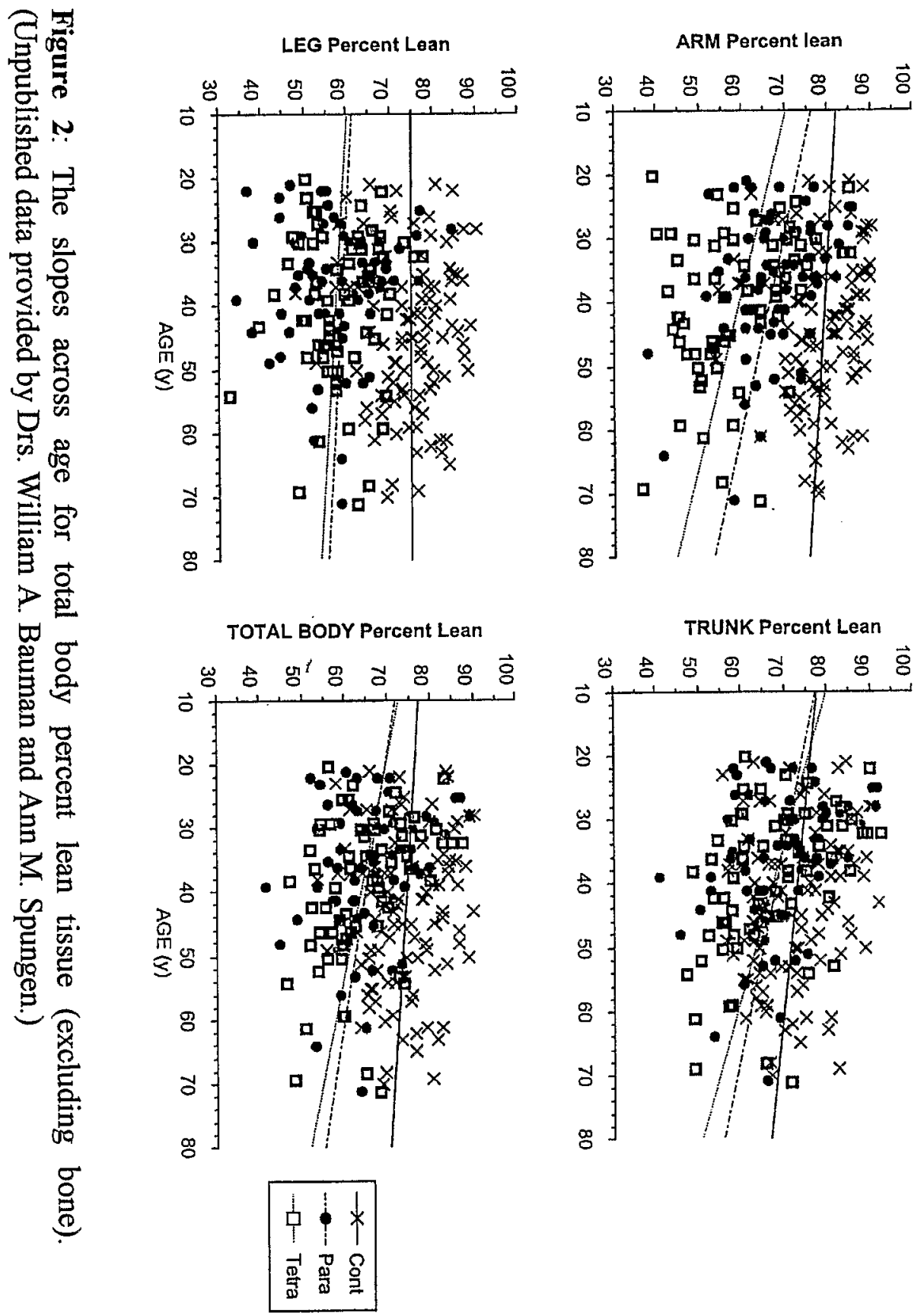




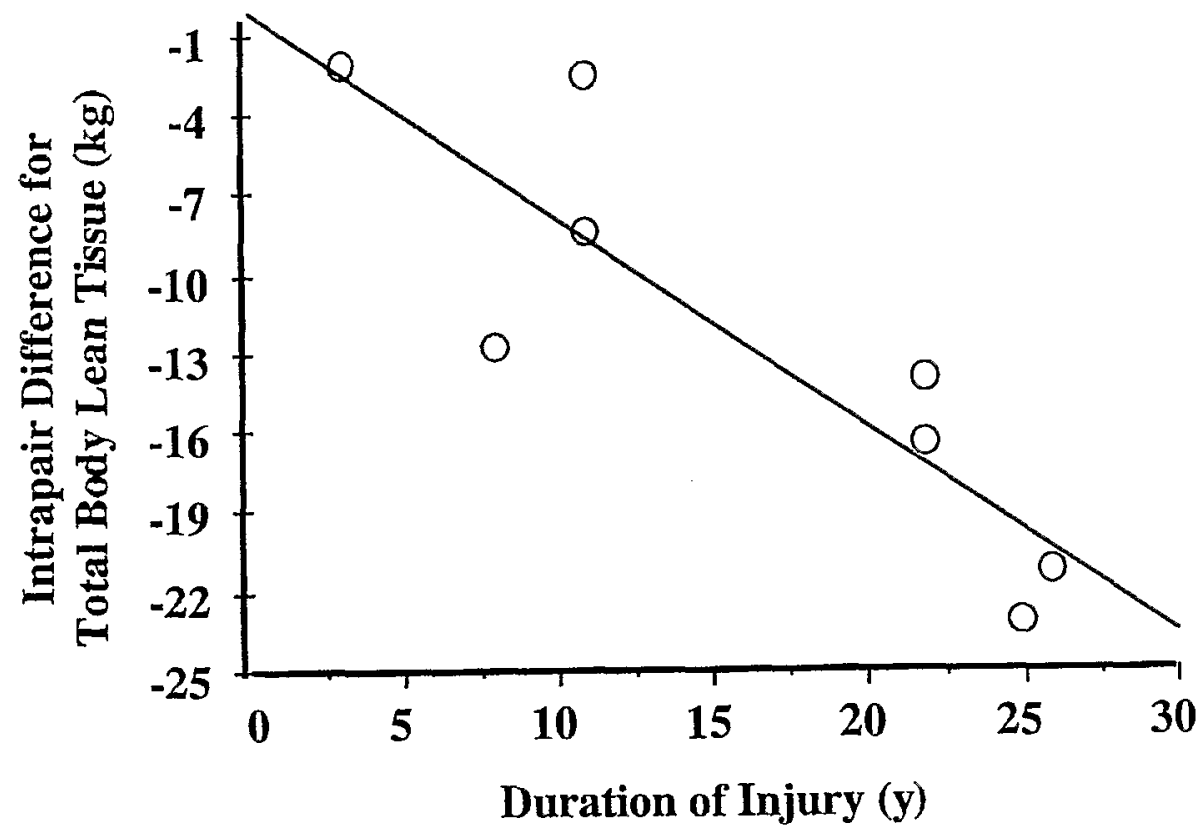

Figure 3: Linear regression analyses of intrapair difference scores (non-injured minus spinal cord injured twin) of leg lean (top) or total body lean (bottom) versus duration of injury. (Modified from Spungen et al. Soft tissue body composition differences in monoozygotic twins discordant for immobilization. J Applied Physiol. 2000;88: 1310-1315.)

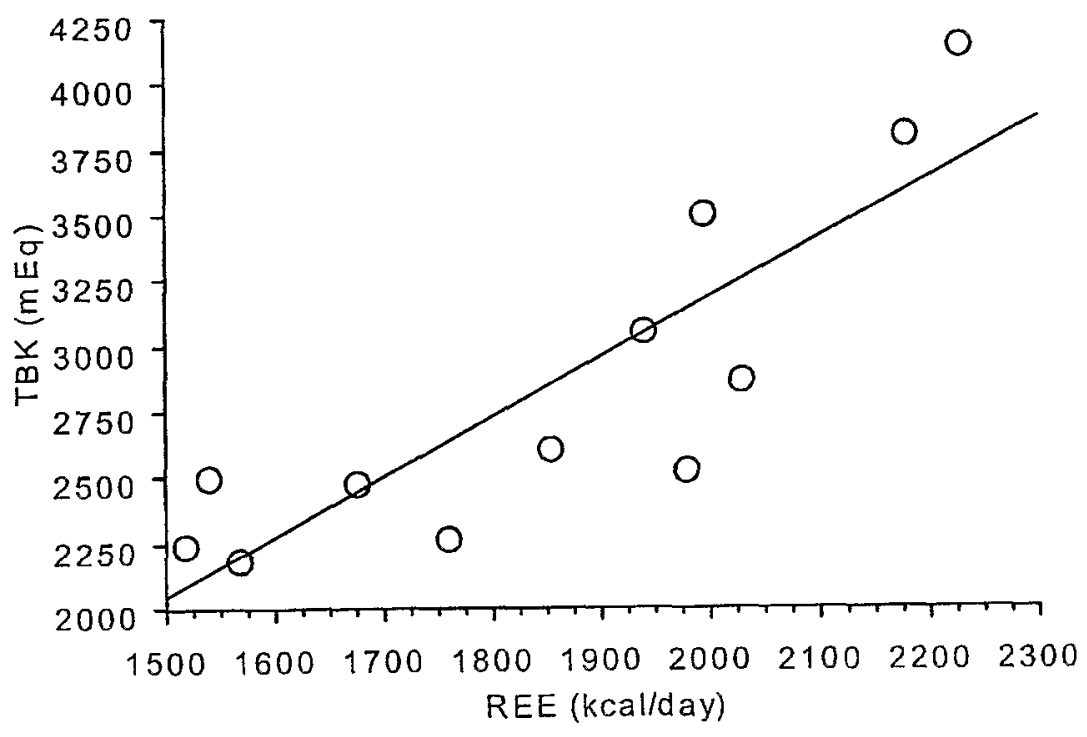

Figure 4: Linear regression analysis between total body potassium (TBK) and resting energy expenditure (REE) (With permission from Spungen AM, et al. The relationship between total body potassium and resting energy expenditure in individuals with paraplegia. Arch Phys Med Rehabil. 1993;73:965-968.) 


\title{
Multi-Component Body COMPosition MOdels: Recent AdVANCES ANd FutuRE DIRECTIONS
}

\author{
STEVEN B. HEYMSFIELD, MD \\ Professor of Clinical Medicine \\ Nutrition Research Center \\ St. Luke's/Roosevelt Hospital Center \\ Columbia College of Physicians and Surgeons
}

\begin{abstract}
This overview summarizes main body composition research concepts, examines new component measurement methodologies, and identifies potential areas for future research. Particular emphasis is placed on the use of imaging methods in both clinical and research settings, as a useful body composition method.
\end{abstract}

\section{Introduction}

Research in body composition research is devoted to the study of three interconnected areas [1]: investigating the steady-state association between components; developing and evaluating methods of quantifying body composition; and evaluating factors which influence body composition. Integral to the study and treatment of human obesity and other nutritional disorders is quantification of the main body components. In this overview, we provide a summary of body composition components and their associations in vivo and body composition methodology.

The human body consists of over 30 components (compartments) distributed across four main organizational levels: atomic, molecular, cellular and tissue system (Fig. 1).

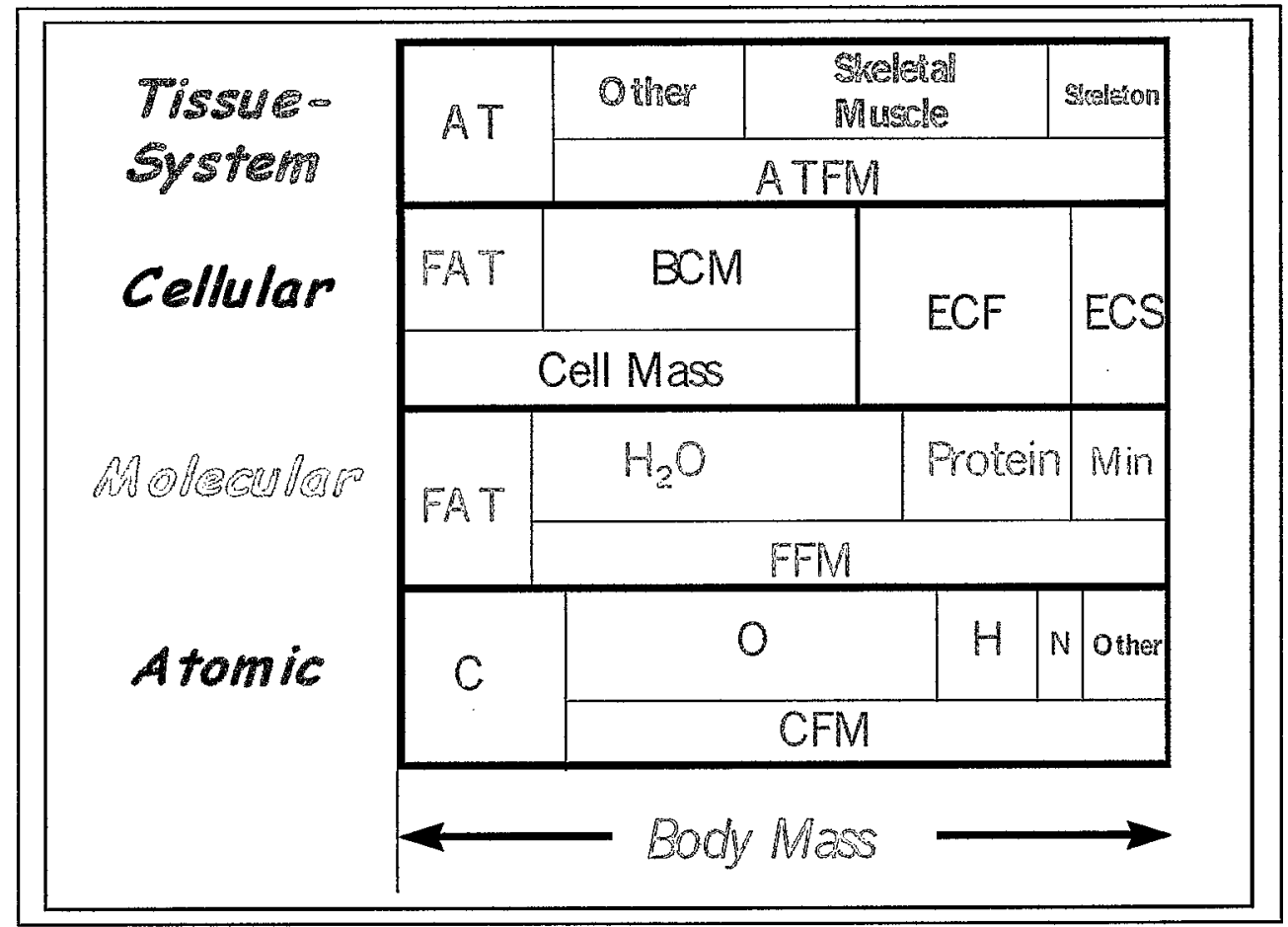


Figure 1. Four organizational levels of the human body and the related compartments.

The sum of all components at each level of body composition is equivalent to total body mass [2]. An understanding of the theoretical and empirical bases of these levels and of the interrelationships among the components at different levels is essential for properly applying body composition methods. We review the main characteristics of each body composition level in turn.

\section{BODY COMPOSITION LEVELS:}

Atomic. More than $99 \%$ of the total human body mass is comprised of 11 elements [1]. These elements are the foundation for reconstructing molecular level components. For example, the average proportions of triglyceride as $\mathrm{C}, \mathrm{H}$ and 0 are stable at approximately $76.7 \%, 12.0 \%$, and $11.3 \%$, respectively $[3,4]$. Elements can also be grouped into larger compartments such as carbon- free body mass (Fig. 1) for use in model development [5]. These stable elemental triglyceride proportions permit the development of methods for deducing total body triglyceride or 'fat' from total body carbon and other elements [6]. Brookhaven National Laboratory is unique in having the world's most complete set of instruments for evaluating the atomic level of body composition.

Molecular. The main elements and additional essential trace elements that are found in small quantities combine to form chemical compounds, which may be grouped into broad classes that define the molecular level of body composition [1]. The main molecular level component consists of lipids, water, proteins, minerals and carbohydrates (Fig. 1). Lipid is the main molecular level component of interest in the study of human obesity and are defined as chemical compounds that are insoluble or partially soluble in water but can be taken up into solution. by organic solvents such as chloroform or petroleum ether [7]. Examples of compounds detected in lipid-solvent extracts of human tissues include triglycerides, sphingomyelin, phospholipids, steroids, fatty acids and terpenes.

Cellular. The cellular level is comprised of the following three main components: cell mass, extracellular fluid and extracellular solids (Fig. 1). Connective, epithelial, nervous and muscular cells are specific cell types. Adipocytes serve as the primary storage site for triglycerides. Storage triglycerides are usually excluded in the estimation of 'body cell mass', a term which refers to the active protoplasmic portion of cells. The cellular level can therefore be considered as fat, body cell mass, extracellular fluid and extracellular solids. The body cell mass advanced by Moore et al. [10] refers to the materials comprising cells that are actively involved in oxygen consumption and heat production. Both body cell mass and molecular-level fat-free body mass are often used in research studies as measures of 'metabolically active' tissue mass.

Tissue-system. The main components at the tissue-system level are adipose tissue, skeletal muscle, bone and visceral organs (e.g. liver, kidneys, heart, etc.). Adipose tissue includes adipocytes with collagenous fibers, fibroblasts, capillaries and extracellular fluid. The four types of adipose tissue are subcutaneous, visceral, interstitial and yellow marrow [4]. Visceral adipose tissue was first quantified with the introduction of computerized tomography (CT) in the late 1970s [11]. Magnetic resonance imaging (MRI) methods now provide an alternative to CT as a means of quantifying visceral adipose tissue and other tissue-system level body composition components [12]. Similar to other body composition levels, components can be grouped into metabolically active compartments such as 'adipose tissue-free body mass' (Fig. 1). The tissue- 
system level is important for the study of energy metabolism because the cells within each organ and tissue consume similar amounts of oxygen and produce equivalent amounts of heat. As the resting energy expenditure (REE) of each organ and tissue is approximately known from catheterization studies, an individual's REE can be estimated from their measured whole-body amounts of various tissues and organs. In a recent study, Gallagher et al. [12] measured organ and tissue volumes in 13 adults using whole-body MRI. The investigators, using reported stable relationships between organs and tissues, other body composition components and REE, estimated REE, body cell mass and fat-free body mass from the measured tissue- system level components [12]. The pooled mean results, shown in Figure 2 [12], demonstrate the linkages between REE and three body composition levels, molecular, cellular and tissue-system.

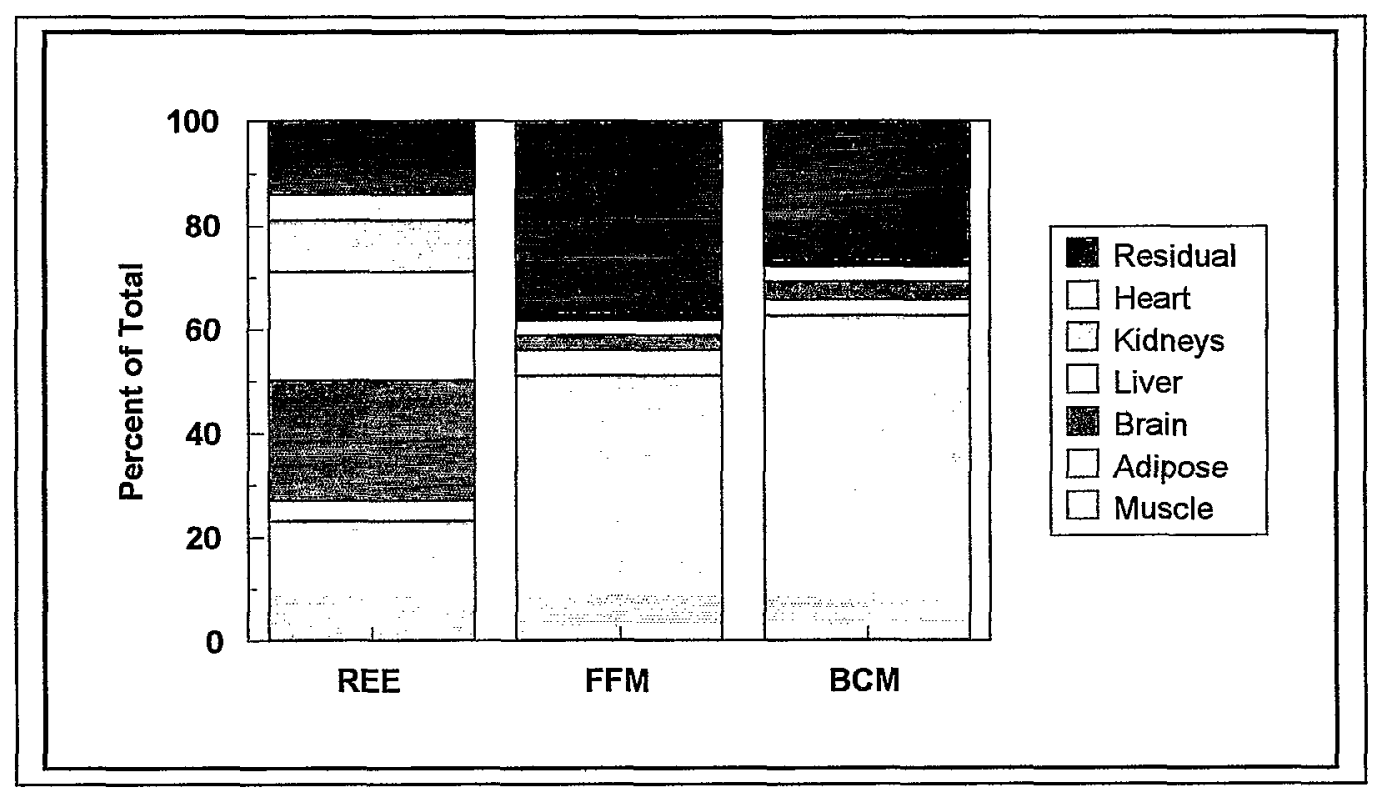

Whole body. The whole body level, not shown in Figure 2, includes characteristics such as body mass, stature, body density, resistance, skinfold thickness and circumference. Most research methods used for estimating the main body composition components in field studies are at the whole-body level of body composition. These measurements, such as skinfold thickness, are often used with prediction equations to estimate components (e.g. fat and skeletal muscle) at the other four-body composition levels [1]. An important body composition methodology concept is that associations exist between components at the same level or at different levels. Some components maintain very stable associations with each other within and between individuals: fat/adipose tissue $=$ approximately 0.80 [4]; total body water/fat-free body mass =approximately 0.73 [9]; and total body oxygen/carbon-free body mass = approximately 0.80 [5]. As noted earlier for total body water, these associations between components are important in developing body composition methods [13]. As an example, adipose tissue mass can be estimated from total body fat if the fat mass/adipose tissue mass ratio is assumed constant at 0.80 . This cothversign 
factor would be useful when comparing, for example, fat mass estimates by dual energy X-ray absorptiometry to adipose tissue volume/mass estimates by MRI.

\section{BODY COMPOSITION METHODS :}

\section{Applications}

The methods we have selected to review are considered appropriate for clinical and research applications and may be divided into descriptive and mechanistic methods. Descriptive methods share in common the following characteristics: 1) a statistically significant correlation between a measured property (e.g. impedance at $50 \mathrm{kHz}$ ) and a body component (e.g. total body water); 2) requirement for a prediction formula linking property to component (e.g. impedance to total body water); and 3) prediction formula development and cross-validation on well characterized individuals using established reference method for component measurement. Descriptive body composition methods are in general relatively simple and inexpensive. The accuracy of descriptive methods depends in part on the more accurate, reproducible and expensive 'laboratory-based mechanistic methods against which they are calibrated. Mechanistic methods are typically based on the aforementioned 'stable' component associations, such as fatfree body mass hydration [9] and density of fat-free body mass [4]. For example, underwater weighing based on a mechanistic model (i.e. known and constant densities of fat and fat-free body mass) is typically used as the reference for estimating fat mass when developing anthropometric prediction formulas.

\section{Descriptive methods}

\section{Anthropometry.}

Anthropometry is the least expensive and most widely used method of assessing human body composition. Anthropometric measurements useful in the clinical and research setting include body weight, stature, skinfold thickness, circumference of the trunk and limbs and sagittal diameter. In addition, anthropometry is useful in clinical and epidemiological studies to grade the degree of malnutrition or obesity in populations.

\section{Bioimpedance analysis.}

Bioimpedance analysis (BIA) was introduced over ten years ago as a simple, safe, and relatively inexpensive means of quantifying body composition components [21]. The National Institutes of Health in 1994 sponsored a Technology Assessment Conference on BIA and this is a good source of technical and research information on this important topic [22].

BIA is based upon the principle that tissues rich in water and electrolytes are less resistant to the passage of an electrical current than lipid-rich adipose tissue. In theory, an individual with no adipose tissue would have minimum impedance, and impedance would increase to a maximum when all lean tissue was replaced by lipid-filled adipose tissue. Impedance methods include an estimate of height to adjust for between-individual differences in electrical path length [23]. The path length typically evaluated is arm-to-leg, although measurement of an isolated limb or trunk impedance is increasing in popularity.

Practically all BIA body composition methods are based on 'descriptive' prediction models. This is important because developed prediction formulas should only be applied to 
populations for whom the regression equation was developed. Inaccurate results can be anticipated when, for example, BIA is applied in obese individuals and component prediction formulas are used that were developed in normal weight individuals.

\section{Mechanistic methods}

\section{Isotope dilution.}

The most important isotope dilution method is the use of isotopically labelled water $\left(\mathrm{H}_{2} \mathrm{O}, \mathrm{D}_{2} \mathrm{O}\right.$ and $\left.\mathrm{H}_{2}{ }^{18} 0\right)$ [27]. The total body water component is of interest per se, and water estimates also allow evaluation of fat-free mass and fat. The classic mechanistic method of estimating fat and fat-free body mass is based on the assumed stable hydration of fat-free mass (i.e. total body water/ fat-free mass $=0.73$ ). Fat-free mass can be calculated using this ratio once total body water is known from isotope dilution. Fat can then be calculated as the difference between body weight and fat-free mass.

The widespread applicability of total body water methods is based on their simplicity, low cost and overall safety, particularly of stable water isotopes. The main limitation of this useful method is the model error introduced when hydration is rendered abnormal (i.e. 0.73) by various diseases and with other states such as growth and aging. Other dilution methods are available for evaluating extra-cellular and intracellular water compartments.

\section{Dual-energy X-ray absorptiometry.}

Although dual energy X-ray absorptiometry (DXA) was originally introduced for measuring the amount of mineral within bone, this important method can also be used to estimate fat and lean soft tissue [28].

The DXA method evolved from the simpler single-photon absorptiometry method used to quantify bone in areas with little overlying soft tissue [29]. When soft tissue is minimal, photons, emitted from a radioactive source, are attenuated almost exclusively by higher atomic weight elements such as calcium and phosphorus in bone. Single-photon absorptiometry was and, to some extent, is still useful in evaluating between-individual regional bone mineral differences. Bones buried deep within soft tissues were not measurable, however, with single photon methods. In 1981, Peppler and Mazess [30] first introduced the concept of dual-photon absorptiometry. Two photon energies were passed through tissue and attenuation measured. The relative attenuation of the two discrete photon streams is a function of tissue elemental composition. This phenomenon can be described using the ratio, or R-value, of low to high photon energy attenuation. The $\mathrm{R}$ - value at any given energy for each element is known and constant. High atomic number elements usually have high R-values [31] for a representative system. Dual-photon systems and the more recent DXA method quantify relative attenuation of the two main photon peaks as they pass through tissue. Bone, rich in calcium and phosphorus, has a high relative attenuation and $\mathrm{R}$-value; fat, which is mainly low atomic number hydrogen and carbon, has a low R-value; and lean soft tissues with oxygen and electrolytes have an intermediate R-value [32]. Although dual-photon methods are complex, systems conceptually measure each pixel's (i.e. picture element) R-value as they pass over regions or the whole body and then reconstruct three compartments, bone mineral, fat and lean soft tissue, using manufacturer-specific reconstruction algorithms [26,29]. Estimated R-values are similar for all lean soft tissues and are not measurably influenced by age [33]. 
Software available on most DXA systems allows evaluation of regional body composition in addition to whole-body estimates. The regional approach provides fat distribution measures and, assuming most extremity lean soft tissue is muscle, a measure of appendicular skeletal muscle mass [31].

There are now many validation studies that demonstrate good correlations between DXA and other reference body composition methods in animals and humans [34,35,36]. However, some discrepancies between DXA and other reference methods are still reported and the reasons for these discrepancies are the subject of current research interest. Additional ongoing concerns are the influence of altered hydration and body thickness on DXA fat estimates [37]. One such concern with dual-photon methods is whether or not changes in soft tissue hydration influence body fat estimates [38]. In order to examine this question, we developed two models of soft tissue hydration [38].

We simulated the errors that would arise with addition of various amounts and proportions of fluid such as water and sodium chloride. The R-value for simulated tissue and solution are known allowing, through a series of complex models, for the analysis of errors arising in body fat estimation by DXA. The simulated fat fraction error, expressed in percentage fat units, and soft tissue baseline composition is assumed to be $25 \%$ fat and $75 \%$ lean. Negative and positive errors as shown in the figure represent under- and overestimates of actual percentage fat, respectively. Our analysis indicates that there are three independent determinants of error magnitude: elemental content of over-hydration fluid, fraction of combined fluid + soft tissue as over-hydration fluid, and initial soft tissue composition. Small but systematic and predictable errors in DXA soft tissue composition analysis thus can arise with fluid balance changes [38].

A major advantage of DXA methods is that whole-body scans require less than 20 min for the average adult or child, requiring minimal subject participation and radiation dosages are very low $(<1 \mathrm{mrem})$. While costs vary, in general the amount charged exceeds that for simpler methods such as BIA or anthropometry. Moreover, DXA is a stationary instrument suitable for laboratory research and at present clinical use for soft tissue analysis is limited.

\section{In-vivo neutron activation analysis - whole body counting}

Oxygen, $\mathrm{C}, \mathrm{H}$ and $\mathrm{N}$ account for $>95 \%$ of body mass and seven additional elements- $\mathrm{Na}$, $\mathrm{K}, \mathrm{P}, \mathrm{Cl}, \mathrm{Ca}, \mathrm{Mg}$ and $\mathrm{S}$ - comprise $>99.5 \%$ of body mass $[1,4]$. Because some elements maintain stable associations with other elements or chemical compounds (e.g. $\mathrm{kg} / \mathrm{kg}: \mathrm{S} / \mathrm{N}=0.062 ; \mathrm{N} /$ protein $=0.16$; and $\mathrm{C} /$ triglyceride $=0.77$ ), estimation of these elements in vivo allows for evaluation of other body composition components (e.g. S, protein and triglyceride).

Most elements of interest can be quantified using a group of methods referred to as neutron activation analysis. These include total body $\mathrm{H}, \mathrm{C}, \mathrm{N}, \mathrm{O}, \mathrm{Na}, \mathrm{Ca}, \mathrm{P}$ and $\mathrm{Cl}$. Additionally, total body potassium (TBK) can be measured with naturally occurring radioactive ${ }^{40} \mathrm{~K}$ [39] and this method is included as part of some neutron activation protocols.

Neutron activation systems are complex instruments that rely on a simple principal: elements within exposed to a neutron flux become 'activated' and the resulting decay products can be counted concurrently (prompting an inelastic scattering neutron activation) or following neutron irradiation (delayed neutron activation). Neutron activation methods are valuable as references for total body fat, protein, extracellular fluid and bone mineral [40]. Neutron activation systems tend to be costly and require specialized personnel for their maintenance and 
operation. As a result, these invaluable methods are only available on a limited scale and they are not widely used at present outside of specialized research facilities such as the National Laboratory at Brookhaven.

TBK can be estimated without neutron irradiation. Potassium found in humans is mainly non-radioactive ${ }^{39} \mathrm{~K}$, although a small portion $(0.0118 \%)$ consists of radioactive 4 'OK. Once the individual's ${ }^{40} \mathrm{~K}$ amount is measured by whole body counting, TBK can be estimated as TBK $(\mathrm{mmol})={ }^{40} \mathrm{~K} / 0.000118$ [41]. TBK can be used to estimate body cell mass, fat and fat-free mass.

\section{Imaging}

CT and MRI provide investigators with the opportunity to evaluate tissue-system level components in vivo [42, 43, 44, 45] Cross-sectional high resolution images can be produced by CT and MRI and multiple cross-sectional images can be used to reconstruct various tissue volumes including total, subcutaneous and visceral adipose tissue, skeletal muscle, brain, organs (i.e. liver, spleen, kidneys and heart), skin, bone and other smaller organs and tissues [42]. The mass of the organ or tissue can then be calculated as organ/tissue volume $\mathrm{x}$ assumed density. The tissue-system level of body composition can be analyzed using CT and MRI methods in vivo with a high degree of accuracy and reproducibility.

Cross-sectional CT images can be used to measure the area of body composition components of interest $[11,42,46-50]$. There are tw̌o methods used to measure tissue areas. The first approach is to visually trace the component's outer edge and then use CT scanner software to provide the component's cross-sectional area. Structures such as liver and some skeletal muscles can be evaluated using this method. The second method is to trace the structure and then use CT scanner software to specify a pixel range for the component of interest. This method assumes that the traced area consists of at least two components. For example, adipose tissue area within a traced region of skeletal muscle can be estimated by selecting the pixels that range between - 190 and - $30 \mathrm{HU}[42,48]$. Components have characteristic pixel ranges that can be experimentally established [51]. The second approach is useful in separating complicated structures that include more than one tissue. Visceral adipose tissue is found anatomically between intestinal loops and other abdominal structures. Visceral adipose tissue would be difficult to directly trace, thus necessitating use of the 'pixel range' method.

MRI scans are analyzed in a manner similar to that described for $\mathrm{CT}$, although the quantification of MRI data is not as straightforward as it is for CT. With CT, pixel values consistently represent specific tissues regardless of slice position or assessed individual, whereas MRI pixel tissue values vary from slice to slice or between individuals. Improvements to MRI hardware and software have reduced artifacts and substantially improved the quality of MRI. Some examples of MRI validation studies are presented in references [50,52-55].

The volume of a tissue or organ is derived in two steps. The volume for each image is first determined by multiplying the area $\left(\mathrm{cm}^{2}\right)$ of the tissue by the slice thickness. Regional or whole body volume is next calculated using a mathematical algorithm [56]. Both CT and MRI body composition estimates have been validated in phantoms and also in living and cadaver animals and humans.

CT and MRI offer the opportunity for three-dimensional tissue volume quantification. The images are sharp and tissue boundaries are relatively clear. No other currently available methods can assess tissue- system level body composition components with the same level of accuracy as CT and MRI. Because CT is associated with ionizing radiation, the trend in recent 
years is to favor MRI as the method of choice when available. Both imaging methods are costly and at present are limited to research applications. A recent review examines the applicability of $\mathrm{CT}$ and MRI to body composition research [55].

Both CT and MRI are widely used in research studies to evaluate lipid, hormonal and other relations to body composition [55,57]. Whole-body [58], partial body [59] and even single slice [60] evaluations are typically used.

\section{Conclusion}

There are now many methods of estimating body composition components and the method selected depends on the specific purpose of the measurements. The nature of the question posed will determine requirements for method accuracy and precision. Additional important considerations include method cost, safety, practicality and availability. The question is no longer whether a specific component can be measured, but which method is the most suitable for the chosen application.

Brookhaven National Laboratory is unique in having the most advanced IVNA facility in the world thus providing human elemental analysis. In turn, these measurements provide an unparalleled reference for other methods, and in addition, gives provides us with the only present means for estimating total body $\mathrm{N}$ and protein in vivo. There are numerous clinical projects that are and can be based on these unique facilities.

\section{References}

1. Wang ZM, Pierson RN Jr, Heymsfield SB. The five level models: a new approach to organizing body composition research. Am J Clin Nutr 1992; 56:19-28.

2. Wang ZM, Heshka S, Pierson RN Jr, Heymsfield SB. Systematic organization of body composition methodology: overview with emphasis on component-based methods. Am J Clin Nutr 1995; 61:457-465.

3. Behnke AR. Role of fat in gross body composition and configuration In: Fat as a tissue. Rodahl K (editor). New York: McGraw Hill; $1964 . \quad$ pp. 285-313.

4. Snyder WS, Cook MJ, Nasset ES, Karhausen LR, Howells GP, Tipton IH. Report of the Task Group on Reference Man. Oxford, UK: Pergamon Press; 1975.

5. Wang ZM, Deurenberg P, Wang W, Pierson RM Jr, Heymsfield SB. Fraction of carbon-free body mass as oxygen: a constant body composition ratio in men. J Nutrition 1998.

6. Keyhayias JJ, Heymsfield SB, LoMonte AF, Wang J, Pierson RN Jr. In vivo determination of body fat by measuring total body carbon. Am J Clin Nutr 1991; 53: 1339-1344.

7. Gurr MI, Harwood JL. Lipid biochemistry. $4^{\text {th }}$ edn. London: Chapman and Hall; 1991.

8. Comizio R, Pietrobelli A, Tan YX, Wang ZM, Withers RT, Heymsfield SB, Boozer, CN. Total body lipid and triglyceride response to energy deficit: relevance to body composition models. Am J Physiol 1998; 274:808-816.

9. Wang ZM, Deurenberg P, Wang W, Pietrobelli A, Baumgartner RN, Heymsfield SB. Fatfree body mass hydration: review and critique of a classical body composition constant. Am J Clin Nutr 1998.

10. Moore FD, Oleson KH, McCurry JD, Parker HV, Ball MR, Boyden CM. Body cell mass and its supporting environment: body composition in health and disease. Philadelphia: WB Saunders; 1963. 
11. Heymsfield SB, Noel R, Lynn R, Kutner M. Accuracy of tissue density predicted by CT. J Comput Assist Tomogr 1979; 3:859-860.

12. Gallagher D, Belmonte D, Beurenberg P, Wang ZM, Krasnow N, Pi-Sunyer FX, Heymsfield SB. Organ tissue mass measurement by magnetic resonance imaging allow accurate in vivo modeling of resting energy expenditure and metabolically active tissue mass. Am J Physiol 1998;

13. Heymsfield SB, Wang ZM, Withers R. Mulicomponent molecular level models of body composition analysis In: Human body composition. Roche A, Heymsfield SB, Lohman TG (editors). Champaign, IL: Human Kinetics; 1996. pp. 129-147.

14. Pietrobelli A, Faith MS, Allison DB, Gallagher D, Chiumello G, Heymsfield SB. Body mass index as a measure of adiposity among children and adolescents: a validation study. $\mathrm{J}$ Pediatr $1998 ; 132: 204-210$.

15. Must A, Dallal GE, Dietz WH. Reference data for obesity: $85^{\text {th }}$ and $95^{\text {th }}$ percentiles of body mass index (wt/ht ${ }^{2}$ ) and triceps skinfold thickness. Am J Clin Nutr 1991; 53:839-846.

16. Gallagher D, Visser M, Sepulveda D, Pierson RM Jr, Harris T, Heymsfield SB. How useful is body mass index for comparison of body fatness across age, sex, and ethnic groups? Am J Epidemiol 1996; 143:228-239.

17. Clasey JL, Kanaley JA, Wideman L, Heymsfield SB, Teates CD, Thorner MO, Hartman ML, Weltman A. Validity of methods of body composition assessment in young and older men and women. J Appl Physiol 1999; 86(5):1728-38.

18. Desprès JP. Lipoprotein metabolism in visceral obesity. Int J Obes 1991; 15:45-52.

19. Poliot MC, Desprès JP, Lemieux S, Moorjani S, Bouchard C, Tremblay A, et al. Waist circumference and abdominal sagittal diameter: best simple anthropometric indexes of abdominal visceral adipose tissue accumulation and related cardiovascular risk in men and women. Am J Cardiol 1994; 73: 460-468.

20. Sjöstrom L. Body composition studies with CR and with CT-calibrated anthropometric techniques In: Recent developments in body composition analysis: methods and applications. Kral JG, VanItallie TB (editors). London: Smith-Gordon; 1993. pp. 17-34.

21. Brodie D, Moscrip V, Hutcheon R. Body composition measurement: a review of hydrodensitometry, anthropometry, and impedance methods. Nutrition 1998; 14(3):296-310.

22. Yanovski SZ, Heymsfield SB, Lukaski HC. Bioelectrical impedance analysis. Am J Clin Nutr 1996; 64 (Suppl 3):387-532.

23. Heymsfield SB, Gallagher D. Grams J, Nuñez C, Wang ZM, Pietrobelli A. Upper extremity skeletal muscle mass: potential of measurement with single frequency bioimpedance analysis. Appl Radiat Isot 1998; 49:473-474.

24. Pietrobelli A, Morini P, Battistini N, Chiumello G, Nuñez C, Heymsfield SB. Appendicular skeletal muscle mass: prediction from multiple frequency segmental bioimpedance analysis. Eur J Clin Nutr 1998.

25. Heymsfield SB, Wang ZM, Visser M, Gallagher D, Pierson RN Jr. Techniques used in the measurement of body composition: an overview with emphasis on bioelectrical impedance analysis. Am J Clin Nutr 1996; 64 (Suppl 3):478-484.

26. Kushner RF, deVries PMJM, Gudivaka R. Use of bioelectrical impedanc analysis measurements in the clinical management of patients undergoind dialysis. Am J Clin Nutr 1996; 54 (Suppl 3): 503-509.

27. Heymsfield SB, Lichtman S, Baumgartner RN, Wang J, Kamen Y, Aliprantis A, Pierson RN Jr. Body composition of humans: comparison of two improved four-compartment models 
that differ in expense, technical complexity, and radiation exposure. Am J Clin Nutr 1990; $52: 52-58$.

28. Mazess RB, Chesnut CH, McClug M, Genant H. Enhanced precision with dual-energy X-ray absorptiometry. Calcif Tissue Int 1992; 33:353-359.

29. Cameron JR, Sorensen J. Measurement of bone mineral in vivo. Science 1963; 42:230-232.

30. Peppler WW, Mazess RB. Total body bone mineral and lean body mass by dual-photon absorptiometry. I. Theory and measurement procedure. Calcif Tissue 1981; 353-359.

31. Pietrobelli A, Formica C, Wang ZM, Heymsfield SB. Dual-energy X-ray absorptiometry body composition model: review of physical concepts. Am J Physiol 1996; 271:941-951.

32. Pietrobelli A, Gallagher D, Baumgartner RN, Ross R, Heymsfield SB. Lean R-value for DXA two-component soft-tissue model: influence of age and tissue or organ type. Appl Radiat Isot 1998; 49:743-744.

33. Heymsfield SB, Smith R, Aulet M, Bensen B, Lichman S, Wang J, Pierson RN Jr. Appendicular skeletal muscle mass: measurement by dual-photon absorptiometry. Am J Clin Nutr 1990; 52:214-218.

34. Wellens R, Chumlea WC, Guo S, Roche AF, Neo NV, Siervogel RM. Body composition in white adults by dual energy X-ray absorptiometry, densitometry, and total body water. Am J Clin Nutr 1994; 59:547-555.

35. Van Loan MS, Mayclin PL. Body composition assessment: dual energy X-ray absorptiometry (DEXA) compared to reference methods. Eur J Clin Nutr 1992; 46:125-130.

36. Hansen RD, Raja C, Aslani A, Smith RC, Allen BJ. Determination of skeletal muscle and fat-free mass by nuclear and dual-energy $x$-ray absorptiometry methods in men and women aged 51-84 y. Am J Clin Nutr 1999; 70:228-33.

37. Wells JC, Fuller NJ, Dewit O, Fewtrell MS, Elia M, Cole TJ. Four-compartment model of body composition in children: density and hydration of fat-free mass and comparison with simpler models. Am J Clin Nutr 1999; 69:904-912.

38. Pietrobelli A, Wang ZM, Formica C, Heymsfield SB. Dual energy X-ray absorptiometry: fat estimation errors due to variation in soft tissue hydration. Am J Physiol 1988; 274:860-866.

39. Heymsfield SB, Wang ZM, Baumgartner RN, Ross R. Human body composition: advances in models and methods. Ann Rev Nutr 1997; 17: 527-558.

40. Heymsfield SB, Waki M, Kehayias JJ, Lichtman S, Dlmannian FA, Kamen Y, et al. Chemical and elemental analysis of humans in vivo using improved body composition models. Am J Physiol 1991; 261:190-198.

41. Forbes GB. Human body composition. New York: Springer-Verlag; 1987.

42. Sjöstrom L, Kvist H, Cederblad A, Tylen U. Determination of total adipose tissue and body fat in women by computed tomography, 40K, and tritium. Am J Physiol 1986; 250:736-745.

43. Foster MA, Hutchinson JMS, Mallard JR, Fuller M. Nuclear magnetic resonance pulse sequence and discrimination of high- and low-fat tissue. Mag Res Imaging 1984; 2:187-192.

44. Thomas EL, Saeed N, Hajnal LV, Brynes A, goldstone AP, Frost G, Bell JD. Magnetic resonance imaging of total body fat. J Appl Physiol 1998; 85:178-85.

45. Mitsiopoulos N, Baumgartner RN, Heymsfield SB, Lyons W, Gallagher D, Ross R. Cadaver validation of skeletal muscle measurement by magnetic resonance imaging and computerized tomography. J Appl Physiol 1998; 85:115-22.

46. Chowdhury B, Sjöstrom L, Alpsten M, Kostanty J, Kvist H, Löfgren R. A multicomponent body composition technique based on computerized tomography. Int J Obes 1994; 18:219234. 
47. Heymsfield SB, Olafson RP, Kutner MH, Nixon DW. A radiographic method of quantifying protein-calorie malnutrition. Am J Clin Nutr 1979; 31:693-702.

48. Heymsfield SB, Fulenwider T, Nordlinger B, Balow, R, Sones P, Kutner M. Accurate measurement of liver, kidney, and spleen volume and mass by computerized axial tomography. Ann Intern Med 1979; 90:185-187.

49. Kvist H, Chowdhury B, Sjöstrom L, Tylen U. Adipose tissue volume determinations in women by computed tomography: technical consideration. Int J Obes 1986; 10:53-67.

50. Seidell JC, Bakker CJC, van de Kooy K. Imaging techniques for measuring adipose-tissue distribution comparison between computed tomography and 1.5-T magnetic resonance. Am J Clin Nutr 1990; 51:953-957.

51. Sjöstrom L. A computer tomography based multicompartment body composition techniques and anthropometric predictions of lean body mass, total and subcutaneous adipose tissue. Int J Obes $1991 ; 15: 19-30$.

52. Sobol W, Rossner S, Hinson B, Hiltbrandt E, Karstaedt N, Stantag P, et al. Evaluation of a new magnetic resonance imaging method for quantitating adipose tissue areas. Int $J$ Obes $1991 ; 15: 589-599$.

53. Ross R, Leger L, Guardo R, de Guise J, Pike BG. Adipose tissue volume measured by magnetic resonance imaging and computerized tomography in rats. J Appl Physiol 1991; 70:2164-2172.

54. Engstrom GM, Loeb GE, Reid JR, Forrest WJ, Avruch L. Morphometry of the human thigh muscles. A comparison between anatomical sections and computer tomographic and magnetic resonance images. J Anat 1991; 176:139--156.

55. Heymsfield SB, Ross R, Wang ZM, Frager D. Imaging techniques of body composition: advantages of measurement and new uses. In: Emerging technologies for nutrition research. Carlson-Newberry SJ, Costello RB (editors). New York: National Academic Press; 1997. pp. 127-150.

56. Ross R, Leger L, Morris D, de Guise J, Guardo R. Quantification of adipose tissue by MRI: relationship with anthropometric variables. J Appl Physiol 1992; 72:787-795.

57. Bhasin S, Stores TW, Berman N, Callegari C, Clevenger 8, Phillips J, et at. The effects of supraphysiologic doses of testosterone on muscle size strength in normal men. $\mathrm{N}$ Eng $\mathrm{J}$ Med 1996; 335:1-7.

58. Ross R. Effects of diet- and exercise-induced weight loss on visceral adipose tissue in men and women. Sports Med 1997; 24:55-@64.

59. Zamboni M, Armellini F, Tureato E, Todesco T, Bissoli L, Bergamo-Andreis IA, Bosello 0. Effect of weight loss on regional body fat distribution in premenopausal women. Am J Clin Nutr 1993; 58:29-34.

60. Ross R, Shaw KD, Martel Y, de Guise J, Avruch L. Sex differences in lean and adipose tissue distribution by magnetic resonance imaging: anthropometric relationships. Am J Clin Nutr 1994; 59:1277-1285. 
THE IMPACT OF GROWTH HORMONE ON THE BODY COMPOSITION OF CHILDREN WITH Chronic Renal Failure

VALERIE L. JOHNSON ${ }^{1 *}$, JACK WANG ${ }^{2}$, FREDERICK J. KASKEL ${ }^{3}$ AND RICHARD N. PIERSON, $\mathrm{JR}^{2}$

${ }^{1}$ Department of Pediatrics, Weill Medical College of Cornell University, New York, NY; ${ }^{2}$ Body Composition Unit, St. Luke's-Roosevelt Hospital Center, Columbia University, New York, NY;

${ }^{3}$ Department of Pediatrics, Montefiore Medical Center, Albert Einstein College of Medicine, Bronx, NY 


\begin{abstract}
Alterations in body composition are seen in children with chronic renal insufficiency (CRI) and end-stage renal disease (ESRD) who have failed to grow. Recombinant human Growth Hormone (rhGH) has been widely used in the past several years to improve the somatic growth of children with CRI/ESRD. Significant correction of body compositional changes already can be seen in these children after 6 mos of rhGH therapy. To evaluate growth and attendant body compositional changes 7 pre-pubertal $(n=6)$ and pubertal $(n=1)$ children $(4.3-13.4$ years) were studied longitudinally with body compositional analyses after 6,12 and 18 mos of rhGH. Total body fat (FM; $\pm 1.8 \%$ ), fat free mass $(\mathrm{FFM} ; \pm 4 \%)$, total bone mineral mass (TBBM; $\pm 1 \%$ ), total body water (TBW; $\pm 1.8 \%$ ), and potassium (TBK; $\pm 4.2 \%$ ) pre- and postrhGH SQ at $0.35 \mathrm{mg} / \mathrm{kg} /$ week were measured.
\end{abstract}

As expected significant increases in height and weight were seen following thGH therapy. These increases were accompanied initially by a decrease in fat $\%$ and $\mathrm{FM}$, which leveled off by 18 mos of rhGH. Concomitantly, FFM, TBK, TBW, and ICW, all measures of body cell mass, significantly increased compared to pre-rhGH values. The improvement in the TBBM was profound with significant increases also observed in TBBM corrected for weight by 18 mos post-rhGH. No significant changes in the Body Mass Index were seen. Growth in these children is occurring with repletion of the FFM and TBBM compartments. BMI measurements alone clearly miss these significant changes.

Total body compositional analysis obviously plays a crucial role in our understanding of how growth is occurring in children with CRI/ESRD. The limitations of the technology, however, have prevented evaluation of infants and small children during a period of one of the most rapid growth phases of childhood. Although calcium accretion is certainly occurring in these children, we also need to know more about the quality as well as quantity of bone mineral.

The key issue in applying serial body composition measurements to growing subjects is to identify the upward vectors of growth, the downward vectors of chronic disease, and the upward vectors of treatment, where the vector parameters are the newly available measurements of body compartments: bone, cell mass, and adipose tissue, in addition to the traditional parameters of renal function. We study children whom we would like to see grow, and any radiation we use must be minimal. Have we, and will we, in the new era we have come to expect from Brookhaven, have enough precision in measuring these compartments to be able to apply these more fundamental measurements to influence patient care? 


\section{INTRODUCTION}

Growth retardation and metabolic bone disease are common complications of chronic renal failure (CRF). Supraphysiologic doses of recombinant human growth hormone ( $\mathrm{rGGH}$ ) have been used in the past several years to treat the growth retardation of children with chronic renal insufficiency (CRI) and end-stage renal disease (ESRD), presumably by overcoming the GH resistance of this condition. In addition to the improvements of standard scores of height velocity, (1-4) weight gain $(2,3)$ and anthropometric measurements (3) have improved. Our earlier studies $(5,6)$ have shown that the TBK and FFM body compartments are both significantly reduced in children with CRI/ESRD consistent with a reduction in body cell and skeletal muscle mass. Although the BMD was comparable to that of normals, the TBBM was substantially reduced, especially in the children $0-5$ years of age, suggesting a profound effect of CRI/ESRD on bone mass. The FM was also reduced, but when fat was expressed as a \% of body weight, no significant changes were seen. In growth hormone deficient patients during growth hormone replacement therapy, growth hormone has been shown to normalize a number of body composition variables (7). As the changes we have seen are similar to those in growth hormone deficient patients, changes in body composition may be anticipated during the rhGH therapy of children with chronic renal failure. However, there have been very few investigators who have examined the effect of GH treatment on body composition with $\mathrm{CRF}$.

There have been numerous studies evaluating the mechanism of renal osteodystrophy in CRF patients, which is a well-known complication of kidney failure affecting the control of bone modeling with high or low bone turnover. Secondary hyperparathyroidism plays a central role in the pathogenesis of the high turnover disease, whereas adynamic bone disease and osteomalacia are examples of lowturnover disease. There is, however, very little data on bone mineral density and bone mineral content of children with CRF.

The objectives of the present study were to assess prospectively body composition and bone density/mineral content of children with CRF treated with rhGH in order to determine if rhGH has any effect on these compartments.

\section{METHODS}

Subjects

We studied seven prepubertal $(n=6)$ and pubertal $(n=1)$ children with $\operatorname{CRI}(n=5)$ and ESRD $(n=2)$. Primary renal diseases were congenital in six, and acquired in one (Table 1$)$. The mean age was $8.22 \pm 3.72$ years at the start of rhGH therapy (Nutropin AQ, Genentech, Inc., South San Francisco, CA). The subcutaneous dose used was $0.35 \mathrm{mg} / \mathrm{kg} /$ week. The patients were studied before and after six, twelve and eighteen months of rhGH therapy.

Inclusion Criteria were as follows: Height $<5$ th percentile for chronological age, and/or SDS score for height more negative than -1.88 , and/or height velocity $\mathrm{SDS}<0$ for six months, Chronic renal failure (estimated creatinine clearance $<75 \mathrm{ml} / \mathrm{min} / 1.73 \mathrm{~m}^{2}$ by the Schwartz formula or ESRD (defined as receiving maintenance $\mathrm{HD}$ or PD), and weight $>13 \mathrm{~kg}$. and age $<21$ years with growth potential demonstrable by bone age. Exclusion Criteria included the following: Inability or unwillingness to adhere to the protocol, additional diagnoses that could impair responsiveness to $\mathrm{GH}$, e.g. dwarfism syndromes or significant extra-renal organ disease, e.g. chronic liver disease, diabetes mellitus, AIDS, medications that influence growth, and slipped capital femoral epiphysis or avascular necrosis of the femoral head. 


\section{Body Composition Studies}

Body composition studies included total body water (TBW); extracellular water (ECW); total body potassium (TBK); total body bone mineral (TBBM) and bone mineral density (BMD), and body fat. All measurements are done while subjects were in a hospital gown, a minimum of one hour after a light breakfast or lunch. Body weight was measured to the nearest $0.2 \mathrm{~kg}$ on a standard physician's office scale, and height was measured to the nearest $0.2 \mathrm{~cm}$ with a stadiometer (Holtain, Britain). Body mass index (BMI) was calculated as $\mathrm{kg} / \mathrm{m}^{2}$. Peritoneal dialysis patients emptied their abdomen of dialysate at 0700 on the day of the studies. Hemodialysis patients were dialyzed the day before the studies were to be performed.

TBW measurements by deuterium oxide.

Deuterium oxide has been extensively used for the measurement of TBW in adults and in children for more than four decades (8). The dose for this study was at $0.05 \mathrm{~g} / \mathrm{lb}$ of body weight. With this dose the $\mathrm{D}_{2} \mathrm{O}$ concentration at equilibrium is less than $0.03 \%$ of body water. On average, plasma and saliva obtained two hours after dosing give identical TBW measurements (9). In this study tracer concentration were measured in saliva 2 hours after ingestion.

ECW measurement by sodium bromide.

Non-radioactive bromide has long been used for the measurement of the ECW space in children. Bromide is non-toxic and produces no discomfort in low concentrations. Non-radioactive sodium bromide has been used for measuring ECW in infants and children for four decades (10). The dose for this study was approximately $2.6 \mathrm{mg} / \mathrm{lb}$ for weights up to $150 \mathrm{lbs}$. With this dose the bromide concentration at equilibrium is less than $2 \mathrm{mg} / 100 \mathrm{ml}$ of ECW, less than $1 / 50$ of the toxic level. We expected no risk or discomfort from this trace amount of bromide. The tracer dose was combined with deuterium oxide and given to subjects orally. Tracer concentrations were measured in the same saliva specimens collected for deuterium oxide 2 hours after ingestion.

TBK by whole body ${ }^{40} \mathrm{~K}$ counting.

The whole body counter method for TBK measurements bypasses all of the problems of exchangeable potassium. The 4-Pi whole body counter used in our laboratory provides satisfactory measurement precision $( \pm 4.2 \%)$ for TBK measurement in subjects $>13 \mathrm{~kg}(11)$. More than 1,000 children 4 to 18 years had TBK measurements in this counter between 1967 and 1970 (12). TBK will be measured by whole body ${ }^{40} \mathrm{~K}$ counting (13).

BMD, TBBM, fat, FFM, and Appendicular Skeletal Muscle Mass by Dual-energy X-ray absorptiometry (DXA).

DXA has rapidly gained acceptance in the study of body composition and bone development in children, from newborns to adolescents with a measurement precision for bone of $\pm 1 \%$ and precision of measurement for body fat of $\pm 3-4 \%(14,15)$. It can detect small changes in bone mineral and body composition (16). The sensitivity of measuring changes has been demonstrated as 
$\pm 40 \mathrm{mg}$ for calcium, $\pm 180 \mathrm{mg}$ for fat and $\pm 270 \mathrm{mg}$ for fat free mass (17). The appendicular skeletal muscle mass will be calculated from each DXA scan as described previously (18).

DXA total body analysis for BMD, TBBM, fat and FFM were performed immediately after the TBK measurement. A Lunar DPX-L scanner (Lunar Corp. Madison, WI) was equipped with pediatric software $(3.8 \mathrm{G})(27,28)$. DXA scans were performed with subjects in a supine position. The entire body of each subject was scanned, beginning at the top of the head and moving in a rectilinear pattern down the body to the feet. Mean measurement time was about 5 min, and radiation exposure is less than 0.2 millirem. Daily quality-assurance testing is performed according to the manufacturer's directions.

Statistics

Results are expressed as mean \pm SD. The paired Student's t-test was used to compare the two time periods and $z$-variates were used to compare to a normal population. A $p$-value $<0.05$ was considered significant.

\section{RESULTS}

Growth measurements before starting and after 6,12 and 18 months of rhGH therapy are shown in Table 2. The children's heights increased significantly in all three post-rhGH time points $(p<0.001)$. Weight also increased significantly $(p<0.001)$. Although the Height SDS decreased, but these changes proved not to be significant over this period of observation. Height velocity increased, but this also was not a significant change. On the other hand, even with significant changes in height and weight the BMI did not significantly change.

There was a significant decrease in and Fat\% at six months (Table 3). The Fat\% fell by $21 \%$ with a $p$-value of $<0.05$. This drop was associated with a concomitant increase in FFM. The FFM increased over the pre-rhGH values by $15 \%$ at 6 months and $27 \%$ by 12 to 18 months with $p$-values between $<0.05$ and $<0.001$ (Tables 4 and 5). TBK was significantly increased as well, the changes paralleling the changes in FFM. Simultaneous changes in both the FM and FFM can be studied by the FM/FFM index. As expected from the above data, the FM/FFM index decreased. The decrease was, however, only significant at six months post-rhGH (Table 3).

The total Body Water (TBW) in these children was $59 \%$ body weight. A small but nonsignificant increase to $63 \%$, is seen 6 months after starting rhGH. At 12 months a significant increase to $64 \%(p=0.003)$ is seen with a further increase to $68 \%$ by 18 months post rhGH (Tables 3 and 4). A small increase in the Extracellular Water (ECW) was seen post-rhGH. However, there was a very substantial increase in the intracellular water (ICW), and therefore, the increase in TBW is largely the result of an increase in the ICW. The ECW/ICW ratio is $0.85 \pm 0.01( \pm$ SEM) in age-matched normal children studied in our laboratory (14). Pre-rhGH this value is higher and as expected decreases post-rhGH because of the greater increase in the ICW.

Most of the body water (all the ICW) is contained within the FFM. The normal TBW/FFM ratio is $72.6 \pm 0.3 \%( \pm$ SEM) in laboratory age-matched control children. This ratio was $68 \%$ in our pre-rhGH children, and remained unchanged following rhGH therapy for 6 
months. By 18 months post-rhGH the ratio had increased by $13 \%$ to a value just slightly greater than that seen in the laboratory age-matched children (Table 5).

The TBBM content is lower in children with CRI and ESRD when compared to agematched normal children (5). Following rhGH there was a significant increase in the TBBM content of $9 \%$ with a $p$-value of 0.001 at 6 months. By 18 months post rhGH the TBBM had increased by $41 \%$. Despite these increases in bone mineralization with growth, only after 18 months of rhGH was a significant increase in the BMD seen.

\section{DISCUSSION}

Recombinant human GH therapy has resulted in significant increases in FFM and decreases in FM and Fat\% of children with CRF. Moreover, during GH treatment bone mineral content increased substantially, consonant with the observed statural growth. These body composition corrections were seen even without significant improvements of the height SDS or increases in growth velocity. These findings differ from those of children with CRF without growth retardation on no GH (21) where no significant change in the SDS scores for FFM, FM, Fat\% or TBBM content is seen over the same time period. Growth hormone is therefore not only allowing growth retarded children with CRF to grow, but is allowing these growth retarded children to appropriately replete body compartments.

Feber (22) has looked at the FM/FFM ratio as a way of expressing simultaneous changes in both the FM and FFM. As expected in our children this index decreased from a time 0 value of 0.13 to a post-rhGH value of 0.10 , a $13 \%$ decrease $(p<0.05)$ after 6 months. This decline highlights the fact that the FM is decreasing at the same time the FFM is increasing, while in normal children the change in body composition in 6 months would have shown a lesser change in FFM and an increase in FM.

The TBW compartment in normal children is $55 \%$ body weight (5). A value of $59 \%$ body weight is seen in our children pre-rhGH with a small increase post-rhGH. As only a $4 \%$ increase in the ECW was seen in the first 6 months post-rhGH, the increase in TBW (3.2 Liters) is largely the result of an increase in the ICW. The significance of this is that the ICW, which also is the potassium containing space, is entirely contained within the body cell mass. This finding highlights the fact that there is no change in the hydration status of these patients post-rhGH. This data using independent methodology is consistent with our DXA results. Others $(23,24)$ have looked at TBW in children with CRF using BIA and anthropometry. Using these indirect techniques Perfumo et al (23) were unable to detect differences in TBW or ECW post-rhGH.

The ECW/ICW ratio is $0.85 \pm 0.01$ in normal children. In most disease states the ECW increases relative to the ICW. In our children a drop was seen from a pre-rhGH value of $1.07 \pm 0.46$ to a value closer to normal, $0.76 \pm 0.15$. As fluid overload is characterized by an increase in this ratio, this does not account for the change seen. The decrease observed in our children is most likely accounted for by an increase in body cell mass and again is internally consistent with our DXA findings. 
Most body water is contained within the FFM. The normal TBW/FFM ratio is $72.6 \pm 0.3 \%$. Stefanidis et al (24) in a group of children with ESRD on CAPD found a value of $74 \pm 1 \%$. The ratio seen pre-rhGH in our children was $68 \%$, very comparable to normals. This ratio did not change substantially post-rhGH, further underscoring the fact that the increase in TBW seen in our study is a consequence of an increase in body cell mass and not secondary to a change in hydration status.

We previously have shown that the TBBM content is lower (from 30\% lower in 11-13 year olds to $45.2 \%$ in $2-5$ year olds) in our patients with CRI and ESRD compared to agematched normal children (5). Following rhGH treatment we saw a significant increase in the TBBM content in our patients. By 18 months post-rhGH the TBBM/weight ratio was also significantly increased $(p<0.05)$. Furthermore, the increase in TBBM was associated with no difference in total body BMD until 18 months post-rhGH, indicating a growth in bone matrix just matching the increase in mineral up until that point.

Unlike children with $\mathrm{CRF}$, children with $\mathrm{GH}$ deficiency have both growth retardation and a decreased BMD $(7,25,26)$. In our studies as well as those of Boot (21) and Vaisman (27) the mean BMD of growth retarded children was not decreased when compared to age-matched control children. On the other hand in a recent report by Lanes (28) baseline total BMD was decreased in prepubertal children with CRF. An increase in both the total BMD and mean pelvis BMD was seen following GH. The latter observations may be partially explained by the fact that the growth retardation (Height SDS $=-3.5 \pm 1.0$ ) was more profound in the children Lanes' studied (28) compared to the children studied by Vaisman (27; Height SDS $=-3.37 \pm 1.18)$ and especially those by Boot (21; Height SDS $=-2.29 \pm 0.49)$ and our study patients (Height SDS = $2.03 \pm 0.56)$.

The BMI has been widely used as an index of body fatness when direct measurements are not available. Our initial observations in children with CRF $(5,6)$ indicated that the BMI is misleading, failing to define the compartmental catabolic losses in FFM in CRF/ESRD children; FM and FFM each contribute to the BMI, but when these change in the opposite direction, particularly when FM increases while body cell mass decreases and vice versa, it is necessary to measure the components separately. As can be seen here, there are no changes in BMI despite the significant alteration in the components making it up pre-compared to post-rhGH.

The anabolic and lipolytic effects of growth hormone are observed early after the initiation of GH therapy of children with CRF. Height, weight, body composition, and total body bone mineral content significantly change following the start of $\mathrm{GH}$ in parallel with what is seen in GH-deficient children following GH treatment. Thus, growth in CRF with GH therapy is taking place with repletion of the lean body and skeletal masses. Multi-compartmental analysis therefore is key to our understanding of how growth is occurring in children with CRF. Without body compositional analysis it is impossible to clearly understand how growth hormone is effecting growth in these children. Traditional ways of assessing growth such as BMI are completely useless in this assessment.

Growth failure is a significant morbidity for children with CRI/ESRD. The "failure to grow" is reflected in the body compositional changes in these children, which bear similarity to 
those seen in other disease states and animal models associated with elevated cytokines. Subsequent recent data links cytokines to the growth hormone-insulin-like growth factor axis through common intracellular pathways utilizing suppressor of cytokine (SOCS) proteins and the JAK-STAT pathways. Correlation of factors like cytokines with body compositional changes is a more precise way to correlate these or other potential factors with "growth failure". Such studies, therefore, place us in a better position to define the mechanisms of growth failure in children with CRI and ESRD.

\section{REFERENCES}

1. Hokken-Koelega ACS, Stijnen T, deMuinck Keizer-Schrama SMPF, Wit JM, Wolff ED, de Jong MCJW, Donckerwolcke RAA, Abbad NCB, Bot A, Blum WF, Drop SLS (1991) Placebo-controlled, double-blind, cross-over trial of growth hormone treatment in prepubertal children with chronic renal failure. Lancet 338:585-590

2. Tonshoff B, Mehls, O, Heinrich U, Blum WF Ranke MB, Schauer A (1990) Growthstimulating effects of recombinant growth hormone in children with end-stage renal disease. J Pediatr 116:561-566

3. Koch VH, Lippe BM, Nelson PA, Boechat MI, Sherman BM, Fine RN (1989) Accelerated growth after recombinant human growth hormone treatment of children with chronic renal failure. J Pediatr 115:365-371

4. Van Renen MJ, Hogg RJ, Sweeney AL, Henning PH, Penfold JL, Jureidini KF (1992) Accelerated growth in short children with chronic renal failure treated with both strict dietary therapy and recombinant growth hormone. Pediatr Nephrol 6:451-458

5. Johnson VL, Wang J, Ibrahim MS, Kaskel FJ, Pierson RN, Jr (1998) Body composition in children with chronic renal insufficiency (CRI) and end stage renal disease (ESRD). Pediatr Nephrol, 12:C184

6. Johnson VL, Ibrahim MS, Kaskel FJ, Wang J, Pierson RN Jr (1998) Alterations of body composition in children with chronic renal insufficiency (CRI) and end-stage renal disease (ESRD). J Am Soc Nephrol, 9:74A

7. Saggese G, Baroncelli GI, Bertelloni S, Cinquanta L, Di Nero G (1993) Effects of long-term treatment with growth hormone on bone and mineral metabolism in children with growth hormone deficiency. J Pediatr 122:37-45

8. Cheek DB, Mellitus D, Elliot D (1966) Body water, height, and weight during growth in normal children. Am J Dis Child 112:312-317

9. Lukasi $\mathrm{H}$, Johnson PE (1985) A simple inexpensive method for determining total body water using a tracer dose of $\mathrm{D}_{2} \mathrm{O}$ and infrared absorption of biological fluids. Am $\mathrm{J}$ Clin Nutr 41:363-370

10. Blackfan $\mathrm{KD}(1961)$ Body water compartments in children changes during growth and related changes in body composition. Pediatr 28:169-181

11. Pierson RN Jr, Wang J, Thornton C, Van Itallie TB, Colt WD (1982) Body composition by 4-Pi counting: an anthropometric correction. Am J Physiol 246:F234-F239

12. Schneider B, Kolesnik S, Arbo J, Wang J, Pierson RN, Jr (1998) Total body potassium measurement: accuracy, efficiency and reproducibility. Experimental Biology, (Abstract)

13. Pierson RN, Jr, Lin, DHY (1972) Measurement of Body Composition in Children: Whole Body Counting and Other Methods. Semin Nucl Med 2:373-382 
14. Pierson RN, Jr, Lin DHY, Phillips, RA (1974) Total Body Potassium in Health: the Effects of Age, Sex, Height and Fat. Am J Physiol 226:206-212

15. Russell-Aulet M, Wang J, Thornton J, Pierson RN, Jr (1991) Comparison of dual-photon absorptiometry systems for total-body bone and soft tissue measurements; dual-energy $\mathrm{X}$-rays versus Gadolinium 153. J Bone Miner Res, 6:411-415

16. Wang J, Heymsfield SB, Aulet M, Thornton JC, Pierson RN, Jr (1989) Body fat from body density: underwater weighing vs. dual photon absorptiometry. Am. J. Physiol 256:E829-834.

17. Going SB, Massett MP, Hall MC, Bare IA, Root PA, Williams DP, Lohman TG (1993) Detection of small changes in body composition by dual photon absorptiometry. Am J Clin Nutr 57:845-850

18. Chan GM (1992) Performance of dual photon absorptiometry in evaluating bone, lean body mass and fat in pediatric subjects. J Bone Miner Res 7:369-374

19. Heymsfield SB, Smith R, Aulet M, Benson B, Lichtman S, Wang J, Pierson RN, Jr (1990) Appendicular skeletal muscle mass; measurement by dual-photon absorptiometry. Am J Clin Nutr 52:214-218

20. Mazess RB, Barden HS, Bisek JP, Hansen J (1990) Dual-energy x-ray absorptiometry for total-body and regional bone-mineral and soft-tissue composition. Am J Clin Nutr 51:11061112

21. Boot AM, Nauta J, de Jong MCJW, Groothoff JW, Lilien MR, van Wijk JAE, Kist-vann Holthe JE, Hokken-Koelega ACS, Pols HAP, de Muinck Keizer-Schrama SMPF (1998) Bone mineral density, bone metabolism and body composition of children with renal failure, with and without growth hormone treatment. Clin Endocrinol 49:665-672

22. Feber J, Cochat P, Lebi J, Krasnicanova H, Stepan J, David L, Braillon P, Bonnet L, Janda J (1998) Body composition in children receiving recombinant human growth hormone after renal transplantation. Kidney Int 54:951-955

23. Perfumo F, Trivelli A, Delucchi P, Sacco P, Canepa A, Gusmano R (1995) Anthropometry and body composition changes in children with chronic renal failure (CRF) treated with recombinant human growth hormone (rhGH). Pediatr Nephrol 9:C71

24. Stefanidis C, Siapera D, Papadopoulou A, Michelis K (1996) Body composition of children on CAPD. Perit Dial Int. 16 (Suppl. 1):S561-S566

25. Zamboni G, Antoniazzi F, Radetti G, Musumeci C, Tato L (1991) Effects of two different regimens of recombinant human growth hormone therapy on the bone mineral density of patients with growth hormone deficiency. J Pediatr 119:483-485

26. Boot AM, Engels MAMJ, Boerma GJM, Krenning EP, de Muinck Keizer-Schrama SMPF (1997) Changes in bone mineral density, body composition and lipid metabolism during growth hormone treatment in children with growth hormone deficiency. J Clin Endocrinol and Metab 82:2423-2428

27. Vaisman N, Zadik Z, Duchan R, Voet H, Lotan D, Drukker A (1994) Changes in body composition of children with chronic renal failure during growth hormone treatment. Pediatr. Nephrol. 8:201-204

28. Lanes R, Gunczler P, Orta N, Bosquez M, Scovino R, Dominguez L, Esaa S, Weisinger JR (1996) Changes in bone mineral density, growth velocity and renal function of prepubertal uremic children during growth hormone treatment. Horm Res 46:263-268 


\begin{tabular}{|llllll|}
\hline \begin{tabular}{llllll|} 
Table 1 \\
Age (vears)
\end{tabular} & Age at Onset & Diagnosis & Sex & CRI/ESRD & Tanner Stage \\
\hline \hline & & & & & \\
13.36 & Birth & Obstructive Uropathy & M & ESRD & III \\
6.2 & Birth & Spina Bifida & F & CRI & I \\
5.7 & Birth & Obstructive Uropathy & M & CRI & I \\
5.1 & Birth & Reflux Nephropathy & M & ESRD & I \\
10.8 & 2 years & Tubulointerstitial Nephritis & F & CRI & II \\
12 & Birth & Obstructive Uropathy & M & CRI & II \\
4.27 & Birth & Obstructive Uropathy & F & CRI & I \\
\hline
\end{tabular}

\begin{tabular}{|lllllll|}
\hline Table 2 & $\begin{array}{l}\text { Time } 0 \\
(\mathrm{n}=7)\end{array}$ & $\begin{array}{l}+6 \text { months } \\
(\mathrm{n}=7)\end{array}$ & $\begin{array}{l}\text { Time } 0 \\
(\mathrm{n}=5)\end{array}$ & $\begin{array}{l}+12 \text { months } \\
(\mathrm{n}=5)\end{array}$ & $\begin{array}{l}\text { Time } 0 \\
(\mathrm{n}=5)\end{array}$ & $\begin{array}{l}+18 \text { months } \\
(\mathrm{n}=5)\end{array}$ \\
\hline \hline Age (years) & $8.22 \pm 3.72$ & $8.87 \pm 3.79^{* * *}$ & $7.18 \pm 3.6$ & $8.39 \pm 3.73^{* * *}$ & $6.68 \pm 3.09$ & $8.49 \pm 3.09^{* * *}$ \\
Height $(\mathrm{cm})$ & $115.9 \pm 20.3$ & $120.8 \pm 20.2^{* * *}$ & $116.9 \pm 21.1$ & $127.4 \pm 20.6^{* * *}$ & $106.4 \pm 14.5$ & $119.3 \pm 13.3^{* * *}$ \\
Weight (kg) & $22.9 \pm 9.8$ & $25.5 \pm 10.9^{* * *}$ & $22.9 \pm 10.6$ & $28.5 \pm 13.0^{* *}$ & $18.6 \pm 6.9$ & $23.6 \pm 7.7^{* * *}$ \\
SDS Score Height & $-2.03 \pm 0.56$ & $-1.71 \pm 0.57$ & $-1.98 \pm 0.65$ & $-1.64 \pm 0.08$ & $-2.26 \pm 0.36$ & $-1.81 \pm 0.66$ \\
SDS Score Weight & $-1.25 \pm 0.24$ & $1.06 \pm 0.33$ & $-1.36 \pm 0.18$ & $-1.048 \pm 0.18^{*}$ & $-1.28 \pm 0.29$ & $-1.02 \pm 0.51$
\end{tabular}

Values are Mean $\pm \mathrm{SD} * p<0.05, * * p<0.005, * * * p<0.001$ 


\begin{tabular}{|llll|}
\hline Table 3 & $\begin{array}{l}\text { Time } 0 \\
(\mathrm{n}=7)\end{array}$ & $\begin{array}{l}+6 \text { months } \\
(\mathrm{n}=7)\end{array}$ & \% Baseline \\
\hline Fat\% & $11.9 \pm 3.6$ & $9.4 \pm 3.8 *$ & 78.9 \\
FM & $2.59 \pm 0.96$ & $2.24 \pm 0.99$ & 86.5 \\
FFM & $20.33 \pm 9.10$ & $23.27 \pm 10.45 * *$ & 114.5 \\
FM/FFM & $0.13 \pm 0.05$ & $0.10 \pm 0.05^{*}$ & 76.9 \\
TBK & $1372 \pm 642$ & $1523 \pm 745^{*}$ & 111 \\
TBK/FFM & $63.39 \pm 4.88$ & $60.82 \pm 6.13$ & 95.9 \\
TBW & $15.44 \pm 5.59$ & $18.62 \pm 7.46^{*}$ & 120.5 \\
TBW/FFM & $0.68 \pm 0.02$ & $0.67 \pm 0.02$ & 98.5 \\
ECW & $7.12 \pm 2.17$ & $7.38 \pm 2.57$ & 103.7 \\
ICW & $8.32 \pm 3.61$ & $11.24 \pm 4.91 *$ & 135 \\
ECW/ICW & $0.95 \pm 0.36$ & $0.68 \pm 0.07$ & 71.5 \\
TBBM & $854 \pm 499$ & $938 \pm 525^{* * *}$ & 109.8 \\
TBBM/Weight & $35.12 \pm 6.92$ & $34.9 \pm 5.88$ & 99.4 \\
TBBM/Height & $6.93 \pm 2.93$ & $7.34 \pm 2.99 * *$ & 105.9 \\
TBD & $0.83 \pm 0.15$ & $0.83 \pm 0.15$ & 100 \\
BMI & $16.3 \pm 1.6$ & $16.7 \pm 1.8$ & 102.4 \\
\hline Values are Mean $\pm \mathrm{SD} .{ }^{*} \mathrm{p}<0.05, * * \mathrm{p}<0.005, * * * \mathrm{p}<0.001$
\end{tabular}




\begin{tabular}{|llll|}
\hline Table 4 & $\begin{array}{l}\text { Time 0 } \\
(\mathrm{n}=5)\end{array}$ & $\begin{array}{l}+12 \text { months } \\
(\mathrm{n}=5)\end{array}$ & \% Baseline \\
\hline Fat\% & $11.16 \pm 2.54$ & $9.3 \pm 4.6$ & 83.3 \\
FM & $2.51 \pm 1.17$ & $2.3 \pm 0.6$ & 91.63 \\
FFM & $20.47 \pm 9.58$ & $26.15 \pm 12.92^{*}$ & 127.7 \\
FM/FFM & $0.13 \pm 0.03$ & $0.10 \pm 0.05$ & 76.9 \\
TBK & $1396 \pm 747$ & $1920 \pm 581^{*}$ & 137.5 \\
TBK/FFM & $60.98 \pm 7.06$ & $71.3 \pm 20.2$ & 116.9 \\
TBW & $14.58 \pm 6.07$ & $20.05 \pm 8.46^{*}$ & 137.3 \\
TBW/FFM & $0.66 \pm 0.03$ & $0.70 \pm 0.04^{* *}$ & 106 \\
ECW & $6.88 \pm 2.42$ & $8.08 \pm 3.1$ & 117.4 \\
ICW & $7.7 \pm 3.8$ & $11.98 \pm 5.47^{*}$ & 155.5 \\
ECW/ICW & $1.01 \pm 0.40$ & $0.71 \pm 0.16$ & 70.3 \\
TBBM & $869 \pm 533$ & $1094 \pm 614^{* *}$ & 125.9 \\
TBBM/Weight & $35.77 \pm 6.97$ & $37 \pm 4.6$ & 103.4 \\
TBBM/Height & $6.99 \pm 3.07$ & $8.17 \pm 3.27^{* * *}$ & 116.9 \\
TBD & $0.85 \pm 0.16$ & $0.87 \pm 0.15$ & 102.3 \\
BMI & $16.03 \pm 1.8$ & $16.66 \pm 2.09$ & 103.9 \\
\hline
\end{tabular}

Values are Mean \pm SD. ${ }^{*} \mathrm{p}<0.05,{ }^{* *} \mathrm{p}<0.005, * * * \mathrm{p}<0.001$ 


\begin{tabular}{|cccc|}
\hline Table 5 & $\begin{array}{c}\text { Time 0 } \\
(\mathrm{n}=5)\end{array}$ & $\begin{array}{c}+18 \text { months } \\
(\mathrm{n}=5)\end{array}$ & $\%$ Baseline \\
\hline & & & \\
Fat\% & $12.7 \pm 4.1$ & $11.78 \pm 3.5$ & 92.7 \\
FM & $2.24 \pm 0.6$ & $2.74 \pm 1.1$ & 122.3 \\
FFM & $16.37 \pm 6.65$ & $20.85 \pm 6.95^{* * *}$ & 127.4 \\
FM/FFM & $0.15 \pm 0.05$ & $0.13 \pm 0.04$ & 86.7 \\
TBK & $1010 \pm 441$ & $1160 \pm 452^{*}$ & 114.9 \\
TBK/FFM & $61.26 \pm 6.18$ & $54.96 \pm 5.50^{*}$ & 89.72 \\
TBW & $12.7 \pm 5.43$ & $18.23 \pm 4.84$ & 143.5 \\
TBW/FFM & $0.67 \pm 0.005$ & $0.76 \pm 0.15$ & 113.4 \\
ECW & $6.1 \pm 1.76$ & $7.63 \pm 1.63$ & 125.1 \\
ICW & $6.6 \pm 3.8$ & $10.6 \pm 3.57$ & 160.6 \\
ECW/ICW & $1.07 \pm 0.46$ & $0.76 \pm 0.2$ & 71 \\
TBBM & $623 \pm 352$ & $882 \pm 393^{* *}$ & 141.6 \\
TBBM/Weight & $32.03 \pm 5.27$ & $36.47 \pm 3.67 *$ & 113.9 \\
TBBM/Height & $5.62 \pm 2.21$ & $7.2 \pm 2.26^{* * *}$ & 128.1 \\
TBD & $0.77 \pm 0.09$ & $0.83 \pm 0.09^{*}$ & 107.8 \\
BMI & $15.99 \pm 1.16$ & $16.2 \pm 1.4$ & 101.3 \\
\hline
\end{tabular}

Values are Mean \pm SD. ${ }^{*} \mathrm{p}<0.05,{ }^{* *} \mathrm{p}<0.005,{ }^{* * *} \mathrm{p}<0.001$ 


\section{Evidence for Intracellular Edema in EUVolemic Heart Failure Patients}

Jonathan Sackner-Bernstein, M.D., Catalin Toma, M.D., Pilar Haynes, Jack Wang, Chris Nunez, John Thornton, Donald Kotler, M.D., Richard N. Pierson, M.D., Steven B. Heymsfield, M.D.

From the Divisions of Cardiology, Endocrinology, and Gastroenterology, and the Obesity Research Center, St. Luke's-Roosevelt Hospital Center, New York, NY.

Address for correspondence:

Jonathan D. Sackner-Bernstein, M.D. Division of Cardiology

St. Luke's-Roosevelt Hospital Center

1111 Amsterdam Avenue

New York, NY 10025

Telephone: $212-523-4009$

Fax: 212-523-3915

Email: jsackner-bernstein@slrhc.org 


\begin{abstract}
Background. Volume overload is the hallmark of congestive heart failure. Yet despite use of diuretics to rid patients of edema, symptoms persist. We hypothesized that patients treated with optimal diuretic doses remain affected by congestion. To test this hypothesis, we evaluated body composition and bioenergetic state in euvolemic heart failure patients.
\end{abstract}

Methods. In the fasting state, clinically euvolemic heart failure patients $(n=18)$ underwent measurement of: 1) extracellular, intracellular and total body water via bromide and deuterium dilution techniques (ECW, ICW, and TBW, respectively), 2) total cell mass measured by total body potassium (TBK) using whole body ${ }^{40} \mathrm{~K}$ counting, and 3) fat-free mass (FFM) by DXA scanning. Results were compared to gender, race, height and age matched normal controls.

Results. Patients had left ventricular ejection fraction $<35 \%$, NYHA Class I ( $n=1)$, II $(n=13)$, III $(n=3)$ or IV $(n=1)$ symptoms, and were $66 \pm 14$ years old. Compared to matched controls, heart failure patients had similar TBW, but ECW was $\downarrow 21 \%$ and ICW increased $\uparrow 21 \%$ and ECW/ICW ratio was $\downarrow 35 \%$. ( $\mathrm{p}=0.002,0.053$, and $<0.0001$, respectively). Intracellular potassium concentration $\left(\mathrm{K}_{\mathrm{i}}\right)$ was $\downarrow 20 \%$, which reflects a $7 \mathrm{mV} \downarrow$ in the calculated average resting membrane potential.

Conclusions. Heart failure patients without clinical evidence of edema, whose TBW is normal, can have "intracellular edema." This intracellular volume expansion is associated with reduced intracellular potassium concentration and calculated resting membrane potential, indicating a potential role of this intracellular edema in the functional limitation and increased risk of arrhythmias for patients with heart failure.

\title{
Background
}

The hallmark physical finding in chronic heart failure is edema, a reflection of volume excess. Historically, this has been a primary focus of treatment, with diuretics a cornerstone of pharmacotherapy. Once the diuretic dose has been adjusted to achieve euvolemia, treatment guidelines emphasize neurohormonal antagonism. ${ }^{1}$ However, even with optimal neurohormonal blockade, patients remain symptomatic.

In advanced heart failure, cachexia develops in parallel with markedly diminished functional capacity. 2,3 In mild and moderate disease, body composition appears grossly normal $^{3}$ Yet changes in composition of the cells could contribute significantly to exercise intolerance, even in the absence of cachexia. For example, altered myocardial myosin heavy chain isoform, with more prominent beta isoform, is an adaptation that permits contraction in a substrate-poor environment. ${ }^{4}$ This shift in composition ensures function, but the energetics is significantly impaired.

In a recent study, aggressive diuresis of non-edematous heart failure patients improved functional capacity. ${ }^{5} \mathrm{~A}$ possible explanation is that altered cell composition, in this case intracellular edema, was reversed by the diuresis. If there were no change in potassium content, this diuresis would increase intracellular potassium concentration and improve bioenergetic state. 
We hypothesized that changes in body composition at the cellular level occur in mild to moderate heart failure, affecting bioenergetic state. Several factors support the relevance of our hypothesis. Although diuresing patients will improve clinical status promptly, neurohormonal activation parallels the azotemia that develops reflecting intravascular volume depletion. Further, therapies that improve clinical outcomes such as the angiotensin converting enzyme inhibitors and beta-blockers improve renal hemodynamics and renal water handling. In addition, the perception that optimal fluid balance is realized when edema resolves is based on scientific reasoning and not on data. Prior studies have not used techniques capable of detecting changes in intracellular water content or potassium concentration, and have permitted standard clinical practices to continue without supportive studies.

\section{Methods.}

Population. Patients with reduced left ventricular systolic function (left ventricular ejection fraction $<0.40$ ) on stable medical therapy was assessed clinically for the presence of volume excess, specifically, the presence of riles, hepatic congestion or lower extremity edema, in conjunction with a standard clinical evaluation. Those considered euvolemic underwent body composition studies for measurement of: 1) extracellular, intracellular and total body water via bromide and deuterium dilution techniques (ECW, ICW, and TBW, respectively), 2) total cell mass measured by total body potassium (TBK) using whole body $4 \mathrm{M}^{40} \mathrm{~K}$ counting, and 3) fatfree mass (FFM) by DXA scanning.

Controls. Normal controls were selected from the database at the St. Luke's-Roosevelt Body Composition Laboratory, matched for gender, race, age and height.

Deuterium Dilution Volume for Total Body Water (TBW). Deuterium oxide was dosed orally, $0.05 \mathrm{~g} / \mathrm{lb}$ of body weight for subjects less than 150 pounds, and $7.5 \mathrm{~g}$ for all subjects over $150 \mathrm{lbs}$. Plasma concentrations were measured at baseline and three hours after dosing on an FTIR system (Avatar-360, Nicolet). ${ }^{6}$

Bromide dilution volume for extracellular water (ECW). Sodium bromide was dosed orally, simultaneously with deuterium oxide, at a dose of $0.04 \mathrm{~g}$ of $4 \mathrm{M}$ sodium bromide for weights up to $150 \mathrm{lbs}$ and $0.03 \mathrm{~g} / \mathrm{lb}$ for all subjects over $150 \mathrm{lbs}$. Plasma concentrations were measured at baseline and three hours after dosing on a HPLC system. ${ }^{6}$

Whole Body ${ }^{40} \mathrm{~K}$ Counting (TBK). The $4 \pi$-whole body counter measures ${ }^{40} \mathrm{~K}$. The ${ }^{40} \mathrm{~K}$ raw counts accumulated over nine minutes are adjusted for body size based using a ${ }^{42} \mathrm{~K}$ calibration equation. The within-subject coefficient of variation in our laboratory for ${ }^{40} \mathrm{~K}$ counting is $4 \%$, the reproducibility for ${ }^{40} \mathrm{~K}$ counting is $\sim \pm 2.4 \%$. Total body potassium is calculated as ${ }^{40} \mathrm{~K} / 0.00118$.. Prior to each subject measurement, bottles approximating the body size and weight of the subject are counted. 7

Dual-Energy X-Ray Absorptiometry (DXA). Body composition is measured in vivo with a whole-body DXA (DPX, Lunar Radiation Corp., Madison, WI) in slow scan mode. The system 
software (Version 3.8G and 1.3Z) provides estimates of three compartments; fat, lean soft tissue, and bone mineral for the whole body and specific regions. Fat-free body mass is calculated as the difference between body weight and fat. Each scan is started at $3-5$ scanning lines to the top of the head to several scanning lines passing the feet. If there was any significant sign of subject movement during scanning, the scan is repeated. The average total scanning time is about 30 minutes, and total radiation dose is less than $3 \mathrm{mRem}$. The DXA scanner is calibrated using an anthropomorphic spine phantom made up of calcium hydroxyapatite embedded in a $17.5 \times 15 \times$ $17.5 \mathrm{~cm}$ block in addition to using ethanol and water bottles to simulate fat and fat-free soft tissues, respectively. 8

\section{Results}

Patients had NYHA Class I $(n=1)$, II $(n=13)$, III $(n=3)$ or IV $(n=1)$ symptoms, and were $66 \pm 14$ years old. Compared to normal values, patients were euvolemic (normal TBW and TBW/FFM) and were not cachectic (normal weight, BMI and FFM). Digoxin was used in 9 of the patients, and none of the measured parameters were statistically different between digoxin and nondigoxin treated patients with respect to water distribution, potassium content or intracellular potassium concentration. However, digoxin treated patients were older.

Compared to matched controls, HF patients had similar TBW, but ECW was $\downarrow 21 \%$ and ICW increased $\uparrow 21 \%$ and ECW/ICW ratio was $\downarrow 35 \%$. ( $\mathrm{p}=0.002,0.054$, and $<0.0001$, respectively). $\mathrm{Ki}$ was $\downarrow 20 \%$, which reflects a $7 \% \downarrow$ in the calculated average resting membrane potential. (table)

\section{Discussion:}

The main finding of this study is that stable heart failure patients without clinical evidence of edema, confirmed by measurement of TBW, can have "intracellular edema." Because total body potassium levels were normal, and serum potassium concentration was normal, the intracellular volume expansion is associated with reduced intracellular potassium concentration. These alterations in body composition would lead to a reduction in the calculated average resting cell membrane potential, indicating a potential role of this intracellular edema both in the functional limitation and increased risk of arrhythmias observed in patients with heart failure.

The data do not provide us with a mechanism for these observations, but two possibilities exist. First, alteration in cell membrane permeability, either by functional or structural changes, could facilitate stimuli to cellular hyperosmolality, which would lead to osmotic forces driving water intracellularly. There is no report in the literature describing a cellular change to support this mechanism. Second, extracellular fluid could be hypoosmolal, which would drive water intracellularly. This could be a manifestation of the potent diuretic therapy utilized in patients with heart failure, whereby natriuresis occurs in excess of diuresis, leading to a tendency to extracellular hypoosmolality, since most sodium in extracellular. Osmotic forces drive the water intracellularly to provide equilibrium across the cell membranes. 
Although our data are unique, and represent the first report of intracellular edema in heart failure patients, the observations are consistent with current models of the disease, and in fact, may explain in part the clinical syndrome of chronic congestive heart failure. Neurohormonal activation is a hallmark of the disease, and our data our consistent with the effects that could be produced by elevated arginine vasopressin levels. Prior studies have demonstrated elevation of this neurohormone in heart failure, in a manner that correlates with disease severity, and therefore, functional limitation. ${ }^{9}$ In addition, the reduction in intracellular potassium concentrations and resultant changes in membrane potential could contribute to decreased cardiac and skeletal muscle function as well as abnormal electrical conduction within the myocardium.

A major limitation of our study is the absence of data to link these changes in body composition with functional parameters. Measurement of maximal oxygen consumption, skeletal muscle endurance, and/or myocardial reserve would be useful means of establishing the clinical and physiologic importance of these changes in body composition. However, this limitation should not diminish the importance of our observations. These patients were typical of an ambulatory heart failure population, and the techniques used provide precise, reproducible and reliable assessments of body composition. In fact, the techniques used in our study provide greater precision than those utilized in prior assesšments of body composition of heart failure patients. In addition, our approach provides much more robust understanding of body composition than prior studies. For example, using only the DXA data would allow interpretation via the 3-compartment model of fat, lean and bone mass and would give the appearance that body composition is normal. If we expanded that to measurement of TBW, it would appear that these patients were optimally managed with respect to water balance. However, by investigating further, and measuring ECW, ICW and TBK, we have identified fundamental abnormalities of water metabolism and cellular bioenergetics in chronic congestive heart failure.

In summary, we have utilized state of the art techniques to assess body composition in stable chronic congestive heart failure patients and detected significant abnormalities in water distribution. Specifically, we have demonstrated that the intracellular edema is associated with significant reductions in intracellular potassium concentration, which indicates important changes in resting cell membrane potential. Such an abnormality has not been detected previously due to the application of less robust models of body composition and techniques that do not fully explore body composition. The clinical and physiologic relevance of these observations warrant further investigations, but these data may explain the functional limitation and increased risk of cardiac arrhythmias that affect patients with chronic congestive heart failure.

\section{References}

1. Packer M, Cohn JN, ActionHF. Consensus Recommendations for Heart Failure. American Journal of Cardiology 1999;83:1A-38A. 
2. Shan $\mathrm{K}$, Kurrelmeyer $\mathrm{K}$, Seta $\mathrm{Y}$ et al. The role of cytokines in disease progression in heart failure. Curr Opin Cardiol 1997;12:218-23.

3. Anker SD, Ponikowski PP, Clark AL et al. Cytokines and neurohormones relating to body composition alterations in the wasting syndrome of chronic heart failure. Eur Heart $J$ 1999;20:683-93.

4. Lowes BD, Minobe W, Abraham WT et al. Changes in gene expression in the intact human heart. Downregulation of alpha-myosin heavy chain in hypertrophied, failing ventricular myocardium. J Clin Invest 1997;100:2315-24.

5. Chomsky DB, Lang CC, Rayos G, WIlson JR. Treatment of subclinical fluid retention in patients with symptomatic heart failure: effect on exercise performance. $J$ Heart Lung Transplant 1997;16:846-53.

6. Waki M, Kral JG, Mazariegos M, Wang J, Pierson RNJ, Heymsfield SB. Relative expansion of extracellular fluid in obese versus nonobese women. Am J Physiol 1991;261:199-203.

7. Pierson RNJ, Lin DHY, Phillips RA. Total-body potassium in health: effects of age, sex, height, and fat. Am J Physiol 1974;226:206-12.

8. Heymsfield SH, Wang J, Funfar J, Kehayias JJ, Pierson RN. Dual photon absorptiometry: accuracy of bone mineral and soft tissue mass measurements in vivo. Am $J$ Clin Nutr 1989;49:1283-9.

9. Francis GS, Benedict C, Johnstone DE, et al. Comparison of neuroendocrine activation in patients with left ventricular dysfunction with and without congestive heart failure. A substudy of the Studies of Left Ventricular Dysfunction (SOLVD). Circulation 1990;82:1724-9. 
Table. 1 Comparison of body composition between patients with heart failure and control subjects, matched for gender, race, age and height. ${ }^{*}=$ significant difference from matched controls

\begin{tabular}{|l|c|c|c|}
\hline Variable & $\begin{array}{c}\text { Heart Failure } \\
\text { Patients }\end{array}$ & $\begin{array}{c}\text { Matched } \\
\text { Controls }\end{array}$ & $\begin{array}{c}p \text { vs. Matched } \\
\text { controls }\end{array}$ \\
\hline Age (years) & $66 \pm 14$ & $65 \pm 14$ & NS \\
\hline Height $(\mathrm{cm})$ & $165 \pm 9.4$ & $166 \pm 8.4$ & NS \\
\hline Weight $(\mathrm{kg})$ & $74 \pm 21$ & $74 \pm 13$ & NS \\
\hline BMI & $26.9 \pm 5.9$ & $26.6 \pm 4.4$ & NS \\
\hline FFM & $50.5 \pm 14.0$ & $49.6 \pm 9.4$ & NS \\
\hline TBK & $2721 \pm 905$ & $2824 \pm 722$ & NS \\
\hline TBK/kg & $36.6 \pm 5.4$ & $38.3 \pm 7.3$ & NS \\
\hline TBW & $36.6 \pm 10.5$ & $36.2 \pm 7.2$ & NS \\
\hline ECW & $13.3 \pm 3.6^{*}$ & $16.9 \pm 3.0$ & 0.002 \\
\hline ICW & $23.3 \pm 7.3$ & $19.3 \pm 4.7$ & 0.054 \\
\hline FAT\% & $31.4 \pm 8.1$ & $32.1 \pm 10.3$ & NS \\
\hline TBK/FFM & $53.6 \pm 5.8$ & $56.4 \pm 5.6$ & 0.14 \\
\hline TBW/FFM & $0.72 \pm 0.02$ & $0.73 \pm 0.05$ & NS \\
\hline ECW/TCW & $0.58 \pm 0.10^{*}$ & $0.90 \pm 0.15$ & $<0.0001$ \\
\hline ICW/FFM & $0.46 \pm 0.03^{*}$ & $0.39 \pm 0.04$ & $<0.0001$ \\
\hline TBK/TBW & $73.6 \pm 7.5$ & $77.6 \pm 9.1$ & 0.16 \\
\hline Ki & $114 \pm 13^{*}$ & $144 \pm 17$ & $<0.0001$ \\
\hline Ek (mV) & $-86 \pm 3^{*}$ & $-92 \pm 3$ & $<0.0001$ \\
\hline
\end{tabular}




\title{
Protein Metabolism in Specific ORgans and Tissues \\ (Regronal Protein Metabolism)
}

\author{
Peter J. GARLiCK
}

Dept. of Surgery

State University of New York

Stony Brook, New York, USA

\begin{abstract}
Injury and disease are frequently accompanied by loss of protein from body tissues, and one of the aims of treatment is to minimize this loss and promote its recovery by nutritional and other therapies. A better understanding of the processes that influence tissue protein gain and loss can be achieved by studies of protein synthesis and degradation in tissues. These two complex and opposing processes are controlled by a variety of hormonal, chemical and physical signals, resulting in the maintenance of protein balance in the healthy adult individual. An imbalance resulting from modulation of either synthesis or degradation is the cause of protein gain or loss, but in this article we will concentrate on measurements of protein synthesis.
\end{abstract}

\section{Measurement of Protein Synthesis}

Rates of protein synthesis have been measured for many years in cells and tissues in vitro and in animal models using radioactively labeled amino acids. These studies have made an invaluable contribution to our understanding of protein metabolism, but their relevance to human disease can only be assessed by direct measurements in humans. Risk of radiation limits the use of radioactive isotopes in humans, however, and they have now been largely replaced by their stable isotope counterparts. The limitations of tissue sampling in humans and the continual improvement of the mass spectrometers used to measure stable isotopes have resulted in the development of a variety of approaches for measuring rates of protein synthesis and degradation in the whole body. The label is administered orally or intravenously, and measurements are made on samples of urine or blood and breath, which are readily available by relatively noninvasive techniques [1]. For example, intravenous infusion of $\left[1-{ }^{13} \mathrm{C}\right]$ leucine for $6-12$ hours results in the attainment of a plateau in the enrichment of free leucine in the blood. This plateau value, together with an estimate of the amount of ${ }^{13} \mathrm{C}$ expired in breath $\mathrm{CO}_{2}$ can then be used to determine the total body turnover of leucine, and also its origin from dietary intake and body protein degradation and its disposition into oxidation and body protein synthesis $[2,3,4]$. These techniques have been used extensively (for reviews see $[1,5,6]$ and have given rise to much useful information, but suffer from the limitation that changes in whole body rates of protein synthesis cannot be ascribed with any certainty to any particular organ, tissue or body compartment. For example, animal studies have shown that inflammation resulting from subcutaneous injection of turpentine is associated with a fall in protein synthesis in skeletal 
muscle, but a rise in the liver [7]. Over the last decade or so, therefore, there has been an increasing interest in measurements of protein synthesis rates in individual tissues of human subjects.

The general procedure for measuring protein synthesis in an individual tissue or organ in vivo is to inject an amino acid labeled with the chosen isotope into the bloodstream and to make measurements during the period that it is incorporated into tissue protein. The determine rates of protein synthesis, a tissue sample is taken at the end of a period of time $t$ (days) and the enrichment of the amino acid in protein $\left(\mathrm{E}_{\mathrm{p}}\right)$ determined. The fractional rate of synthesis $\left(\mathrm{k}_{\mathrm{s}}\right.$, in $\%$ per day) is then calculated from the equation: $k_{s} \times E_{f} \times t=E_{p} \times 100$. The amount of label incorporated into protein can be measured directly on a tissue sample, or inferred from its disappearance from the blood. The other necessary information is the average enrichment of the free amino acid that is being incorporated into protein. This latter measurement has given rise to much debate. Theoretically this measurement should be made on the pool of amino acyl tRNA in the tissue, but this is complicated by the extremely rapid rate of turnover of this pool and its small size, requiring large tissue samples. For most practical purposes the alternative is to use either the plasma or the tissue (intracellular) free amino acid. However, the isotopic enrichment in these two compartments is not necessarily the same, which has led to uncertainty in the calculated values for protein synthesis and has been influential in determining the way in which the labeled amino acid is administered. Both of the procedures commonly used today were originally suggested by the work of R.B. Loftfield in the 1950's. When a labeled amino acid was given to rats by continuous intravenous infusion, the enrichments (specific radioactivities) in the plasma and tissues rapidly rose to constant (plateau) values, but in the tissues the values remained substantially lower than in the plasma [8]. The interpretation made was that the intracellular pool was derived partially by transport of amino acid into the cell from the plasma and partially from the degradation of unlabeled protein. Moreover, it would be difficult to calculate rates of protein synthesis with confidence, because it was not known which, if either, of these two values would be appropriate as the precursor enrichment. Rates of protein synthesis were not therefore calculated, and instead a different method of label administration was devised, with the aim of making the intra- and extracellular enrichments the same, thus minimizing the ambiguity. This was achieved by injecting the labeled amino acid together with a large amount of unlabeled amino acid, sufficiently to dominate (flood) the small endogenous pool of unlabeled free amino acid [9]. This approach has become known as the "flooding method". Both of these approaches have been used extensively in animals with radioactively labeled amino acids [1,10]: their use in human subjects will now be described in more detail.

\section{Constant Infusion Method.}

The first studies with this method in humans involved measurement of protein synthesis in muscle with $\left[{ }^{15} \mathrm{~N}\right]$ lysine [11] and in GI tissues, including tumors, with $\left[{ }^{15} \mathrm{~N}\right]$ glycine [12]. Subsequently, the majority of constant infusion studies have used $\left[1-{ }^{13} \mathrm{C}\right]$ leucine, which is moderately priced and relatively easily measured [13]. Infusions lasting between $4-12 \mathrm{~h}$ are generally primed [13], to achieve plateau labeling more quickly, and are followed by tissue sampling, which in the case of skeletal muscle, can be done by percutaneous needle biopsy. The enrichment of the amino acid in protein from the tissue biopsy has usually been measured by chromatographic isolation of the leucine from protein and decarboxylation followed by 
measurement of the enrichment of the $\mathrm{CO}_{2}$ produced by gas isotope ratio mass spectrometry (GIRMS).

The precursor enrichment is obtained from serial samples of blood taken during the infusion. The choice is between free leucine in blood or blood "ketoisocaproic acid (KIC), which is the transamination product of leucine and is thought to be representative of the intracellular leucine in skeletal muscle [14]. The KIC enrichment is typically $70-80 \%$ of that of leucine [14]. It is often thought that the KIC gives the best estimate of the precursor enrichment, but this remains unproven. The KIC in blood might not be derived entirely from muscle, and at best it represents an average enrichment for all muscles, which might differ from the enrichment in the single muscle under study [15]. Moreover, there is the possibility that the enrichment of leucyl tRNA might sometimes be lower than that of the KIC or the intracellular leucine $[16,17]$. Although the KIC has been used for non-muscle tissues such as liver [18], this is not advisable, as there is little reason to suppose that the $\mathrm{KIC}$ reflects the liver free leucine enrichment. For liver synthesized proteins (eg. serum albumin), a far more reliable measure of the precursor enrichment can be derived from measurements of the ApoB protein of very low density lipoprotein in the blood. As this pool turns over very rapidly, it achieves the same enrichment as its own precursor within the liver after a few hours of infusion [19].

The constant infusion method has been used for many investigations of muscle protein synthesis in volunteers and patients [20]. Its advantages are that simultaneous measurement can also be made of whole-body protein turnover, and that the labeled amino acid is given as a tracer, unlike the flooding method, and therefore should not disturb metabolism. Its disadvantages are the need for a metabolic steady state during the infusion, which might preclude observations when acute metabolic changes in are occurring (eg. after a meal, in acute illness or during surgery), and the uncertainty regarding the precursor enrichment.

\section{Constant Infusion during Limb or Organ Balance Measurement.}

Arterio-venous differences in blood amino acid concentrations coupled with measurement of blood flow has often been used to measure the net balance of amino acids across a limb or organ [21]. When this procedure is performed during a constant infusion of a labeled amino acid, then rates of protein synthesis and degradation can also be obtained [22]. In this case, synthesis is not derived from the amount of label that appears in protein of a biopsy, but instead from the amount of label that disappears from the blood as it passes through the tissue. For an amino acid that is not metabolized in the tissue under study, eg. phenylalanine in muscle, the rate of uptake of label from the blood must equal the amount incorporated into protein, if the tissue free amino acid pool does not expand or contract. In other respects, the assumptions are the same as those for the constant infusion method. In particular, a value for the precursor enrichment is needed, and this is usually taken from the free amino acid in the venous blood.

The major advantage of this method is that a value for protein degradation can also be obtained, by subtracting the net balance from the rate of synthesis. It should be recognized, however, that this is not an independent estimate. If there is any error in synthesis, eg. arising from the precursor measurement, then the rate of degradation will also be in error. A recent modification of this technique employs a tissue biopsy at the end of the procedure [23]. This enables the rate of synthesis to be calculated from the intracellular enrichment, which is useful, 
as there is no metabolite of phenylalanine equivalent to $\mathrm{KIC}$ which can be used as an indicator of intracellular enrichment. In addition, it is possible to calculate the rates of transport of the amino acid between the blood and the intracellular pools.

The balance method can only be done on a tissue or organ with a well defined arterial and venous vasculature. In addition to the disadvantages of the infusion method, there is also the need for arterial catheterization and precise blood flow measurement.

\section{Flooding Method.}

Preliminary experiments showed that $4 \mathrm{~g}$ of $\left[1{ }^{13} \mathrm{C}\right]$ leucine per $80 \mathrm{~kg}$ body weight resulted in almost complete equalization of enrichment in the plasma and intracellular pools in muscle of healthy volunteers over a two hour period (illustrated in Fig.1b,[24]). The rate of muscle protein synthesis is calculated from the enrichment of leucine in muscle protein at $90 \mathrm{~min}$. and the average value for precursor enrichment, derived from serial measurements on plasma leucine or $\mathrm{KIC}$ at intervals between 0 and $90 \mathrm{~min}$ [24]. The value obtained was $1.86 \mathrm{sem} 0.12 \% /$ day when the precursor was taken to be the plasma leucine and $1.95 \mathrm{sem} 0.12 \%$ /day when the plasma KIC was used as an index of intracellular labeling [24]. These values are expressed as fractional rates, in the units of \% per day, which represent the amounts of protein synthesized as percentages of the amount in that tissue.

Although the flooding method successfully equalizes the rates calculated from intracellular and plasma enrichments, these values are higher than those measured by constant infusion of $\left[1-{ }^{13} \mathrm{C}\right]$ leucine, eg. 1.10 sem $0.07 \%$ /day [25]. This discrepancy has led to much debate about the validity of these two methods $[10,20]$, which is not yet resolved. There do not appear to be similar discrepancies in tissues of animals such as rats, or in human tissues other than skeletal muscle [10]. Apparently higher values for colon, liver and serum albumin synthesis obtained by flooding reported by Rennie et at [20] can readily be explained. In liver, the longer period of labeling with infusion means that only non-secretory proteins are measured, whereas total synthesis is measured by flooding [10]. Similarly, with albumin there is turnover of the newly synthesized pool in the plasma during a long infusion, resulting in an underestimate of the synthesis rate [10].

Two possible reasons for the discrepancy in human muscle have been suggested. The first is the possibility that the enrichment of the precursor amino acid is not being accurately reflected by measurements on plasma leucine or KIC during a constant infusion. There is evidence that this can occur in cell culture [16], but confirmation that this can occur in human tissues in vivo is so far lacking (see [10]). If the enrichment at the site of protein synthesis were lower than the KIC, this might result in an underestimate of the rate of synthesis by constant infusion [26]. Conversely, it has been suggested that the large amount of labeled amino acid given during flooding might itself stimulate muscle protein synthesis, thus giving rise to an artifactually high measured rate by this method [20]. There is no direct proof that this can occur except from studies using the constant infusion approach [27], which does not provide independent evidence. Moreover, labeled phenylalanine and valine both give similar values to that with leucine, when given in flooding amounts, and injection of leucine does not alter the distribution of polyribosomes in muscle [28]. 
Both the infusion and flooding methods have been used to investigate the control of protein synthesis in a variety of human tissues. Fig. 1 illustrates the wide range of fractional rates of synthesis (FSR) observed in various healthy tissues taken from volunteers and from patients during surgery. The fractional rates of synthesis of two plasma proteins (as fractions of the intravascular pool), albumin and fibrinogen, are also shown.

\section{Muscle Protein Synthesis in Pathological States}

In an attempt to elucidate the muscle wasting that takes place after surgical injury, measurements of muscle protein synthesis were made in cholecystectomy patients before and after surgery (Fig. 2). A short period of anesthesia without surgery did not affect muscle protein synthesis, but immediately after the completion of surgery (open cholecystectomy), there was already a 30\% fall [29]. By day 3 after surgery, the decrease in protein synthesis had enlarged to $50 \%$ [30]. These data suggest that muscle wasting after surgery results at least in part from an immediate and sustained decrease in muscle protein synthesis. Further experiments were performed to see whether this change was dependent on the degree of trauma, and whether it could be modified by strategies designed to alleviate the wasting. Minor surgery for breast lump removal did not affect muscle protein synthesis [31]. The effect of major surgery was no greater than that of cholecystectomy [31], and the rates in patients in the intensive care unit were on

Figure 1

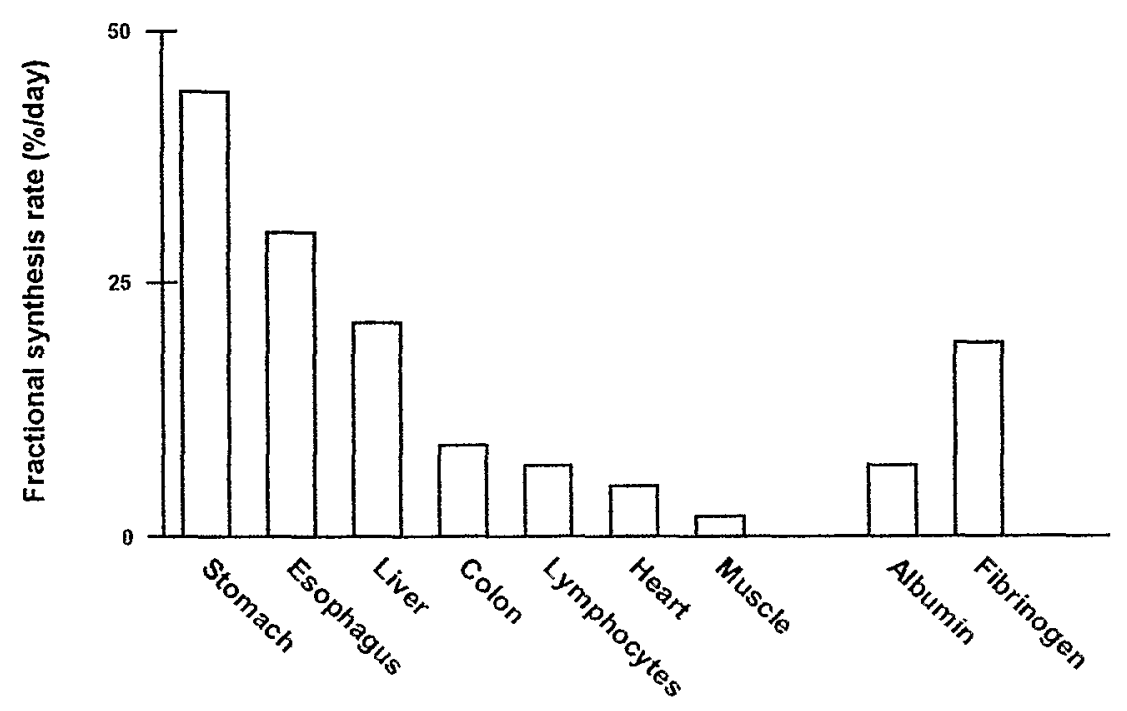

average less depressed those after surgery, although the range of values, shown in Fig. 2 by the upper part of the bar, was considerable [32]. Surprisingly, laparoscopic surgery did not produce a smaller response than conventional, open surgery (Fig.2), even though its beneficial effects on recovery are well accepted [33]. Moreover, postoperative intravenous nutrition did not diminish the decrease in protein synthesis [30]. These results suggest that new strategies, such as 
Figure 2

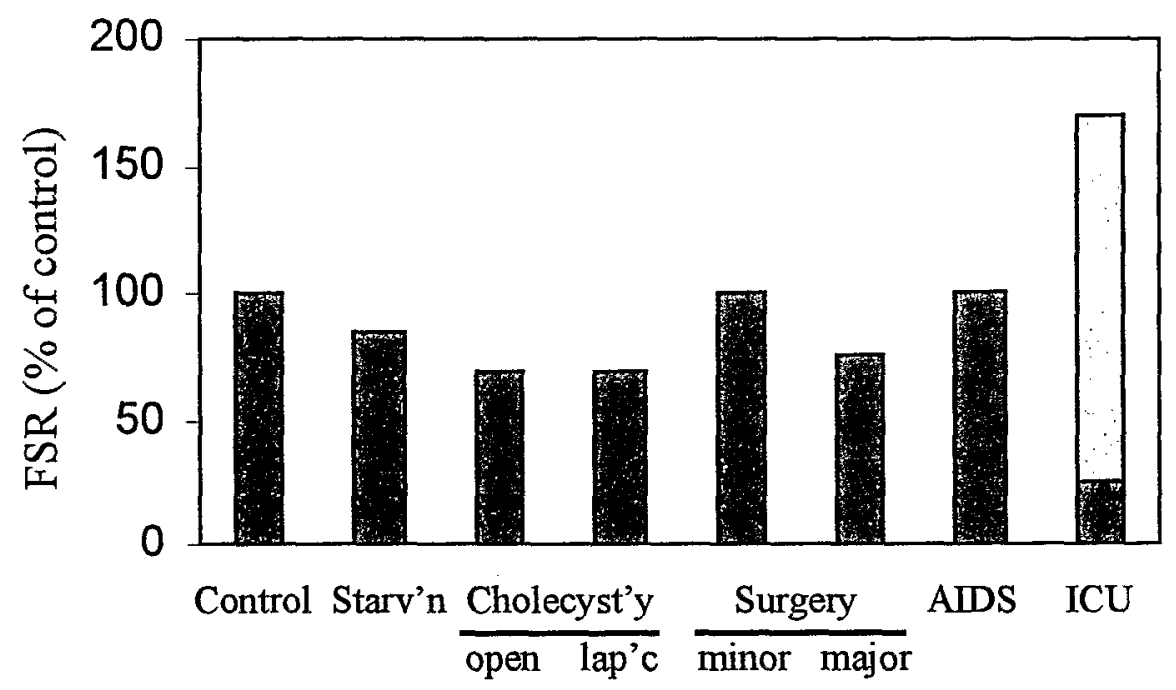

provision of glutamine in TPN [34], or treatment with growth hormone [35], might be needed to minimize protein loss after surgery and optimize recovery.

Muscle wasting also occurs in chronic diseases, such as HIV/AIDS. In this case we have shown that protein synthesis is not depressed, even in patients who show overt muscle wasting do not have lower rates of muscle protein synthesis (Fig 3.). However, when these patients were given a 2-week course of treatment with growth hormone, the reason for the wasting became clear, as there was a stimulation in muscle protein synthesis in the healthy controls and in asymptomatic HIV patients, but an inhibition of protein synthesis in AIDS patients who were wasted (Fig. 3) [36]. This suggests that the trophic mechanisms involved in maintaining muscle mass, such as growth hormone and IGF-I, become deficient as the HIV disease advances [36]. Although the GH treatment stimulated protein synthesis in healthy subjects and not in AIDS patients, it was not possible to determine whether this resulted similar differences in protein gain, as there is no technique for measuring changes in muscle or limb protein content that are sufficiently accurate to show changes 
Figure 3

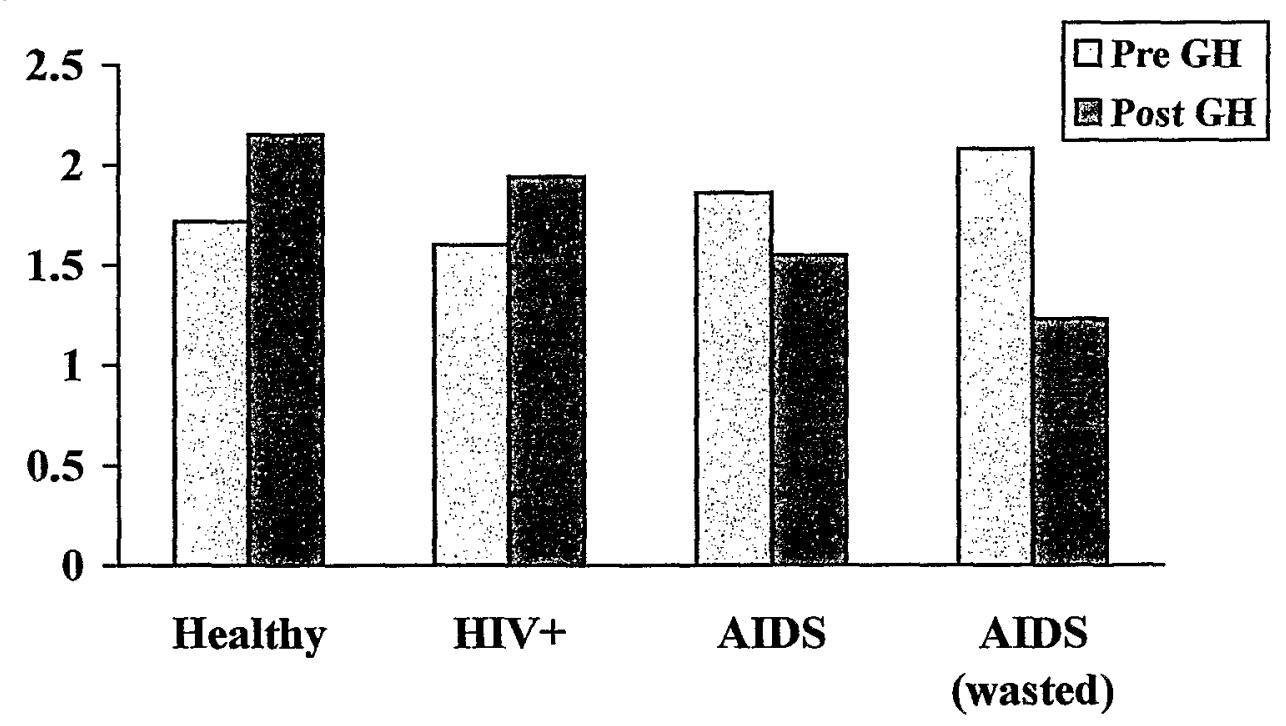

in a two week period. This is important, as other studies of the effect of GH treatment, using measurements of lean body mass or nitrogen balance, have suggested that there is a recovery of whole body protein mass, even in AIDS patients [37:39].

\section{Concluisions}

These examples illustrate the range of studies of protein synthesis and degradation that can now be performed in human volunteers and patients. The overall aim of such studies of protein synthesis and degradation is to gain a better understanding of the mechanisms causing loss of protein or growth failure, and thereby enable better therapies to be devised. However, in order for this to be successful, we must have methods for accurately assessing the loss of protein and its recovery. At the whole body level this is possible, using stable isotopes to measure protein kinetics and neutron activation to measure body nitrogen. This is, however, a rather blunt approach, since the body consists of many tissues, each with its own particular mechanisms of control. Even skeletal muscle is a heterogeneous tissue, with each separate muscle being strongly influenced by trophic factors related to its own function and work load. Although we can now determine the factors that control protein synthesis and degradation in individual tissues or regions, there are no equivalent methods for assessing changes in protein content, that would tell us whether the treatments that are given are resulting in sustained changes in protein content of a tissue or region. Even the arteriovenous difference approach, which measures the balance of a single amino acid in the tissue over a short period of a few hours, cannot be continued long enough to determine whether a loss or gain was sustained. There is therefore an urgent need for the development of techniques for determining the protein (nitrogen) content of individual regions of the body. This will complement our knowledge of the regulation of protein synthesis and degradation, and aid in the development of new strategies for combating lean tissue wasting. 


\section{References}

1. Waterlow, J.C., Garlick, P.J. \& Millward, D.J. Protein Turnover in Mammalian Tissues and in the Whole Body. Amsterdam: North Holland, 1978

2. James, W.P.T., Sender, P.M., Garlick, P.J. \& Waterlow, J.C. The choice of label and measurement technique in tracer studies in man. In Dynamic Studies with Radioisotopes in Medicine, Vol 1, pp. 461-472. IAEA, Vienna, 1974

3. O'Keefe, S.J.D., Sender, P.M. \& James, W.P.T. 'Catabolic' loss of body nitrogen in response to surgery. Lancet 2: 1035-1037, 1974

4. Motil, K.J., Matthews, D.E., Bier, D,M., Burke, J.F., Munro, H.N. \& Young, V.R. Whole body leucine and lysine metabolism: response to dietary protein intake in young men. Am. J. Physiol. 240:E712-E721, 1981

5. Garlick. P.J., McNurlan, M.A. \& Ballmer, P.E. Influence of dietary protein intake on wholebody protein turnover in humans. Diabetes Care, 14: 1189-1198, 1991

6. Young, V.R. Kinetics of human amino acid metabolism, nutritional implications and some lessons. Am. J. Clin. Nutr. 46: 709-725, 1987

7. Ballmer, P.E., McNurlan, M.A., Southorn, B.G., Grant, I. \& Garlick, P.J. Effects of human recombinant interleukin- $1 \beta$ on protein synthesis in rat tissues compared with a classical acute-phase reaction induced by turpentine. Biochem. J., 279: 683-688, 1991

8. Loftfield, R. B. and A. Harris. Participation of free amino acids in protein synthesis. J. Biol. Chem. 219: 151-159, 1956.

9. Loftfield, R. B. and E. A. Eigner. The time required for the synthesis of a ferritin molecule in rat liver. J. Biol. Chem. 231: 925-943, 1958.

10. Garlick, P.J., McNurlan, M.A., Essén, P. \& Wernerman, J. Measurement of tissue protein synthesis rates in vivo: a critical analysis of contrasting methods. Am. J. Physiol., 266: E287-E297, 1994

11. Halliday, D. and R. O. McKeran. Measurement of muscle protein synthetic rate from serial muscle biopsies and total body protein turnover in man by continuous intravenous infusion of L-[ $\alpha-{ }^{15}$ N]lysine. Clin. Sci. Mol. Med. 49: 581-590, 1975.

12. Stein, T. P., J. L. Mullen, J. C. Oram-Smith, E. F. Rosato, H. W. Wallace, and W. C. Hargrove. Relative rates of tumor, normal gut, liver and fibrinogen synthesis in man. Am. J. Physiol. 234: E648-E652, 1978.

13. Rennie, M. J., R. H. T. Edwards, D. Halliday, D. E. Matthews, S. L. Wolman, and D. J. Millward. Muscle protein synthesis measured by stable isotope techniques in man: the effects of feeding and fasting. Clin. Sci. 63: 519-523, 1982.

14. Matthews, D. E., H. P. Schwartz, R. D. Young, K. J. Motil, and V. R. Young. Relationship of plasma leucine and $\alpha$-ketoisocaproate during a L- $\left[1-{ }^{13} \mathrm{C}\right]$ leucine infusion in man: a method for measuring human intracellular leucine tracer enrichment. Metabolism 31: 1105-1112, 1982.

15. Bennet, W. M., A. A. Connacher, C. M. Scrimgeour, K. Smith, and M. J. Rennie. Increase in anterior tibialis muscle protein synthesis in healthy man during mixed amino acid infusion: studies of incorporation of $\left[1-{ }^{13} \mathrm{C}\right]$ leucine. Clin. Sci. 76: 447-454, 1989.

16. Low, R. B., W. S. Stirewalt, S. R. Rittling, and R. C. Woodworth. Amino acid pools in cultured muscle cells. J. Cell. Biochem. 25: 123-129, 1984. 
17. Baumann, P.Q., Stirewalt, W.S., O'Rourke, B.D. Howard, D. and Nair, K.S. Precursor pools of protein synthesis: a stable isotope study in a swine model. Am. J. Physiol. 267: E203E209, 1994

18. De Feo, P., Horber, F.F. and Hatmond, M.W. Meal stimulation of albumin synthesis: a significant contributor to whole body protein synthesis in humans. Am. J. Physiol. 263:E794E799, 1992

19. Cryer, D. R., T. Matsushima, J. B. Marsh, M. Yudkoff, P. M. Coates, and J. Corter. Direct measurement of apolipoprotein B synthesis in human very low density lipoprotein using stable isotopes and mass spectrometry. J. Lipid Res. 27: 508-516, 1986.

20. Rennie, M.J., Smith, K. and Watt, P.W. Measurement of human tissue protein synthesis:an optimal approach. Am. J. Physiol. 266:E298-E307, 1994

21. Felig, P. \& Wahren, J. Protein turnover and amino acid metabolism in the regulation of gluconeogenesis. Federation Proc. 33:1092-1097, 1974

22. Barrett, E.J., Revkin, J.H., Young, L.H., Zaret, B.L., Jacob, R. \& Gelfand, R.A. An isotopic method for measurement of muscle protein synthesis and degradation in vivo. Biochem. J. 245:223-228, 1987

23. Biolo, G., Chinkes, D., Zhang, X.J., Wolfe, R.R. A new model to determine in vivo the relationship between amino acid transmembrane transport and protein kinetics in muscle. $\mathrm{J}$. Parrent. Ent. Nutr. 16:305-315, 1992

24. Garlick, P.J., Wernerman, J., McNurlan, M.A.; Essén, P., Lobley, G.E., Milne, E., Calder, A.G. \& Vinnars, E. Measurement of the rate of protein synthesis in muscle of postabsorptive young men by injection of a 'flooding dose' of [1- ${ }^{13}$ C $]$ leucine. Clin. Sci., 77: 329-336, 1989

25. Halliday, D., P. J. Pacy, K. N. Cheng, F. D. Dworzak, J. N. A. Gibson, and M. J. Rennie. Rate of protein synthesis in skeletal muscle of normal man and patients with muscular dystrophy; a reassessment. Clin. Sci. 74: 237-240, 1988.

26. Heys, S.D., Park, K.G.M., McNurlan, M.A., Miller, J.D.B., Eremin, O. \& Garlick, P.J. Protein synthesis rates in colon and liver: stimulation by gastrointestinal pathologies. Gut, 33: $976-981,1992$

27. Smith, K., J. M. Barua, P. W. Watt, C. M. Scrimgeour, and M. J. Rennie. Flooding with $\mathrm{L}-\left[1-{ }^{13} \mathrm{C}\right]$ leucine stimulates human muscle protein incorporation of continuously infused L-[1- ${ }^{13}$ C]valine. Am. J. Physiol. 262: E372-E376, 1992.

28. McNurlan, M.A., Essén, P., Heys, S.D., Buchan, V., Garlick, P.J. \& Wernerman, J. Measurement of protein synthesis in human skeletal muscle: further investigation of the 'flooding' technique. Clin. Sci., 81: 557-564, 1991

29. Essén, P., McNurlan, M.A., Wernerman, J., Vinnars, E. \& Garlick, P.J. Uncomplicated surgery, but not general anesthesia, decreases muscle protein synthesis. Am. J. Physiol., 262: E253-E260, 1992

30. Essén, P., McNurlan, M.A., Sonnenfeld, T., Milne, E., Vinnars, E., Wernerman, J. \& Garlick, P.J. Muscle protein synthesis after operation: the effects of intravenous nutrition. Eur. J. Surg., 159: 195-200, 1993

31. Tjäder, I., Essén, P., Thörne, A., McNurlan, M.A., Calder, A.G., Garlick, P.J. \& Wernerman, J. Minor surgery has no immediate effect on protein synthesis rate in human skeletal muscle. Clin. Nutr. 12:7, 1993

32. Essén, P., Thorell, A., McNurlan, M.A., Ljungqvist, O., Wernerman, W. \& Garlick, P.J. Laparoscopic cholecystectomy does not prevent the postoperative protein catabolic response in muscle. Ann. Surg. 222:36-42, 1995 
33. Essén, P., McNurlan, M.A., Gamrin, L., Hunter, K., Calder, A.G., Garlick, P.J. \& Wernerman, J. (1998) Tissue protein synthesis rates in critically ill patients. Critical Care Medicine 26:92-100.

34. Hammarqvist, F., Wernerman, J., Ali, M.R., von der Decken, A. \& Vinnars, E. Addition of glutamine to total parenteral nutritionafter elective abdominal surgery spares free glutamine in muscle. counteracts the fall in muscle protein synthesis, and improves nitrogen balance. Ann. Surg. 209: 455-461, 1989

35. Hammarqvist, F., Strömberg, C., von der Decken, A., Vinnars, E. and Wernerman, J. Biosynthetic human growth hormone preserves both muscle protein synthesis, the decrease in muscle free glutamine and improves whole body nitrogen economy postoperatively. Ann. Surg. 216: 184-191, 1992

36. McNurlan, M.A., Garlick, P.J., DeChristofaro, K.A., Frost, R.A., Lang, C.H., Johnson, R.W., Santasier, A.M., Steigbigel, R.T., Fuhrer, J. \& Gelato, M.C. (1997) Responsiveness of muscle protein synthesis to growth hormone administration in HIV infected individuals declines with severity of disease. J. Clin. Invest. 100:2125-2132

37. Krentz, A.J., Koster, F.T., Crist, D.M., Finn, K., Johnson, L.Z., Boyle, P.J. \& Schade, D.S. (1993) Anthropometric, metabolic, and immunological effects of recombinant human growth hormone in AIDS and AIDS-related complex. J. AIDS 6:245-251.

38. Mulligan, K., Grunfeld, C., Hellerstein, M.K., Neese, R.A. \& Schambelan, M. (1993) Anabolic effects of recombinant human growth hormone in patients with wasting associated with human immunodeficiency virus infection. J. Clin. Endocrinol. Metab. 77:956-962.

39. Schambelan, M., Mulligan, K., Grunfeld, C., Daar, E.S., LaMarca, A., Kotler, D.P., Wang, J., Bozzette, S.A., Breitmeyer, J.B. 1996, Recombinant human growth hormone in patients with HIV-associated wasting. Ann. Intern. Med. 125:873-882 


\author{
Multiple Sclerosis \\ Patricia K. COYLe, M.D. \\ Professor of Neurology and \\ Director, Stony Brook MS Comprehensive Care Center \\ Health Sciences Center \\ SUNY at Stony Brook \\ Stony Brook, NY 11794-8121
}

\title{
Extended Abstract
}

Multiple Sclerosis (MS) is an organ-specific immune mediated disease, the major nontraumatic neurologic disorder of young adults. 350,000 Americans, and one to 2.5 million individuals worldwide, are affected. In 1994 US dollars, the cost of MS was 10 billion dollars a year. Such costs reflect that most MS patients become disabled.

MS affects the central nervous system (CNS), both the brain and spinal cord. Blood immune cells and water move into the CNS through a break in the blood brain barrier (BBB). This results in damage to myelin and axons, destruction of oligodendrocytes (the CNS myelin making glia), and astrocytic gliosis. These focal lesions (called plaques) occur in waves throughout the disease course. They produce disrupted nerve conduction and multiple clinical abnormalities. Most plaques are clinically silent, detected only by magnetic resonance imaging (MRI). MRI is considered the best MS current disease marker. It reveals widespread abnormalities in normal appearing brain tissue, BBB disturbances, heterogeneous pathology, variable iron deposition, chemical disturbances, ongoing atrophy, and axon abnormalities.

The following are current major clinical issues in MS:

- We do not know the cause of MS; it is likely heterogeneous. It may involve CNS infection, a cross reactive immune attack on a CNS component, or a metabolic or toxic process.

- There is no one definitive diagnostic test for MS.

- Clinical evaluation grossly underestimates disease status. At the current time there is no effective way to follow disease activity and severity.

- There is no established way to follow individual response to therapy.

Body composition research offers a new venue to examine MS brain and spinal cord for:

- Water content. This is likely to reflect disease activity/blood brain barrier abnormalities. It could be used to measure disease severity/course, and response to treatment.

- Iron content. Iron deposition disturbances have been described in MS. The question of an iron disturbance could be addressed directly.

- MS heterogeneity could be examined based on CNS chemical changes.

- Early chemical changes might give us clues to the etiology of this disease. 
- A chemical which measured a specific pathologic process (myelin breakdown, remyelination, oligodendrocyte loss, axon/neuron dysfunction, gliosis, inflammation) could offer a novel and valuable assessment tool.

- Correlates of MS fatigue and cognition

Body composition research will provide a new window to the CNS to investigate MS. At the least, accurate measure of CNS water content will be valuable in this disease. At the most, this methodology could lead to critical new insights into MS pathogenesis, severity, and response to therapy.

\section{Summary}

Multiple Sclerosis (MS) is a major neurologic disease in which central issues remain to be resolved. These issues include disease pathogenesis, how to measure disease activity, and how to determine response to therapy. Body composition research is a new technique which can be applied to study MS in a novel manner. It could provide critical new insights into this disease.

\section{Communication}

Multiple sclerosis (MS) is an immune-mediated disease which affects the central nervous system (CNS) (Noseworthy et al,2000). It is the major nontraumatic neurologic disease of young adults. Up to 350,000 Americans have been diagnosed with MS, and over a million individuals are estimated to be affected worldwide. The natural history of MS indicates that it is a highly variable and unpredictable disease that can result in significant morbidity (Table 1) (Coyle, 2000). MS is also a disease characterized by a number of symptoms which are poorly understood. In particular, both fatigue and cognitive disturbances affect large numbers of patients. Effective therapies have not been developed for these symptoms, in part because their pathogenesis is unknown.

Table 1. Natural History of MS

- Demographic profile

Young age of onset (average 28 to $30 \mathrm{yrs} ; 90 \%$ have onset from $15-50 \mathrm{yrs}$ )

Caucasian $(>90 \%)$

Female predominance

Lifespan only mildly shortened

- Variable/heterogeneous disease pattern

Initial relapsing course (unpredictable disease attacks with unpredictable recovery)

Later progressive course (slow worsening without recovery)

- Significant disability ultimately develops in $90 \%$ of patients

- Recently developed disease modifying therapies appear to influence this course 
The etiology of MS is also poorly understood. It involves a complex interplay between three factors: the host's intrinsic genetic makeup, extrinsic environmental exposures, and the host's intrinsic immune system. There is an increasing appreciation that a number of genes contribute to MS disease risk, as well as to disease severity. Most of the genes linked to disease risk and severity involve the immune system, suggesting that the immune system conveys baseline susceptibility to MS. Superimposed on a susceptible genetic background, certain environmental exposures appear to play an important role in the development of MS. There are recognized low, medium, and high risk geographic zones for MS. There is little disease at the equator, but increasing numbers of cases as one moves north and south. Migration studies, as well as a point epidemic in the Faroe Islands, supports extrinsic exposures as risk factors. These environmental exposures are believed to involve ubiquitous infectious agents, both viruses and bacteria. In particular, recent studies have suggested roles for human herpes virus type 6, an endogenous retrovirus, Epstein Barr virus, and the bacterium Chlamydia pneumoniae, in the development of MS (Ablashi et al, 2000; Sriram et al, 1998; Myhr et al, 1998;. Rieger et al, 2000). Extrinsic pathogens could trigger an immune attack against the CNS by a number of different mechanisms such as molecular mimicry, superantigen, direct infection, or bystander damage. This attack results in localized immunologic reactions which damage adjacent CNS tissue to cause the neuropathologic lesions of MS referred to as plaques.

The immunopathology of MS is being increasingly defined (Table 2). It involves binding of activated blood lymphocytes to CNS endothelial cells via adhesion molecules, After release of enzymes called matrix metalloproteinases, the immune cells are able to penetrate basement membrane and extracellular matrix to enter the CNS compartment. Once in situ, cells are locally activated. There is release of cytokines and chemokines, and upregulation of immune activation molecules. Focal blood brain barrier (BBB) permeability allows other systemic immune cells to penetrate. In at least a proportion of MS patients, antibodies are synthesized by B cells/plasma cells, and along with complement contribute to the local tissue damage (Archelos et al, 2000). This local immune reaction damages a variety of CNS tissue components. Both the myelin sheath as well as the underlying neuronal axon fiber are damaged by immune/inflammatory factors (Trapp et al, 1998). As a result, there is disruption of nerve conduction. Depending on the site of the damaged area (referred to as a plaque), there may be no obvious clinical problem, or there can be a variety of sensory, vision, motor, or coordination difficulties. It is not know what triggers immune cell entry into the CNS, or the local cell activation which cause myelin and axon damage, as well as oligodendrocyte loss. There is also some degree of repair of fixed damage, with variable degrees of remyelination. Ultimately there is loss of CNS tissue volume, with measurable atrophy of both brain and spinal cord. There has been a recent emphasis in particular on axon damage in MS, because it appears to be the neuro and atomic substrate of permanent clinical deficit.

\section{Table 2. Immunopathology of MS}

- Earliest detectable changes are focal disruptions in the blood brain barrier $\uparrow$ water, localized edema.

- This is followed by cell infiltration and a localized immune response with CNS tissue damage. 
- Heterogenous pathology
Edema
Inflammation
Demyelination
Remyelination $(\sim 70 \%)$
Axon damage
Gliosis
Oligodendrocyte loss without replacement ( $\sim 30 \%$ early)
Tissue loss/atrophy

- CNS lesions (plaques) form in waves within both silent (80-90\%) and eloquent (10$20 \%$ ) areas of the CNS.

At the current time neuroimaging, and specifically magnetic resonance imaging (MRI), has become the most useful investigative technique to study MS. Computerized axial tomography is very insensitive in MS, and is now rarely used. Other neuroimaging techniques such as positive emission tomography and single photon emission computerized tomography, have very limited applications to study this disease. MRI is being used in both clinical practice and basic research in a number of areas to learn more about MS (Table 3) With regard to the diagnosis of MS, the most widely used diagnoštic test is brain MRI. In addition, expert consensus panels also find it to be the most useful current marker of disease activity in the major relapsing and progressive forms of this disease (Miller et al, 1998). The earliest detectable abnormality on MRI is gadolinium enhancement, consistent with BBB breakage and focal vasogenic edema.

\section{Table 3. MRI as Applied to the Study of MS}

- Brain MRI is the current diagnostic test of choice

Ultimately abnormal in $95 \%$ of patients

Characteristic T2W hyperintense white matter lesions

Suggestive lesion features include multiplicity, asymmetry, size $>3 \mathrm{~mm}$, ovoid shape, perpendicular to ventricles, periventricular/juxtacortical/posterior fossa location, enhancement

- Spinal MRI not as sensitive but helpful in specific situations

Ultimately abnormal in up to $75 \%$ of patients

Lesions are limited to spinal cord in up to $20 \%$ of patients

Useful in patients over age 50 , with normal brain MRI, or clinical spinal cord presentations

- Frequent brain MRI studies find most new lesions are clinically silent

- Different MR techniques detect distinct features

Contrast enhancement (blood brain barrier damage)

$\mathrm{T} 2 \mathrm{~W}$ hyperintensity (heterogeneous)

T1W hypointensity (tissue damage)

$\mathrm{T} 1 \mathrm{~W}$ and $\mathrm{T} 2 \mathrm{~W}$ lesion burden

MR spectroscopy (chemical disturbances)

Atrophy (tissue loss) 
- Certain MR techniques detect abnormalities in normal appearing brain tissue/white matter

MR spectroscopy (to measure $\mathrm{N}$ acetyl aspartate, lactate, phospholipids)

Magnetization transfer imaging

Diffusion weighted and diffusion tensor imaging

High magnet ( $\geq 3$ Tesla)

- Brain MRI measures are used as primary outcomes in Phase I-II Trials, and as secondary outcomes in Phase III Trials

T2W lesion burden

Contrast enhancing lesions

Number of new/active lesions

There is no question that MRI has changed our understanding of the MS disease process, and has become a cornerstone in diagnosis, daily clinical management, and treatment trials.

At the current time there are a number of major clinical issues in MS. First, there is no definitive diagnostic test. The most frequently used diagnostic criteria involve a combination of clinical and laboratory abnormalities (Poser et al, 1983). Unfortunately, the misdiagnosis rate of MS remains about 5 to $10 \%$. Second, there is no validated and widely used surrogate disease activity marker. No test is sufficiently standardized and economically viable to be used on a regular basis. Third, MS is probably quite heterogeneous based on clinical, pathologic, neuroimaging, and immunologic criteria. Certain patients appear to have a process mediated by an autoimmune attack against myelin, while others have a process mediated by damage to oligodendrocytes from an infectious, metabolic or toxic process (Lucchinetti et al, 2000). In fact, there may be distinct immunopathogenic mechanisms to damage CNS tissues. Fourth, clinical evaluation grossly underestimates true disease activity. Most new brain lesions are not tied to recognizable disease attacks. Both the patient and physician are unaware there has been new damage to the nervous system. Finally, in this new era of disease modifying therapies for MS, there is no established way to measure treatment response. Simple clinical follow-up is often not very accurate.

The possibility of using body composition research to evaluate a specific organ now permits this technique to be applied to human medical diseases. The ability to examine the CNS means that it will provide a new way to study a number of neurologic problems. It has never been used to study MS. Yet it offers many potential applications, particularly when it is used in combination with MRI techniques, including MR spectroscopy (Table 5). Evaluation of cell membrane potential allows a novel way to assess axonal integrity in MS. This is an especially urgent need, since it will allow in vivo measurement of axon function that could be used to assess disease worsening as well as response to therapy.

Table 4. Potential Applications of Body Composition Research to MS

- Unique technique to examine brain and spinal cord

- May provide parameters to evaluate disease activity and response to therapy 
Measure of water content as measure of blood brain barrier permeability

Measure of intracellular vs. extracellular water content to evaluate cell damage, intracellular vs. extracellular component

- Early chemical changes may provide clues to etiology

- Unique chemical pattern may provide a diagnostic test

- Evaluation of disease heterogeneity could be based on distinct chemical changes

- To examine the role of specific chemicals in MS pathology

Iron deposition as well as other substances

- To evaluate cell membrane potential and conduction capacity in the CNS

Investigate a potential measure of the symptoms of fatigue and cognitive dysfunction

- To evaluate chemical changes to assess the specific pathologic processes

Inflammation

Myelin breakdown and myelin repair

Oligodendrocyte loss and regeneration

Axon and neuron dysfunction

Gliosis

In summary, MS is a major CNS disease with many unanswered clinical issues. The ability to perform a chemical analysis of this body organ provides a new assessment tool. The ability to examine CNS water content is likely to be an important measure of disease activity. The ability to measure cell membrane potential may provide important insights into major symptoms of MS such as fatigue and cognitive dysfunction. Chemical analysis could provide an assessment of disease heterogeneity as well as pathologic differences. Body composition research is a promising technology which offers a new way to evaluate organ specific diseases such as MS. It will probably be best used in concert with MRI in order to connect chemical to structural changes.

\section{Commentary}

Once body composition research is modified to examine a specific organ such as the brain, it will offer a potentially powerful tool to address major research issues in MS. The ability to measure changes in both intra and extracellular chemicals, in cell membranes potentials, and in various chemicals during disease activity or during treatment, will be applicable to many diagnostic, therapeutic, and pathogenetic issues. Body composition research can serve as an important complementary technique to MRI in the study of MS.

\section{References}

Ablashi DV, Eastman HB, Owens, CB et al. Frequent HHV-6 reactivation in MS and CSF patients. J Clin Virol 2000;16:179-191.

Archelos JJ, Storch MK, Hartung HP. The role of B cells and autoantibodies in MS. Ann Neurol 2000; 47:694-705. 
Coyle PK. Multiple Sclerosis. In Textbook of the Autoimmune Diseases, Lahita RG, Chiorazzi, $\mathrm{N}$ and Reeves WH, eds. Lipincott Williams \& Wilkins: Philadelphia, PA. 2000, p.545-609.

Gonen O, Catalaa I, Babb JS, et al. Total brain N-acetyl aspartate: a new measure of disease load in MS. Neurology 2000; 54:15-19.

Lucchinetti O, Bruck W, Parisi J et al. Heterogeneity of MS lesions: implications for the pathogenesis of demyelination. Ann Neurol 2000; 47:707-717.

Miller $\mathrm{DH}$, Grossman $\mathrm{RI}$, Reingold SC, McFarland HF. The role of magnetic resonance techniques in understanding and managing multiple sclerosis. Brain 1998;121:3-24.

Myhr KM, Riise T, Barrett-Connor E, et al. Altered antibody pattern to Epstein-Barr virus but not to other herpes viruses in multiple sclerosis: a population based case-control study from western Norway. J Neurol Neurosurg Psychiatry 1998;64:539-542.

Noseworthy JH, Lucchinetti C, Rodriguez M, Weinshenker BG. Multiple Sclerosis. N Engl J Med. 2000;343:938-952.

Poser CM, Paty DW, Scheinberg L, et al. New diagnostic criteria for multiple sclerosis: guidelines for research protocols. Ann Neurol 1983; 13:227-231.

Rieger F, Pierig R, Cifuentes-Diaz C, et al. New perspectives in multiple sclerosis: retroviral involvement and glial cell death. Pathologie Biologie 2000;48:15-24.

Sriram S, Mitchell W, Stratton C. Multiple sclerosis associated with Chlamydia pneumoniae infection of the CNS. Neurology 1998;50:571-572.

Trapp BD, Peterson J, Ransohoff RM, et al. Axonal transection in the lesions of multiple sclerosis. NEngl J Med 1998;338:278-285. 


\section{SUMMARY}

This meeting was held to recap the present status of the body composition analysis program (BCAP), to identify its future trends and novel clinical applications. However, the principal objective was to recognize the role and the future uses of BCAP at BNL. Present were representatives of the administration at BNL, Dr. Peter Paul, Deputy Director for Science, Dr. Linda Chang, Chairperson of the Medical Dept., and Mr. William Gunther, Special Asst. to Dr. Nora Volkov, Associate Laboratory Director for Life Sciences. From the Central Office of DOE was present Dr. Peter Kirchner, Program Manager of Medical Sciences. Members present from the working staff of BCAP at BNL were Dr. Lucian Wielopolski (principal physicist), Dr.

Walton Shreeve (principal physician), and other members of the staff. The main user of BCAP at $\mathrm{BNL}$ for more than 15 years (and continuing into the future) has been the Body Composition Unit of the Center for Research in Clinical Nutrition (CRCN) at St. Luke's/Roosevelt Hospital Med. Ctr. in NYC. Dr. Richard N. Pierson, Jr., Dr. Steven Heymsfield, Dr. Jack Wang and Dr. Dympna Gallagher represented this large and active Center for BCAP at the meeting. Investigators of body composition by various methods, who have expressed interest in future use of the present or potential facilities for BCAP at BNL, were present from such nearby clinical centers as SUNY, Stony Brook, DVA Hospital, Bronx and St. Luke's/Roosevelt Hospital, NYC (other than the CRCN). Two other notable persons, Dr. David Chattle physicist from McMaster University in Canada and Dr. David Vartsky physicist from Nahal Soreq in Israel, both experienced analysts in in vivo measurements in the field of BCAP, were invited to participate in the general discussion. Other interested persons were present in the audience.

After initial welcoming remarks from Dr. Paul and Dr. Chang, Dr. Pierson (Principal Investigator (PI) for most studies for more than a decade) framed the history of BCAP (in general) over the past 50-75 years. Progressing through epochs, which utilized successively such methods as under-water weighing (UWW) and skin-fold thickness to indicator dilution techniques to in vivo neutron activation analysis (IVNAA) to the more recent imaging with CT and MRI. He emphasized the need for better and more precise (and regional) functional numerators to correlate to anatomical denominators being provided with increasing sophistication by CT and especially MRI. While pointing out the continuing value of whole body measurements of certain elements (indicative of function) for diseases such as osteoporosis, AIDS and obesity, he indicated the new need for higher-resolution, regional representation of function to evaluate, for instance, changes in membrane potential in individual organs such as liver, heart and brain. He described briefly the "quantum leap" in BCAP that would be provided by the new development at BNL of gamma nuclear resonance absorption (GNRA), with its elemental imaging capabilities.

Dr. Wielopolski reviewed the basic physics of elemental analysis by IVNAA, including the divisions into "delayed gamma", "prompt gamma" and "inelastic neutron scattering" (INS). He described how such indirect, surrogate methods as dual x-ray absorptiometry (DXA), bioimpedance analysis (BIA) and UWW for analysis of major body compartments were initially and continue to be cross-calibrated by the BCAP at BNL, and he indicated the need for further such calibrations in abnormal or diseased populations. Further, he explained in some detail the new method of GNRA and enumerated its novel and unique elemental imaging capabilities and its advantages and applications for analysis of particular major elements in vivo. 
Dr. Heymsfield (successor to Dr. Pierson as the P.I.of the NIH-funded BCA Program Project Grant (PPG) at St. Luke's/Roosevelt) gave a comprehensive review of various kinds of 4compartment models of body composition (at atomic, molecular, cellular and tissue-system levels) and the various "direct" and "indirect" methods for measuring components at different levels. While expounding on the growing importance and applications of the imaging methods (CT, MRI and PET), he reiterated the unique value of elemental analysis (especially $\mathrm{K}, \mathrm{N} \mathrm{Cl}$, and C) as reference methods by which to calibrate measurements (by indirect, surrogate methods) of normal and abnormal populations. He pointed out the growing relevance of finer phenotyping to relate to genotype.

Dr. William Bauman and Dr. Ann Spungeon (co-workers at Dept. Veterans Administration, Bronx and Mt. Sinai School of Medicine) described their studies of body composition changes in patients with spinal cord injury (SCI), especially those for whom normal identical twins serve as controls. Dr. Bauman described the changes in bone during acute and chronic phases after immobilization both in human subjects and in rat models. A noteworthy observation has been the surprisingly long duration of bone loss in SCI not related to age of onset. Different relationships between bone vs. lean tissue and bone vs. fat mass in SCI vs. normal twins, as indicated by nonspecific DXA, needed verification and validation by independent means, such as IVNAA. Both whole body IVNAA and regional GNRA would be of tremendous help to provide critical results, not available by other means, of pharmacologic and other interventions.

Dr. Spungeon gave an analogous talk on changes in soft tissue composition in SCI vs. control twins. As with bone, findings include unusually long duration of lean tissue loss after SCI exceeding that due to age. Adverse hormonal changes (decrease testosterone, growth hormone and IGF-1) are contributory. IVNAA is needed to validate the extreme changes (and possible therapeutic reversals) now observable only by DXA (limited by its variability due to selfabsorption and lack of specificity) or by TBK. Particularly useful would be measurement by GNRA of changes in intercostal muscles in tetraplegics.

Dr. Valerie Johnson (of Cornell Univ.) reported on behalf of her co-workers (at St. Luke's/Roosevelt and Albert Einstein College of Medicine) that growth-retarded children with chronic renal failure benefit from treatment for 18 months with thGH by increase of height, ICW (representing lean mass) and bone parameters relative to age-matched normal children, while showing a decrease in \% fat. She pointed out that total body $\mathrm{K}$ and instrumentation with low radiation doses, for body composition analysis, will be of extreme value in studying and maintaining these children.

Dr. Jonathon Sachner-Bernstein (of St. Luke's/Roosevelt) described the exceptional finding of "intracellular edema", as evidenced by decreased ECW with normal TBW, and therefore increased ICW, in patients with mild or moderate heart failure compared to matched controls. A resultant dilution of intracellular $\mathrm{K}$ causes decreased membrane potential, which could contribute to decreased cardiac and skeletal muscle function and abnormal myocardial electro-conductivity leading to arrhythmias. Further measurements of individual organ composition as it relates to its function would be instrumental and very helpful in understanding the physiology and in patient's maintenance. 
Dr. Peter Garlick (of SUNY, Stony Brook) described the studies of his group on turnover of protein (synthesis and degradation) by the use of stable isotope-labeled amino acids. He emphasized the need for better knowledge of nitrogen balance in view of certain inaccuracies or inconveniences of old or present methods. Finding on the effects of $\mathrm{GH}$ in post-surgical or inflammatory states or in AIDS were described. There is a need for non-invasive and longitudinal studies of TBN and of $\mathrm{N}$ in individual tissues in order to evaluate sustained loss or gain.

Dr. P. K. Coyle (SUNY, Stony Brook) outlined the pathogenesis (little known), clinical characteristics and course of multiple sclerosis (MS). The problems of heterogeneity of MS and the high prevalence of clinically silent lesions were described. The current special values of MRI, and also its limitations, were reviewed. Hope was expressed that techniques (high-strength MRI, MRS, local NAA or GNRA) presently under construction at BNL could throw light on the nature of ups and downs of this chronic active neurologic disease and efficacy of therapies.

In the round table concluding discussion both Dr. Kirchner, the moderator, and Dr. Chang posed a question as to what kind of role (if any) the BCA P and its facilities at BNL could play in the future, vis-à-vis the same or similar facilities developing at individual clinical centers. A simple answer is that BNL is a unique center in the USA in which new methodologies for in vivo measurements are being developed. The only other similar facility on the East Coast is in Boston and in the south is in Houston Texas. The Department of Agriculture operates both for conventional measurements. Furthermore, these two facilities do not operate a delayed neutron activation facility and for $\mathrm{K}$ measurement a simple shadow counter is used in Boston. Thus BNL operates unique facilities nationwide and provides a unique community resource not available elsewhere. In the near future the measurements at BNL (most uniquely the DGNAA for TBCa) are integral components of the renewed studies of obesity and of aging as required within the NIH-funded "PPG-3" grant for the next 5 years based at St. Luke's/Roosevelt. Within that time the development of a whole body carbon/nitrogen facility at St. Luke's would require thorough cross calibration with BNL facilities. It is critical in order not to invalidate the integrity of the worldwide uniqueness of the body composition database that contains thousands of entries accumulated over the years. In this context an explicit and important role for BCAP at BNL was identified to provide a national, and for that matter an international, reference calibration laboratory for in vivo elemental analysis. It was pointed out that BNL might well continue to be a national (and international) center for "reference bodies" of different gender, age, ethnicity, body shapes and sizes which could further refine phenotypes of body composition that could be related to particular genotypes. Furthermore, the proliferating of new commercial non-specific surrogate methodologies for body composition analysis must be validated by direct methods before they gain the confidence of the clinical physician and an established status in a clinical practice. For example the need for calibrating DXA for bone mass in aberrant body types and in disease was clearly demonstrated in SCI patients. A reference laboratory role is one that befits that of a national laboratory. A further point was made about the strong back up of major physics and engineering facilities at BNL as a whole.

For the more distant (or even near) future the application of regional body measurements at $\mathrm{BNL}$, which are possible in a limited way (e.g., TBN, hence muscle, in the thigh) with present 
equipment and more effectively by development of 3-D imaging with GNRA, is the direction most desired. Various speakers at this seminar have described specific interests in that direction, particularly in order to evaluate better the effects of various therapies. It was recognized that the GNRA method could eventually be applied to regional carbon (for specific locations of fat) and calcium (for specific areas of bone). This could follow the initial development for measurement of regional $\mathrm{N}$. It was again emphasized that $\mathrm{CT}$ or MRI measurements would have increased meaning when co-registered with direct methods.

Meanwhile, study of other kinds of transportable subjects (e.g., HIV+, aging men, pre- vs. postoperative states) may be continued, renewed or newly applied. Application of body composition analysis to new patient populations and their clinical relevance, e.g., SCI, pediatrics, and cardiac patients, were pointed out in four presentations.

It was evident that this day's gathering of investigators from several disciplines had not only been uniquely instructive but also clearly pointed out the future roles that BNL, not only have but, must play. One, in serving as a reference laboratory for in vivo measurements, and two, providing a center for new advanced instrumentation such as GNRA. Suggestions were brought out about examining body composition and related function by unusual means. These included MR spectroscopy (MRS) of 1-H in particular chemical compounds by high Tesla magnets, MRS of 31-P in brain phospholipids, MRS of $15-\mathrm{N}$ in various sites, PET of 15-O2 in individual organs for metabolic rates, planar gamma or SPECT of 43-K for local muscle mass and analysis of $\mathrm{Mn}, \mathrm{Al}$, and $\mathrm{Fe}$ because of concerns of toxicity. However, the necessity of these methods to be calibrated against primary ones was not overlooked. All of the objectives stated in the introduction were achieved, as manifested in this report, with a clear mandate and a call for continuation of the Body Composition Analysis Program at BNL. Dr. Paul ended with the comment that acquisition of a major new facility at BNL, such as the special accelerator needed for GNRA, ought to have some particular conceptual goals defined and reasonably justified, but, as usually is the case, might well have unexpected rewards that could go beyond the original envisioned potential. 